ANA PAULA BELTRAN MOSCHIONE CASTRO

\title{
Determinação das concentrações séricas de lgE específica para o leite de vaca e suas frações no diagnóstico de alergia ao leite de vaca
}

Tese apresentada à Faculdade de Medicina da Universidade de São Paulo para obtenção do título de Doutor em Ciências

Área de Concentração: Pediatria

Orientadora: Profa Dra. Cristina Miuki Abe Jacob

SÃO PAULO

2009 
Dados Internacionais de Catalogação na Publicação (CIP)

Preparada pela Biblioteca da

Faculdade de Medicina da Universidade de São Paulo

Creprodução autorizada pelo autor

Castro, Ana Paula Beltran Moschione

Determinação das concentrações séricas de IgE específica para o leite de vaca e suas frações no diagnóstico de alergia ao leite de vaca / Ana Paula Beltran Moschione Castro. -- São Paulo, 2009.

Tese(doutorado)--Faculdade de Medicina da Universidade de São Paulo. Departamento de Pediatria.

Área de concentração: Pediatria.

Orientadora: Cristina Miuki Abe Jacob.

Descritores: 1.Hipersensibilidade alimentar/diagnóstico 2.Teste de radioalergoabsorção 3.Leite de vaca 4.Criança 5.Adolescente

USP/FM/SBD-495/09 
"Eles não sabem, nem sonham, que o sonho comanda a vida, que sempre que um homem sonha o mundo pula e avança como bola colorida entre as mãos de uma criança”

António Gedeão Lisboa, $1906-1997$ Frase escolhida por Eugénia Maria Grilo Carnide 


\section{DEDICATÓRIA}

Aos meus queridos pais por me apoiarem sempre, mesmo sem saber exatamente o que tudo isto representa.

Ao meu irmão que me acompanha ao longo desta jornada.

Ao meu marido e filhos muito amados, este trabalho é dedicado a vocês que são a inspiração e razão para quase tudo nesta vida. 


\section{DEDICATÓRIA}

Ao meu grupo, a Unidade de Alergia e Imunologia do Instituto da Criança do Hospital das Clínicas da Faculdade de Medicina da Universidade de São Paulo. Este trabalho é nosso, resultado do estímulo diário que todos vocês me proporcionaram 


\section{AGRADECIMENTOS}

Ao finalizar um trabalho olhamos para trás e percebemos que não realizamos nada sozinhos. Portanto, temos muitos a quem agradecer...Ainda bem.

À querida orientadora Prof ${ }^{a}$ Dra. Cristina Miuki Abe Jacob, uma guerreira na vida e na ciência, um exemplo que transcende esta tese. Muito obrigada por tantos ensinamentos.

Ao Dr Antonio Carlos Pastorino, entre tantos motivos de agradecimento, recebe em destaque o meu obrigado pela sua participação essencial e tão importante ao final desta tese

À Dra Ângela Bueno Ferraz Fomin, companheira de pós graduação, pelo estímulo ao trabalho juntas

Às muito competentes e queridas amigas do Ambulatório de Alergia Alimentar: Andréa Keiko Fujinami Gushken, Ana Cláudia Brandão, Cleonir de_Moraes Lui Beck e Glauce Hiromi Yonamine, vocês merecem muito mais do que uma frase de agradecimento, têm meu respeito, amizade e carinho para sempre.

A tantos e tão queridos médicos que passaram pelo Ambulatório de Alergia Alimentar, seria injusto mencionar alguns. Agradeço por serem meu estímulo à pesquisa e ao ensino, tarefa que tanto gosto. Obrigada pelos sorrisos, carinho e incentivo sempre.

Ao Dr Ulysses Doria Filho, obrigada pela paciência em tornar conceitos estatísticos palatáveis em todos os momentos desta tese. 


\section{AGRADECIMENTOS}

À Dra Cristina Kokron, ao Carlos R. O. Palma e demais componentes do LIM-60 pela gentileza e disponibilidade na realização das pesquisas de $\operatorname{lgE}$ específicas séricas.

À Phadia Diagnósticos Ltda representada pelo Sr Fabio Arcuri, agradeço a disponibilidade da doação dos primeiros testes a serem realizados e a Vanessa Hurtado pela colaboração na pesquisa literária.

À bibliotecária Mariza K. U. Yoshikawa, pela contribuição na revisão bibliográfica e por ter sempre uma palavra amiga e um sorriso.

À Milena e Nivaldo, pelo carinho e por estarem sempre prontos a nos ajudar nos momentos finais e sempre urgentes da tese.

Aos professores titulares desta instituição por permitirem e facilitarem um ambiente favorável à pesquisa.

Às minhas irmãs de coração Ana Cristina, Cristiane e Elnara, saber da possibilidade de suas mãos estendidas sempre e seu carinho incondicional traz conforto e serenidade. Obrigada.

Finalmente a você, Prof $\mathrm{Dr}$ Fábio Fernandes Morato Castro, um agradecimento especial, meu carinho e respeito por este profissional e amigo querido que alia ciência, ética, bom senso, desprendimento com uma pitada de humor. Espero que mais pessoas possam ter oportunidade de descobrir como é tranqüilo e gratificante trabalhar com você. 
Esta tese está de acordo com as seguintes normas, em vigor no momento desta publicação:

Referências: adaptado de International Committee of Medical Journals Editors (Vancouver)

Universidade de São Paulo. Faculdade de Medicina. Serviço de Biblioteca e Documentação. Guia de apresentação de dissertações, teses e monografias. Elaborado por Anneliese Carneiro da Cunha, Maria Júlia de A.L. Freddi, Maria F. Crestana, Marinalva de Souza Aragão, Suely Campos Cardoso, Valéria Vilhena. $2^{\mathrm{a}}$ edição. São Paulo: Serviço de Biblioteca e Documentação; 2005.

Abreviaturas dos títulos dos periódicos de acordo com List of Journals Indexed in Index Medicus 


\section{Sumário}

Lista de Figuras

Lista de Anexos

Resumo

Summary

1. Introdução.

1

A. Alergia Alimentar ................................................................. 2

B. Alergia à Proteína do Leite de Vaca .......................................... 6

C. Diagnóstico de Alergia à Proteina do Leite de Vaca ...................... 10

a. Anamnese ................................................................ 10

b. Exames Complementares ............................................... 11

1. Pesquisa de IgE específica através do teste cutâneo de hipersensibilidade imediata. 11

2. Pesquisa de $\lg E$ sérica específica 13

3. Testes de provocação oral

D. Dosagem sérica de lgE específica para diagnóstico de alergia a proteína do leite de vaca: uma alternativa ao Teste de Provocação Oral Duplo Cego Placebo Controlado......................................... 19

2. Objetivos..................................................................................... 23

3. Métodos ..................................................................................... 25

A. Casuística.......................................................................... 26 
B. Exames complementares ....................................................... 28

a. Teste de Provocação Oral Duplo Cego Placebo Controlado.... 28

b. Teste cutâneo de hipersensibilidade imediata.......................... 29

c. Dosagem de IgE específica................................................... 30

C. Grupo Controle...................................................................... 31

D. Aspectos Éticos …..................................................................... 32

E. Análise estatística ……............................................................ 32

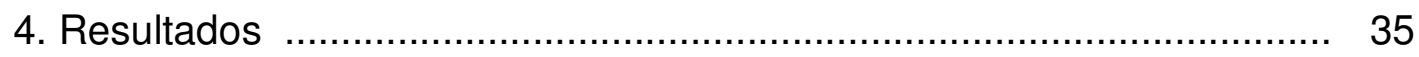

A. Caracterização da Casuística ………………………………..... 36

B. Concentração discriminante de IgE específica para leite de vaca e frações para o diagnóstico de alergia à proteína do leite de vaca.......... 42

a. Curvas ROC para obtenção das concentrações

discriminantes de IgE específica para leite de vaca e frações..... 42

b. Curvas ROC para obtenção das concentrações

discriminantes de IgE específica para leite de vaca em

pacientes com anafilaxia â proteína do leite de vaca

50

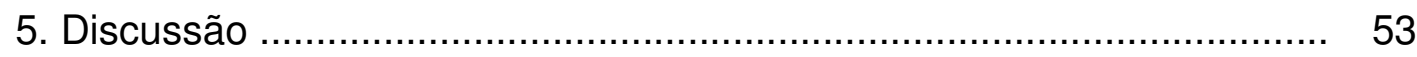

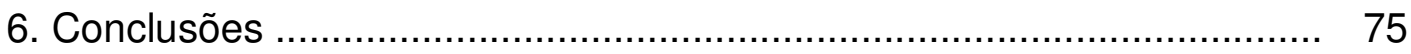

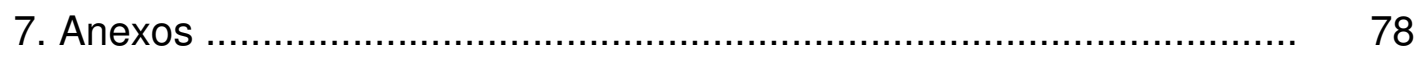

8. Referências Bibliográficas ………………………………………... 104 


\begin{tabular}{|c|c|c|}
\hline \multicolumn{2}{|r|}{ Lista de Figuras } & \multirow{2}{*}{$\begin{array}{c}\text { Página } \\
36\end{array}$} \\
\hline Figura 1 & $\begin{array}{l}\text { Distribuição dos } 123 \text { pacientes com APLV segundo } \\
\text { os critérios de inclusão. }\end{array}$ & \\
\hline Figura 2 & $\begin{array}{l}\text { Idade do início dos sintomas de APLV em } 123 \text { pacientes } \\
\text { avaliados. }\end{array}$ & 37 \\
\hline Figura 3 & $\begin{array}{l}\text { Distribuição das manifestações clínicas de } 123 \text { pacientes } \\
\text { com APLV segundo os sistemas envolvidos. }\end{array}$ & 38 \\
\hline Figura 4 & $\begin{array}{c}\text { Distribuição das manifestações clínicas dos } 87 \text { pacientes } \\
\text { com APLV segundo a associação de sistemas } \\
\text { envolvidos. }\end{array}$ & 39 \\
\hline Figura 5 & $\begin{array}{l}\text { Distribuição de outras manifestações alérgicas referidas } \\
\text { pelos } 123 \text { pacientes com APLV. }\end{array}$ & 41 \\
\hline Figura 6 & $\begin{array}{c}\text { Distribuição dos } 123 \text { pacientes com APLV segundo os } \\
\text { antecedentes familiares de atopia. }\end{array}$ & 41 \\
\hline Figura 7 & $\begin{array}{l}\text { Curva ROC para determinação de ponto de corte para } \\
\text { valores de lgE específica para leite de vaca para o } \\
\text { diagnóstico de APLV. }\end{array}$ & 43 \\
\hline Figura 8 & $\begin{array}{l}\text { Curva ROC para determinação de ponto de corte para } \\
\text { valores de lgE específica para } \alpha \text {-lactoalbumina para o } \\
\text { diagnóstico de APLV. }\end{array}$ & 44 \\
\hline
\end{tabular}




\begin{tabular}{|c|c|c|}
\hline Figura 9 & $\begin{array}{c}\text { Curva ROC para determinação de ponto de corte para } \\
\text { valores de lgE específica para } \beta \text {-lactoglobulina para o } \\
\text { diagnóstico de APLV. }\end{array}$ & 45 \\
\hline Figura 10 & $\begin{array}{c}\text { Curva ROC para determinação de ponto de corte para } \\
\text { valores de lgE específica para caseína para o } \\
\text { diagnóstico de APLV. }\end{array}$ & 46 \\
\hline Figura 11 & $\begin{array}{l}\text { Curva ROC para determinação de ponto de corte para } \\
\text { valores de IgE específica para leite de vaca para o } \\
\text { diagnóstico de APLV com sintomas de anafilaxia } \\
\text { comparados a pacientes com APLV sem sintomas de } \\
\text { anafilaxia. }\end{array}$ & 51 \\
\hline Figura 12 & $\begin{array}{l}\text { Curva ROC para determinação de ponto de corte para } \\
\text { valores de lgE específica para leite de vaca para o } \\
\text { diagnóstico de APLV com sintomas de anafilaxia } \\
\text { comparados a pacientes com APLV sem sintomas de } \\
\text { anafilaxia e grupo controle. }\end{array}$ & 52 \\
\hline
\end{tabular}




\section{RESUMO}

CASTRO APBM. Determinação das concentrações séricas de lgE específica para o leite de vaca e suas frações no diagnóstico de alergia ao leite de vaca. (Tese). São Paulo: Faculdade de Medicina da Universidade de São Paulo; 2009. 118 p.

As proteínas do leite de vaca são os principais alérgenos relacionados à alergia alimentar em crianças e o diagnóstico inclui a realização do teste de provocação oral duplo cego placebo controlado (TPODCPC). Apesar da acurácia, este teste envolve riscos, necessita condições especiais para sua realização e apresenta limitações em crianças de baixa idade e em pacientes anafiláticos. Assim, há necessidade de métodos diagnósticos alternativos, entre eles o estabelecimento de pontos de corte de concentrações de lgE sérica específica para leite de vaca, que permitam o diagnóstico mesmo sem a realização do TPODCPC. O objetivo deste estudo foi estabelecer uma concentração discriminante de IgE sérica específica para leite de vaca e suas frações protéicas para o diagnóstico de alergia à proteína do leite de vaca (APLV) e avaliar se há diferentes concentrações discriminantes de lgE específica para este alérgeno no grupo de pacientes com anafilaxia. Realizou-se um estudo de coorte histórica incluindo pacientes com APLV e grupo controle composto por pacientes com suspeita não confirmada de APLV. Para estes objetivos, foram construídas curvas ROC para os seguintes alérgenos: leite de vaca, caseína, $\alpha$ lactoalbumina e $\beta$-lactoglobulina. Os níveis de $\operatorname{lgE}$ específica foram avaliados posteriormente, em separado, nos pacientes com anafilaxia. Foram incluídos 123 pacientes (1,3M:1F mediana = 1,91 anos, com idade de 3,5 meses a 13,21 anos) com diagnóstico confirmado de APLV através de TPODCPC $(n=26)$, presença de anafilaxia à proteína do leite de vaca $(n=46)$ ou história clínica fortemente sugestiva de APLV associada à 
pesquisa positiva de $\operatorname{lgE}$ específica através de teste cutâneo $(n=51)$. Entre os 65 pacientes com anafilaxia, 19 confirmaram o diagnóstico posteriormente, através de testes de provocação. O grupo controle foi composto por 61 pacientes (1M:1,1F) com idade variando entre 0,66 e 16,7 anos (mediana $=6,83$ anos). A metodologia adotada para estabelecimento dos pontos de corte foi a construção de curva ROC e posterior cálculo dos valores preditivos positivos e negativos. Os pontos de corte obtidos considerando-se uma especificidade de $98 \%$ e um valor preditivo positivo acima de $95 \%$ foram: 3,06 kU/L para o leite de vaca, 2,06 kU/L para $\alpha$ lactoalbumina, 1,85 kU/L para $\beta$-lactoglobulina e 1,47 kU/L para caseína. $O$ valor de IgE específica para leite de vaca revelou-se com maior capacidade discriminante que os encontrados para as frações, tornando estes últimos dispensáveis. Com relação à anafilaxia, a curva ROC construída a partir de uma análise comparativa entre pacientes com e sem esta manifestação, indicou um ponto de corte elevado de $39 \mathrm{kU} / \mathrm{L}$, tornando impossível sua utilização na prática clínica. $O$ presente estudo mostrou que um ponto de corte de IgE específica para leite de vaca é suficiente para o diagnóstico de APLV, não sendo necessária a avaliação das frações protéicas. $\mathrm{Na}$ presença de anafilaxia desencadeada pelo leite de vaca não há necessidade da utilização de pontos de corte de IgE específica, sendo os dados clínicos e a sensibilização ao leite suficientes para o diagnóstico de APLV.

Descritores: Hipersensibilidade alimentar/diagnóstico, Teste de radioalergoabsorção, Leite de vaca, Criança, Adolescente 


\section{SUMMARY}

CASTRO APBM. Determination of serum concentration of specific IgE to cow`s milk and its fractions for the cow's milk allergy diagnosis (Thesis). São Paulo: Faculdade de Medicina da Universidade de São Paulo; 2009. 118 p.

Cow's milk proteins are the main allergens related to food allergy in children and the diagnosis include the double blind placebo controlled food challenge (DBPCFC). Although this test presents accuracy, it involves risks, it is necessary special conditions and it presents limitations in infants and anaphylactic patients. It is necessary other diagnostic methods, among them the cut off values for IgE specific for milk to allow the cow's milk allergy (CMA) diagnosis without the need to perform the DBPCFC. The objective of this study was to establish a discriminating concentration of specific $\lg E$ to cow's milk and its proteins fractions for the diagnosis of allergy to CMA and to assess if there are different discriminating concentrations of specific IgE to this allergen in the group of patients with anaphylaxis. It was carried out a historical cohort study including patients with CMA and the control group was composed by patients with excluded CMA suspicion. To obtain the cutoff points for diagnosis of CMA, ROC curves were constructed for the following allergens: cow's milk, casein, $\alpha$-lactalbumin and $\alpha \beta$-lactoglobulin. The levels of specific IgE were later evaluated, separately, in patients with anaphylaxis. The study included 123 patients $(1.3 \mathrm{M}$ : $1 \mathrm{~F}$ median = 1.91 years, ranging 
from 3.5 months to 13.21 years) with confirmed diagnosis of CMPA through DBPCFC $(n=26)$, the presence of anaphylaxis triggered by cow's milk protein $(n=46)$ or strongly suggestive clinical history associated with positive specific lgE through skin test $(n=51)$. Among the 65 patients with anaphylaxis, 19 confirmed the diagnosis through challenge tests. The control group was consisted of 61 patients (1M: 1.1 F) with ages ranging between 0.66 and 16.7 years (mean 6.86 , median $=6.83$ years). The methodology to stablish the cutoff was the construction of a ROC curve and subsequent calculation of positive and negative predictive value. The cutoff points obtained considering a $98 \%$ specificity and positive predictive value above 95\% were: $3.06 \mathrm{kU} / \mathrm{L}$ for cow's milk, $2.06 \mathrm{kU} / \mathrm{L}$ for/ $\alpha$-lactalbumin, $1.85 \mathrm{kU} /$ $L$ for/ $\beta$-lactoglobulin and $1.47 \mathrm{kU} / \mathrm{L}$ for casein. The value of specific $\lg E$ to cow's milk showed better discriminant capacity than those found for the fractions, being these last values dispensable. In relation to anaphylaxis, the ROC curve constructed from a comparative analysis between patients with and without this manifestation indicated a very high cutoff of $39 \mathrm{kU} / \mathrm{L}$, being without value for the clinical practice. This study showed that the cut off point detected for hole cow's milk was enough for CMA diagnosis, without necessity of the milk fractions evaluation. In the presence of cow's milk anaphylaxis, it is not necessary the $\operatorname{lgE}$ specific cut off value, being the clinical data and the sensitization to cow's milk enough for the CMA diagnosis. 
Descriptors: Food Hypersensitivity / diagnosis, cow's milk, Radioallergosorbent test Methodology, Child,Adolescent 
Introdução 


\section{INTRODUÇÃO}

\section{A. ALERGIA ALIMENTAR}

A alergia alimentar (AA) esta inserida no extenso e variado grupo de reações adversas a alimentos, sendo caracterizada pelo envolvimento do sistema imunológico em sua gênese. Neste contexto, são três os mecanismos atualmente descritos para o desencadeamento destas reações: mediados pela IgE, não mediadas pela $\lg \mathrm{E}$, onde ocorrem preferencialmente respostas imunológicas decorrentes da ativação celular e os processos mistos (Johansson et al, 2004).

A alergia alimentar é especialmente prevalente na faixa etária pediátrica, acometendo entre $6 \%$ a $8 \%$ dessa população e cerca de $2 \%$ a $4 \%$ dos adultos. Assim como ocorreu com os demais processos alérgicos, detectou-se um aumento em sua prevalência nas últimas décadas (SAMPSON, 1999). Em recente publicação do National Center for Health Statistics (CDC-NCHS) avaliando a evolução temporal da prevalência das doenças alérgicas, observouse que, entre o período de 1997 a 2007 , houve um aumento de $18 \%$ nos casos de alergia alimentar nos indivíduos abaixo dos 18 anos de idade (Branum \& Lukacs 2008). 
Entre os fatores de risco associados à maior prevalência de alergia alimentar incluem-se: história familiar de atopia entre parentes de primeiro grau (pais ou irmãos), presença de dermatite atópica e agravos que ocorram no trato gastrintestinal (Wahn \& Von Mutius, 2001; Garside et al, 2004; Björkstén, 2005). Fatores genéticos têm sido estudados merecendo destaque a avaliação da função dos linfócitos $T$ reguladores e os polimorfismos associados aos genes das citocinas IL-10 (Interleucina-10) e TGF- $\beta$ (Transforming growth factor- $\beta$ ) (Frossard et al 2004; Chehade \& Mayer, 2005)

As manifestações clínicas apresentadas pelos pacientes com alergia alimentar podem ser variáveis e dependentes do mecanismo imunológico envolvido. Nos quadros mediados por IgE, os sintomas se iniciam em geral nas duas primeiras horas após a ingestão do alimento. Na pele, as manifestações mais comuns são a urticária e o angioedema; no trato gastrintestinal (TGI), pode ocorrer a síndrome da alergia oral ou vômitos e diarréias imediatos e as manifestações respiratórias incluem o broncoespasmo e sintomas de rinite imediatamente após a ingestão do alimento. Nas alergias alimentares com mecanismos mistos, os pacientes podem apresentar dermatite atópica ou doenças eosinofílicas no TGI com destaque à esofagite eosinofílica. Pacientes cuja alergia alimentar é desencadeada por mecanismos celulares, apresentam frequentemente manifestações gastrintestinais destacando-se a enteropatia e proctite (Nowak-Wegrzyn \& Sampson, 2006, Shaker \& Woodmansee, 2009). 
Um dos aspectos mais importantes da alergia alimentar mediada por lgE é a possibilidade de desenvolvimento de anafilaxia, ressaltando-se que cerca de um terço dos quadros de reação anafilática é desencadeado pela ingestão ou contato com alimentos. Entre os fatores de risco para morte em anafilaxia desencadeada por alimentos, destacam-se a presença de asma de qualquer gravidade, retardo na administração de adrenalina, alergia a amendoim, pacientes adultos jovens e reações a pequenas quantidades de alérgenos (Macdougall et al, 2002; Summers et al, 2008; Arias et al, 2009).

Pacientes com alergia alimentar ou mesmo apenas sensibilizados ao alimento apresentam real risco de desenvolvimento de outras doenças alérgicas especialmente os quadros respiratórios como asma e rinite alérgica (Illi et al 2001). Estudos longitudinais, como a coorte de Poole, confirmam esta afirmação, pois entre os pacientes sensibilizados a alérgenos do leite e ovo havia um risco (odds ratio) 10,7 vezes maior para desenvolvimento de alergias respiratórias (Hanh et al, 2005).

Embora haja uma grande ingestão de alimentos com elevada carga antigênica, cerca de $85 \%$ das manifestações de alergia alimentar estão relacionadas a um grupo pequeno de alimentos destacando-se leite, ovo, soja, trigo, amendoim, crustáceos e castanhas (Sicherer \& Sampson, 2006). Estes alimentos apresentam propriedades estruturais e físico-químicas que mantêm parte de sua estrutura protéica íntegra, mesmo após processos de cocção ou digestão pelo trato gastrintestinal permitindo a manutenção de epítopos 
lineares ou conformacionais que estimulam o sistema imunológico à síntese de lgE específica (Sampson, 1999; Aalberse et al, 2001).

O diagnóstico adequado é ponto crucial em alergia alimentar para evitar a exclusões dietéticas desnecessárias do alimento. A abordagem diagnóstica baseia-se na anamnese, nos exames laboratoriais e nos testes de provocação, em especial o teste de provocação oral duplo cego placebo controlado (TPODCPC). (Vandenplas et al, 2007; Kiml, 2008). A anamnese cuidadosa permitirá avaliar se o sintoma é compatível com alergia alimentar, qual o mecanismo imunológico envolvido e quais os alimentos implicados. É importante ressaltar que a percepção dos pais e pacientes, com relação aos alimentos envolvidos na gênese do sintoma, apresenta pouca acurácia (Bock, 1987; Sicherer \& Sampson, 2006). Considerando a proteína do leite de vaca Bock e Host, em relatos diferentes, descrevem que a prevalência de alergia à proteína do leite de vaca (APLV) baseada apenas em dados de anamnese pode variar entre $5-15 \%$, mas quando os pacientes são avaliados através de critérios mais rigorosos que incluem exames laboratoriais e testes de provocação, a prevalência cai para 2 a 5\% (Bock, 1987; Host, 2002). Desta maneira os exames subsidiários ganham importância como complementares à anamnese. Pacientes com alergia mediada por $\operatorname{lgE}$ podem se beneficiar pesquisa da lgE específica através dos testes de puntura ou pesquisa de $\lg E$ no soro, mas algumas vezes é necessária a realização dos testes de provocação, especialmente o teste de provocação oral duplo cego placebo controlado (TPODCPC), ainda considerado padrão ouro para o diagnóstico de alergia 
alimentar (Williams \& Bock, 1999). Entretanto este teste demanda estrutura adequada e profissionais treinados, não sendo isento de riscos (Niggemann \& Beyer, 2007). Esta é uma das razões para o aprimoramento de métodos diagnósticos cujo objetivo é conseguir maior acurácia, conforto e segurança ao paciente.

\section{B. ALERGIA À PROTEÍNA DO LEITE DE VACA}

A alergia a proteína do leite de vaca apresenta importância singular na faixa etária pediátrica por uma série de fatores: trata-se de um dos alérgenos mais frequentes, o início dos sintomas pode ser bastante precoce, inclusive durante o aleitamento materno e a confirmação do seu diagnóstico implica na exclusão de alimento muito consumido pelas crianças e que constitui uma das bases para sua nutrição, especialmente quando ocorre o desmame (Benhamou et al, 2009). Por outro lado observa-se um número grande de diagnósticos inadequados de APLV que podem levar a dietas restritivas desnecessárias e comprometimento do desenvolvimento da criança sendo, portanto, fundamental o diagnóstico adequado (Rona et al, 2007).

Entre as proteínas que compõem o leite de vaca destacam-se as caseínas, que constituem a parte sólida do leite e as proteínas do soro do leite: $\alpha$-lactoalbumina e $\beta$-lactoglobulina, todas com elevado potencial de alergenicidade por suas características fisicoquímicas destacando-se o peso 
molecular entre 10 e 70 kDa. As caseínas apresentam várias isoformas ( $\alpha$ s1,

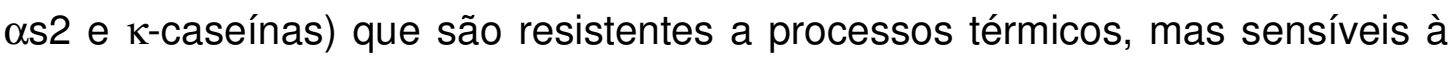
proteólise (Sampson, 1999). Entretanto, mesmo fragmentos resultantes da ação proteolítica podem conservar parte da alergenicidade da proteína íntegra. A sensibilização à $\alpha$ s1-caseína parece estar associada à persistência de alergia à proteína do leite de vaca. A $\beta$-lactoglobulina é um dímero que apresenta peso molecular de $36 \mathrm{kDa}$ sendo bastante resistente à hidrolise ácida, ação das proteases e demais processos digestivos atingindo as porções mais inferiores do trato gastrintestinal em sua forma intacta. A $\alpha$-lactoalbumina apresenta peso molecular de 14,4 kDa e apresenta grande homologia com a $\alpha$-lactoalbumina humana (Wal, 2004).

As manifestações clínicas dos pacientes com APLV mediada por lgE ou mistas não apresentam características específicas quando comparadas a pacientes com alergia a outros alimentos, entretanto, podem ser bastante variadas incluindo quadros gastrintestinais, cutâneos ou sistêmicos (Sampson, 2003; Benhamou et al, 2009). Desta maneira, embora a fisiopatologia da alergia alimentar seja semelhante nestes casos, outros fatores, genéticos e ambientais, podem contribuir para gerar diferenças no quadro clínico ou mesmo na interpretação dos exames laboratoriais utilizados para diagnóstico (Hauk, 2008; Garcia et al 2007). A associação entre alergia alimentar e dermatite atópica ilustra esta situação. 
A dermatite atópica (DA) acomete 15 a 20\% da população pediátrica e cerca de $50 \%$ dos casos se iniciam no primeiro ano de vida (Rance, 2008). Trata-se de uma doença multifatorial onde inúmeros aspectos estão envolvidos. Fatores genéticos contribuem para o comprometimento da barreira cutânea e as alterações imunológicas favorecem a instalação de um intenso processo inflamatório e os fatores ambientais atuam como desencadeantes e agravantes dos sintomas destacando-se agentes infecciosos, fatores irritantes, aeroalérgenos e alérgenos alimentares (Fonacier et al, 2009; Akdis et al, 2006). A concomitância entre dermatite atópica e alergia alimentar ocorre especialmente entre pacientes com quadros moderados e graves, marcadamente em lactentes e pré escolares, variando entre $33 \%$ a $63 \%$ nos diversos estudos publicados entre 1998 e 2008. Já entre os adultos com DA esta associação é pouco comum, atingindo cerca de $2 \%$ dos pacientes (Burks et al,1998; Niggemann et al,1999; Eigenmann \& Calza, 2000; Muto et al, 2003; Rance, 2008). Desta maneira pacientes pediátricos com dermatite atópica constituem um dos grupos que apresenta maior prevalência de alergia alimentar e as proteínas do leite de vaca e do ovo são o principais alérgenos alimentares envolvidos (Werfel et al, 2007).

A anafilaxia é sempre uma situação de extrema urgência e requer todos os cuidados para controle da crise, sendo, um passo obrigatório na abordagem desses pacientes, a detecção dos agentes desencadeantes para se evitar novos episódios. Os alimentos são os principais desencadeantes dos processos 
anafiláticos em muitos dos estudos realizados (WANG \& SAMPSON 2007). No Reino Unido, as admissões em pronto socorro por quadros de anafilaxia cresceram nos últimos vinte anos. No período de 1990 a 1991, foram registrados cinco casos de anafilaxia por milhão de habitantes, já em 2003 e 2004 ocorreram trinta e seis casos (Gupta et al, 2007). Com relação aos alérgenos alimentares, houve um crescimento de cinco por milhão para vinte e seis por milhão, particularmente na população pediátrica. Na Austrália, observou-se um aumento médio anual de 8,8\% na taxa de admissão de pacientes com anafilaxia nos pronto socorros entres os anos de 1994 e 2005 (Poulos et al , 2007).

Os sintomas clínicos de anafilaxia são variados e muitas vezes há um envolvimento sistêmico. Classicamente, o comprometimento cutâneo está presente em 70 a $80 \%$ dos casos caracterizado por prurido, vermelhidão na pele, urticária e angioedema na maior parte dos casos. Vômitos, diarréia, cólica abdominal, dificuldade respiratória, hipotensão, sincope e choque também são descritos como sintomas clássicos. Mais raramente podem ocorrer cefaléia, dor retroesternal e convulsões (Wang et al, 2008).

As proteínas do leite de vaca também estão entre os alimentos que podem causar anafilaxia, mas os alimentos mais classicamente relacionados a reações anafiláticas não fatais são amendoim, castanhas, peixes e crustáceos (Burks \&Sampson, 1999). O leite de vaca parece ter importante papel nas crianças menores, estando relacionado a óbitos por 
anafilaxia nesta faixa etária. Os riscos para óbito decorrente de uma reação anafilática incluem: adolescentes e adultos, presença de asma, consumo de alimentos preparados fora de casa, retardo na admnistração de adrenalina e alergia a amendoim e castanhas (Shah \& Pongracic, 2008).

\section{DIAGNÓSTICO DE ALERGIA À PROTEINA DO LEITE DE VACA}

\section{a. Anamnese}

O diagnóstico de APLV assim como a maior parte das doenças envolve inicialmente uma anamnese cuidadosa que deve permitir:

- a caracterização do sintoma

- a detecção da relação temporal entre início dos sintomas e ingestão do alimento

- a reprodutilbilidade do sintoma após a nova ingestão do alimento, mesmo sem seu reconhecimento na preparação alimentar

- a quantificação do alimento ingerido que supostamente causou o desencadeamento

- a avaliação do tempo de aleitamento materno

- a detecção o momento do primeiro contato com a proteína do leite de vaca

- a avaliação dos hábitos alimentares da família 
- o reconhecimento da presença de antecedentes familiares ou pessoais de atopia

Em situações onde o alérgeno não foi identificado, pode-se orientar a construção de um recordatório alimentar. Tal procedimento permitirá a avaliaçao dos hábitos familiares e a identificação de ingredientes, entre outros aspectos (Kurowski \& Boxer, 2008).

O exame físico deve ser realizado de maneira cuidadosa, mas pode ser absolutamente normal. Deve-se estar atento a sinais de desnutrição, presença de dermatite atópica ou sinais de outras doenças alérgicas, como rinite e asma (Pastorino et al, 2010).

\section{b. Exames complementares}

Os exames laboratorias que auxliam na detecção do alimento ou dos alimentos envolvidos na gênese do sintomas são: a pesquisa da IgE específica in vivo através do teste de puntura ou teste cutãneo de hipersensibilidade imediata, pesquisa de lgE específica in vitro e os testes de provocação (Castro et al, 2010).

1. Pesquisa de IgE específica através do teste cutâneo de hipersensibilidade imediata 
O teste cutâneo de hipersensibildade imediata (TCHI) foi idealizado em 1924, mas modificado por Pepys na década de 70 (Pepys, 1975). Este teste baseia-se nos efeitos causados pela histamina após sua liberação pelo mastócito. Estas células liberam seus mediadores pré-formados após a interação do alérgeno com moléculas de $\lg E$ específica ligadas a receptores de superfície. A inoculação do alérgeno na pele através de uma pequena puntura inicia todo este processo nos pacientes previamente sensibilizados, ou seja, que já possuem IgE específica para o alimento a ser testado.

Trata-se de um teste de simples execução, cujos resultados podem ser obtidos em quinze minutos após sua realização. Entretanto se não for realizado com técnica e material padronizados e , principalmente, sem uma adequada avaliação dos alérgenos a serem investigados, pode-se induzir a conclusões inadequadas. Desta forma, a realização do TCHI para auxílio diagnóstico em alergia alimentar deve partir das observações obtidas na anamnese. No caso da suspeita de APLV pode-se realizar o teste utilizando os extratos comercials do leite de vaca e suas frações ou aplicando-se o próprio alimento in natura, em uma técnica conhecida como prick to prick (Rance et al 1997).

$\mathrm{O} \mathrm{TCH}$ tem sido útil no diagnóstico de alergia à proteína do leite de vaca. A utilização de extratos padronizados confere a este teste elevada especificidade (85 a 90\%), que pode diminuir um pouco em lactentes abaixo de um ano de idade para cerca de $80 \%$. Entretanto, apresenta baixo valor preditivo positivo (40\%), desta maneira, testes podem ser positivos mesmo em pacientes sem qualquer reatividade clínica, pois o TCHI aponta apenas sensibilização e 
não estabelece de maneira isolada uma relação causal entre a presença de lgE específica e os sintomas apresentados pelos pacientes (Sampson \& Albergo, 1984; Bock et al 1988).

Este teste apresenta outros aspectos que ainda devem ser destacados tais como os riscos envolvidos em sua realização, principalmente em pacientes com relato prévio de anafilaxia ao alimento a ser testado, a dificuldade de sua execução em pacientes com diagnóstico de dermatite atópica grave ou a utilização de alguns medicamentos como anti-histamínicos, antidepressivos, corticosteróides orais, estes últimos por tempo prolongado, que alteram a resposta cutânea e influenciam os resultados do exame (Hamilton, 2003; Castro et al, 2010).

\section{Pesquisa de IgE sérica específica}

Logo após a descrição de IgE pelo casal Ishizaka, em 1967, iniciaram-se uma série de estudos para desenvolvimento de métodos laboratoriais para detecção de IgE específica in vitro (Wide et al, 1967). Em 1974, passou-se a adotar comercialmente a primeira técnica de RAST (Radioallergosorbent Test) para avaliação e quantificação de IgE especifica para os diversos alérgenos, incluindo-se alérgenos alimentares. O teste assemelha-se à técnica de ELISA (Enzyme Linked Immuno Sorbent Assay), uma vez que o soro do paciente, que pode conter a $\lg \mathrm{E}$ específica, entra em contato com o alérgeno associado a uma fase sólida e a mensuração do resultado pode ser evidenciada após a 
adição de substância para que pode ser de caratér radioativo, enzimático, entre outros (Ahlstedt et al, 2002). Pelas características técnicas dos primeiros RASTs os resultados eram exibidos de maneira semi quantitativa em classes que variavam de 0 a 6 onde classe 0 significava ausência de reação e classe 6 resultados superiores a 100kU/L (Hamilton, 2003). Nos últimos 10 anos, houve uma evolução tecnológica do método que ainda mantém os mesmos princípios, mas os resultados podem ser avaliados de maneira quantitativa sendo exemplos deste testes o CAP System FEIA, UniCAP, ImmunoCAP® (Phadia Uppsala Pharmacia, 2009) entre outros (Dolen, 2000; Poms et al, 2004; Ahlstedt \&Murray, 2006).

Estes avanços abrangem um aspecto importante do exame que é a construção da fase sólida dos alérgenos. No caso da alergia a proteína do leite de vaca, a fase sólida deve contemplar todos os principais alérgenos ( $\beta$ lactoglobulina, $\alpha$-lactoalbumina e as diferentes caseínas), para que se possa obter o maior número possível de pacientes alérgicos reativos. No ImmunoCAP $P^{\circledR}$ há 85 a $100 \%$ de ligação do soro do paciente alérgico com o alérgeno a ser testado. Ainda com relação aos avanços, houve possibilidade de melhora das curvas de calibração e diluição que conferiram melhor precisão, linearidade e paralelismo às curvas 0 que permitiu a reprodutibilidade dos testes em diversas populações. Atualmente aplica-se a denominação RAST a todos os testes que quantificam a lgE específica no soro dos pacientes (Dolen, 2000; Ahlstedt at al, 2002; Ahlstedt \& Murray, 2006). 
Em alergia alimentar, o RAST apresenta grande utilidade, pois à semelhança do $\mathrm{TCHI}$, detecta e quantifica a presença de $\lg \mathrm{E}$ específica para os diversos alimentos. Uma vantagem em relação ao teste cutâneo é a possibilidade de realização em pacientes que apresentaram anafilaxia, dermatite atópica grave ou que estejam utilizando quaisquer medicações não recomendadas para realização do $\mathrm{TCHI}$. Assim como no $\mathrm{TCHI}$, pode-se realizar a pesquisa de IgE específica para leite e suas fraçoes na suspeita de APLV. O RAST apresenta elevado valor preditivo negativo, mas se positivo indica apenas sensibilização. Desta maneira, a adequada interpretação dos resultados deve ser feita associando-se a informações obtidas na anamnese (Vandenplas et al , 2007).

\section{Testes de provocação oral}

Os testes de provocação oral podem ser realizados para reproduzir os sintomas de alergia alimentar referidos na história ou afastar uma suspeita não confirmada na anamnese. Um aspecto importante a ser ressaltado é o extremo cuidado que se deve ter ao indicar um teste de provocação, pois se trata de procedimento que pode envolver risco de acordo com a sintomatologia. Podem ser realizados de três maneiras:

- Provocação aberta: onde médico e paciente conhecem o momento que o alimento será ingerido. Indicado nos casos onde a história aponta para a 
ausência de correlação entre o sintoma e o alimento suspeito. Este teste de provocação pode ser feito em casa ou em ambiente hospitalar

Teste simples-cego: onde apenas o paciente desconhece o momento que o alimento será ingerido Teste indicado nos casos em que as crianças ou seus familiares apresentam resistência quanto a ingestão de determinado alimento, sendo necessário mascará-lo para que não haja desencadeamento de sintomas apenas pela expectativa de sua ingestão. Nos testes simples-cego é fundamental que o profissional que oferece o alimento não transmita em nenhum momento qualquer sinal do tipo de alimento que está sendo oferecido. Há uma série de veículos sugeridos para o mascarar do alimento a ser testado desde purês de batata, suco de maçã, fórmulas de soja ou mesmo hidrolisados. O teste simples cego deve ser realizado em ambiente adequado ao tratamento de reação adversa e está contra-indicado nos pacientes que apresentam anafilaxia.

- Teste de provocação oral duplo-cego placebo controlado (TPODCPC): onde o momento do alimento ser ingerido é desconhecido pelo médico e pelo paciente, sendo necessária uma fase placebo. Este teste é considerado o padrão ouro para diagnóstico de alergia alimentar. Embora seja, na maior parte das vezes, adotado para fins acadêmicos, há inúmeras situações na prática clínica onde ele pode ser aplicado. Para sua realização é necessária equipe treinada, pois não se trata de teste isento de riscos, devendo ser realizado sempre em ambiente hospitalar. 
Nas últimas décadas, o TPODCPC tem sido considerado o "padrão ouro" para o diagnóstico de alergia alimentar em diversos estudos (Bock et al,,1988; Williams \& Bock, 1999; Niggemann \& Beyer, 2007), pois apresenta qualidades que permitem com que seja usado como referência na determinação de um novo método diagnóstico. Entretanto, em alguns casos de pacientes com história de alergia alimentar bastante sugestiva, o teste de provocação aberta pode ser o exame de escolha para o diagnóstico (Niggemann \& Beyer, 2007),

O TPODCPC apresenta como principal característica a possibilidade de reproduzir os sintomas desencadeados em uma exposição natural sem que pacientes, familiares ou mesmo equipe médica possam influenciar nos resultados, com isto há uma significativa redução de resultados falso positivos. Estima-se que entre $1,8 \%$ a $5 \%$ dos testes apresentem resultados falso negativos decorrentes de doses insuficientes para desencadeamento do sintoma, ausência de contato do alimento com a pele e mucosa oral ou comprometimento da alergenicidade durante o preparo do alimento para a realização do teste. Através deste teste pode-se estimar a dose de alimento necessária para induzir os sintomas e determinar a aquisição de tolerância (Bock \& Atkins, 1990; Williams \& Bock, 1999; Sicherer et al., 2000; Caffarelli \& Petroccione, 2001).

Embora "padrão ouro", há uma série de desvantagens associadas ao TPODCPC destacando-se o tempo necessário para sua realização, os custos envolvidos, estrutura física e a necessidade de mobilização de pessoal treinado 
análise dos resultados e possíveis eventos adversos. Há dificuldades na escolha do veículo que oculte adequadamente o alimento a ser testado, especialmente em crianças pequenas, principal grupo com APLV, pela dificuldade da ingestão do alimento em cápsulas (Niggemann \& Beyer, 2007; Nowak-Wegrzyn et al, 2009).

Quando se tem um teste de excelência para obtenção de determinado diagnóstico espera-se que o resultado seja positivo ou negativo, o que nem sempre ocorre quando se realiza o TPODCPC. Há dúvidas quando o paciente apresenta alguns episódios de vômitos, que podem ser um sinal de teste positivo, mas também uma manifestação de origem psicológica (Niggemann \& Beyer, 2007), tanto que se recomenda apenas interromper o teste se os vômitos forem graves ou repetidos. A localização das urticárias também pode gerar dúvidas, pois pápulas peri-orais podem estar relacionadas a urticária de contato sem qualquer conseqüência após a ingestão do alimento, entretanto lesões à distância já podem indicar um teste positivo. Sintomas subjetivos também podem ser difíceis de serem avaliados, formigamento na língua, palpitações e dor abdominal são queixas que podem ser o início de um processo mais generalizado, mas não são suficientes para a interrupção do TPODCPC (Niggemann \& Beyer, 2007; Nowak-Wegrzyn et al, 2009).

Por todos estes aspectos buscam-se alternativas à realização do TPODCPC para o diagnóstico de alergia alimentar. 


\section{DOSAGEM SÉRICA DE IGE ESPECÍFICA PARA DIAGNÓSTICO DE ALERGIA A PROTEÍNA DO LEITE DE VACA: UMA ALTERNATIVA AO TESTE DE PROVOCAÇÃO ORAL DUPLO CEGO PLACEBO CONTROLADO.}

O desenvolvimento destas novas técnicas de detecção sérica da lgE específica, em especial o ImmunoCAP® , permitiu a obtenção de resultados quantitativos que poderiam ter uma maior relação com o diagnóstico de alergia alimentar (Sampson \& Ho, 1997; Sampson 2001; Garcia-Ara et al 2001, Boyano-Martinez et al 2001).

O objetivo foi construir curvas que pudessem estabelecer pontos de corte ou concentrações de lgE discriminantes acima dos quais os valores preditivos positivos (VPP) e negativos (VPN) fossem bastante elevados podendo ser evitada a realização do TPODCPC.

Nos últimos 10 anos vários trabalhos foram publicados propondo e discutindo os valores de corte para o diagnóstico de alergia alimentar (Sampson \& Ho, 1997; Sampson, 2001; Garcia-Ara et al, 2001; Boyano-Martinez et al ,2001). O que se almeja são resultados com grande poder diagnóstico objetivando-se, desta maneira, elevados valores preditivos positivos (VPP). Entretanto desde os primeiros estudos publicados, observou-se uma grande variação de pontos de corte para um mesmo alimento. Tomando-se como exemplo o leite, os primeiros relatos de Sampson e Ho, em 1997 descreveram pontos de corte para leite de vaca com valores de IgE específica acima de 32 $\mathrm{kU} / \mathrm{L}$ que conferiram VPP de $95 \%$, sensibilidade de $51 \%$ e especificidade de 
98\%. Porém, a casuística foi composta exclusivamente de pacientes com dermatite atópica que apresentam, pelas características fisiopatológicas da doença, valores muito elevados de $\lg E$ total e uma prevalência de alergia alimentar bem maior que a população em geral (Werfel \& Breuer, 2004). Esta observação foi ratificada pelos novos valores apresentados por Sampson et al em uma segunda avaliação que incluiu 62 pacientes com alergia alimentar, onde $61 \%$ apresentavam dermatite atópica, um número ainda grande de pacientes (2001). Desta vez o resultado obtido de lgE específica com elevado VPP (94\%) com sensibilidade de $57 \%$ e especificidade de $94 \%$ foi de $15 \mathrm{kU} / \mathrm{L}$. Garcia-Ara et al (2001) também se destacaram avaliando lactentes até um ano de idade e encontraram valores de $\lg E$ específica de $5 \mathrm{kU} / \mathrm{L}$, com elevados valores preditivos positivos (95\%).

Em 2007, Sopo et al avaliaram os diversos estudos publicados (QUADRO 1) referentes ao estabelecimento de um valor de $\lg E$ discriminante para o diagnóstico de alergia alimentar e teceram comentários bastante pertinentes relacionados às diferentes metodologias adotadas e os resultados obtidos. Segundo os autores, estas variações podem estar relacionadas a diversos aspectos: sintomas apresentados pelo grupo de pacientes incluídos, sua faixa etária e características genéticas. Outro fator a ser observado é que nenhum dos estudos avaliou o papel das diferentes frações da proteína do leite de vaca para obtenção de valores de corte com adequados valores preditivos. 
Quadro 1. Características da metodologia e resultados dos diversos estudos publicados sobre a tentativa de se estabelecer um valor discriminante de concentração de lgE específica para diagnóstico de APLV.

\begin{tabular}{|c|c|c|c|c|c|}
\hline Autores & População avaliada & $\mathbf{N}$ & $\begin{array}{c}\text { Concentração de lgE } \\
\text { específica para leite de } \\
\text { vaca }\end{array}$ & VPP & Obs \\
\hline $\begin{array}{c}\text { Sampson e Ho } \\
1997\end{array}$ & $\begin{array}{c}\text { Pacientes com } \\
\text { dermatite atópica }\end{array}$ & 109 & $32 \mathrm{kU} / \mathrm{l}$ & $95 \%$ & $\begin{array}{l}\text { Se: } 51 \% \\
\text { Es: } 98 \%\end{array}$ \\
\hline $\begin{array}{l}\text { Sampson } \\
2001\end{array}$ & $\begin{array}{l}61 \% \text { DA, } 82 \% \text { alérgico } \\
\text { a mais de um alimento }\end{array}$ & 62 & $15 \mathrm{kU} / \mathrm{l}$ & $95 \%$ & VPP: 95 \\
\hline $\begin{array}{l}\text { Roehr et al. } \\
2001\end{array}$ & Todos com DA & 71 & $50 \mathrm{kU} / \mathrm{l}$. & $95 \%$ & $\begin{array}{l}\text { Valores inferiores } \\
\text { revelaram baixos VPP e Es }\end{array}$ \\
\hline $\begin{array}{c}\text { Garcia-Ara et al } \\
2001\end{array}$ & $\begin{array}{c}\text { Todos abaixo de } 1 \\
\text { anos }\end{array}$ & 170 & $5 \mathrm{kU} / \mathrm{l}$. & $95 \%$ & $\begin{array}{l}\text { Se: } 30 \% \\
\text { Es: } 98 \%\end{array}$ \\
\hline $\begin{array}{l}\text { Saarinen et al } \\
2001\end{array}$ & $\begin{array}{l}\text { Envolveu crianças com } \\
\text { suspeita IgE mediada } \\
\text { ou não. Provocação } \\
\text { Aberta }\end{array}$ & 118 & $3.5 \mathrm{kU} / \mathrm{l}$ & $94 \%$ & $\begin{array}{l}\text { Se:25\% } \\
\text { Es:98\%; }\end{array}$ \\
\hline $\begin{array}{l}\text { Celik-Bilgili et al. } \\
2005\end{array}$ & $88 \%$ com DA & 501 & $88.8 \mathrm{kU} / \mathrm{l}$. & $90 \%$ & $\begin{array}{c}\text { Não calculou para este } \\
\text { valor }\end{array}$ \\
\hline
\end{tabular}

$\mathrm{Se}=$ sensibilidade, $\mathrm{Es}=$ especificidade 
A obtenção de um método diagnóstico pouco invasivo e com elevado grau de eficácia (adequado valor preditivo positivo e negativo) garante segurança ao médico em diagnosticar, de maneira correta, pacientes com alergia à proteína do leite de vaca mediado por lgE. Com isto, é possível introduzir a terapêutica apropriada e garantir à criança adequado desenvolvimento nutricional e minimização de riscos de reações mais graves. A Unidade de Alergia e Imunologia do Instituto da Criança do Hospital das Clínicas da FMUSP conta com um ambulatório específico de alergia alimentar onde a maior parte dos pacientes apresenta alergia à proteína do leite de vaca desencadeada por mecanismos IgE mediados ou mistos. Desta maneira a avaliação dos valores de $\lg E$ sérica específica para leite de vaca nestes pacientes pode contribuir para o estabelecimento de pontos de corte na nossa população. 
Objetivos 


\section{OBJETIVOS}

\section{Objetivo primário}

- Estabelecer uma concentração discriminante de $\operatorname{lgE}$ sérica específica para leite de vaca e suas frações proteicas para o diagnóstico de alergia à proteína do leite de vaca (APLV).

\section{Objetivo secundário}

- Avaliar se há diferentes concentrações discriminantes de $\lg E$ específica para leite de vaca no grupo de pacientes com anafilaxia desencadeada pela proteína do leite vaca. 
Métodos 


\section{MÉTODOS}

\section{A. Casuística}

Após aprovação do projeto pelos comitês de ética em pesquisa da instituição e do complexo hospitalar, foi constituída uma amostra de conveniência composta por todas as crianças matriculadas no ambulatório de alergia alimentar da Unidade de Alergia e Imunologia do Instituto da Criança (ICr) HCFMUSP. O estudo apresentou dados prospectivos com informações coletadas em prontuário, sendo avaliadas as crianças já matriculadas e todas as novas crianças admitidas a partir do início do estudo até março de 2009.

Foram adotados os seguintes critérios de inclusão:

- Crianças que apresentaram história clínica sugestiva de alergia à proteína do leite de vaca e teste duplo cego placebo controlado positivo ao desencadeamento pelo leite de vaca.

- Crianças que apresentaram história clínica sugestiva de alergia à proteína do leite de vaca com manifestações de anafilaxia em pelo menos um episódio associado com a ingestão confirmada do leite de vaca. O critério de definição de anafilaxia adotado foi o proposto pelo Second symposium on the definition and management of anaphylaxis (Joint Task Force on Practice Parameters, 2005) 
- Crianças que apresentaram história sugestiva de alergia alimentar associada à provocação oral aberta positiva e deteç̧ão de lgE específica através do TCHI.

Foram excluídas crianças que no momento da inclusão no ambulatório já se apresentavam tolerantes à proteína do leite de vaca ou cujos exames diagnósticos excederam ao período de um ano desde o último relato de presença de sintomas após provocação aberta ou TPODCPC.

Todas as crianças foram incluídas em um protocolo padronizado de avaliação clínica que contempla historia detalhada dos sintomas, antecedentes pessoais e familiares de atopia, hábitos de vida incluindo tempo de aleitamento materno, data da primeira introdução do leite de vaca e escapes ocorridos até a realização do exame para diagnóstico.

Com relação às manifestações clínicas não anafiláticas, os seguintes sintomas foram considerados como relacionados à APLV mediados por lgE caso ocorram em até 2 horas após ingestão confirmada deste alérgeno (Nowak-Wegrzyn \&, Sampson 2006)

a. Pele: urticária, angioedema, eczema, exantema morbiliforme urticária de contato.

b. Sistema digestório: vômitos, diarréia, dor abdominal, síndrome da alergia oral.

c. Sistema respiratório: broncoespasmo tosse estridor, rinoconjuntivite, dispnéia, cianose. 


\section{B. Exames Complementares}

a. O teste duplo cego-placebo controlado foi realizado no Hospital Dia do Instituto da Criança, sendo adotada técnica padronizada pela Unidade de Alergia e Imunologia e baseada nas descrições de Willians e Bock (1999)

Este teste foi dividido em três fases, a saber:

Fase 1: Pré-teste. Responsáveis pelo paciente foram reorientados quanto à necessidade de exclusão do leite de vaca e não administrar antihistamínicos 10 dias antes do procedimento, corticosteróides, 1 mês e qualquer medicamento nas 12 horas que antecedem ao teste. Pacientes foram encaminhados ao teste com jejum de 6 horas.

Fase 2. Teste. O teste foi realizado em ambiente hospitalar, com duração de aproximadamente dez horas e foi dividido em dois períodos: manhã e tarde. Nestes períodos o paciente recebeu volumes fixos de $60 \mathrm{~mL}$ em intervalos de 15 a 30 minutos até completar $300 \mathrm{~mL}$. No período em que recebeu o leite de vaca, foram administradas doses crescentes deste (5, 10, 15, 20 e $25 \mathrm{~mL}$ ) sempre adicionadas ao veículo para perfazer um volume total de $60 \mathrm{~mL}$. É importante ressaltar que o veículo utilizado mascarou o sabor e o aspecto do leite de vaca e que somente um profissional não envolvido diretamente com o paciente soube qual dos períodos continha o leite ou apenas o veículo. Além disto, utilizou-se leite com baixo teor de lactose para excluir manifestações clínicas relacionadas à intolerância ao açúcar contido no leite. 
Estas duas fases do exame puderam ou não ser realizadas no mesmo dia, dependendo do sintoma a ser deflagrado, por exemplo, piora da dermatite atópica poderá ocorrer até 48horas após a ingestão do alérgeno, portanto nestes casos há necessidade de dois períodos em dias diferentes com intervalo de sete dias entre eles. Ao fim do teste, caso o resultado tivesse sido negativo, o paciente realizou uma fase aberta onde foi ingerido o leite de vaca aguardando-se um período de pelo menos 1 hora ainda em ambiente hospitalar. Ao apresentar qualquer sintoma durante o teste, o paciente foi avaliado pelo médico responsável que decidiu quais condutas seriam tomadas inclusive medicação e interrupção do teste, sendo todo o procedimento registrado em formulário específico (Gushken, 2009).

Fase 3. Pós-teste. O responsável pelo paciente foi orientado a acompanhar, informar e anotar eventuais sintomas ocorridos até uma semana após finalização do teste, permanecendo em dieta de exclusão. No retorno, o paciente recebeu as orientações com relação às próximas condutas a serem tomadas.

\section{b.. O teste cutâneo de hipersensibilidade imediata (TCHI) para} pesquisa de IgE específica in vivo foi realizado na Unidade de Alergia e Imunologia do Instituto da Criança. Em todos os pacientes foi utilizada a região volar do antebraço, onde foi aplicada uma gota do extrato de leite de vaca e frações $\alpha$-lactoalbumina, $\beta$-lactoglobulina e caseína, uma gota de controle positivo (histamina) e outra gota de controle negativo. Foi 
realizada uma pequena puntura com dispositivo padronizado e estéril, aguardando-se cerca de 15 minutos para a leitura. A resposta foi baseada na reação de hipersensibilidade do tipo I onde, pela presença de IgE específica contra o alimento testado, ocorre a degranulação de mastócitos e liberação de histamina que, após 15 minutos, leva à vasodilataçao, hiperemia e prurido, formando uma pápula, cuja medida permitiu a leitura de resultados. A pápula formada foi comparada à pápula produzida pela histamina (controle positivo) e pelo controle negativo (excipiente utilizado no extrato alergênico). Consideraram-se positivos resultados de pápula superior a três milímetros desde que se mantivesse uma diferença mínima de dois $\mathrm{mm}$ em relação ao controle negativo. Foi realizada também uma variação deste teste denominada prick to prick, onde, ao invés da utilização de extratos, o leite pode ser oferecido na forma in natura aplicado sobre a pele do paciente, sendo considerados positivos os mesmos valores no teste convencional (Pepys, 1975)

c.. Todos os pacientes com diagnóstico de alergia a proteína do leite de vaca foram submetidos à dosagem de IgE específica para os seguintes alérgenos: leite de vaca, caseína, $\alpha$-lactoalbumina, $\beta$-lactoglobulina. Todos os testes foram realizados no Laboratório de Investigação Médica - 60 da Faculdade de Medicina da USP. Foi considerado para a avaliação o primeiro exame realizado pelo paciente ao ingresso no ambulatório. Esta dosagem foi realizada através do ImmunoCAP $P^{T M}$, um ensaio de que imunoenzimático e fluorescência. Para a realização do teste, selecionaram-se os alérgenos que apresentados em cápsulas individuais denominadas caps. A cada um 
destes caps foram adicionados $50 \mu$ de soro do paciente para que, se houvesse $\lg \mathrm{E}$ específica ao alérgeno, ocorresse a ligação. Concomitantemente foram preparados caps para a determinação de concentrações conhecidas de $\lg \mathrm{E},(0,35 ; 0,7 ; 3,5 ; 17,5 ; 50$ e $100 \mathrm{kU} / \mathrm{I})$, para construção de curva padrão e comparação dos resultados. Após esta etapa, foi iniciado o processo de agitação e lavagem realizado em aparelho específico para esta técnica. Ocorreu, então, um período de incubação de 30 minutos. Antes do término deste período, foram adicionados $50 \mu \mathrm{l}$ de anticorpo anti-IgE ligado a enzima ( $\beta$-galactosidase ligada a anticorpos desenvolvidos em coelho). Novamente houve agitação e incubação por 150 minutos e subseqüente lavagem. Foram adicionados $50 \mu$ da solução de desenvolvimento (substrato fluorescente para a ação da enzima) e esta mistura permaneceu em incubação por dez minutos e foi interrompida através da adição de carbonato de sódio. A leitura de fluorescência foi realizada em aparelho próprio e os valores obtidos serão comparados aos obtidos pela curva-padrão, calculada a partir da $\lg E$ total dosada. Os concentrações obtidos foram expressos em kU/L (Leimgruber at al 1989; Bousquet et al 1990 ; Johansson \& Yman 1988)

\section{Grupo Controle}

Para a avaliação dos dados obtidos foi necessária a inclusão de um grupo controle composto por crianças encaminhadas ao ambulatório de alergia alimentar com suspeita diagnóstica de alergia a proteína do 
leite de vaca cuja avaliação através da anamnese, exames laboratoriais ou teste de provocação permitiu a exclusão deste diagnóstico.

\section{Aspectos éticos}

Este projeto foi avaliado e aprovado pelos comitês de ética em pesquisa da instituição Comitê de Ética em Pesquisa do Instituto da Criança do HCFMUSP e pela CAPPesq (Comissão de Ética para Análise de Projetos de Pesquisa do HCFMUSP) sob número ํㅜ1375/06. É importante ressaltar que os dados utilizados neste projeto relacionam-se a procedimentos de rotina diagnóstica do ambulatório de alergia alimentar da Unidade de Alergia e Imunologia do Instituto da Criança- HCFMUSP e familiares e/ou pacientes já assinam TCLE (termo de consentimento livre e esclarecido) previamente à realização dos procedimentos.

\section{E. Análise Estatística}

Os dados relacionados às características epidemiológicas e clínicas foram apresentados em figuras e tabela para a caracterização da amostra avaliada.

Foi elaborada uma receiving operating characteristic curve (curva ROC) para determinação da concentração de lgE específica para leite de vaca e suas frações que conferisse adequados valores de sensibilidade e especificidade. A curva ROC foi considerada adequada quando a área 
sobre a curva, que representa a acurácia do método, foi maior que 0,8. A construção da curva ROC utilizou o programa Med Calc10 1.2.0 sendo selecionados os pontos que atenderam os seguintes critérios: especificidade $\geq 95 \%$, sensibilidade adequada e razão de verossimilhança positiva $\geq 10$. A razão de verossimilhança é definida como o quociente obtido da razão entre pacientes alérgicos que apresentam teste positivo (sensibilidade) e pessoas não alérgicos que também apresentam testes positivos (falsos positivos). (Deeks \& Altman, 2004)I

Uma nova curva ROC foi elaborada para determinação da concentração de IgE específica para leite de vaca considerando-se os seguintes grupos distintos: pacientes com anafilaxia e pacientes sem anafilaxia para avaliação dos valores de sensibilidade e especificidade (Doria-Filho, 1999)

As concentrações obtidas de $\lg E$ específica para proteína do leite de vaca e suas frações (caseína, $\alpha$-lactoalbumina, $\beta$-lactoglobulina) também foram avaliados em tabelas de contingência para cálculo do valor preditivo positivo (VPP), valor preditivo negativo (VPN).

Os valores que conferiram os melhores resultados (adequado VPP, VPN e razão de verossimilhança) foram considerados valores de corte para diagnóstico da alergia a proteína do leite de vaca, considerando-se todos os alérgenos testados.

Estes mesmos parâmetros (sensibilidade, especificidade, VPP, VPN e razão de verossimilhança) foram avaliados considerando-se as 
concentrações de lgE especifica para o leite de vaca previamente propostas pela literatura (5kU/L, Garcia-Ara et al e $15 \mathrm{kU} / \mathrm{L}$, Sampson) como determinantes para o eximir o paciente do TPODCPC.

Para cálculo destes valores foi utilizado o programa Graphpad Instat 3 
Resultados 


\section{RESULTADOS}

\section{A. Caracterização da Casuística}

Foram incluídos 123 pacientes (1,3M:1F) com diagnóstico de alergia a proteína do leite de vaca, de acordo com a definição dos critérios de inclusão e exclusão, com predomínio de pacientes diagnosticados através de provocação aberta (Figura 1) seguidos de 53,6\% dos pacientes incluídos que apresentaram pelo menos um episódio de anafilaxia. Dez pacientes que apresentaram inicialmente anafilaxia foram submetidos ao TPODCPC pelo menos um ano após o episódio sem que tivesse havido repetição desta manifestação.

Figura 1- Distribuição dos 123 pacientes com APLV segundo os critérios de inclusão

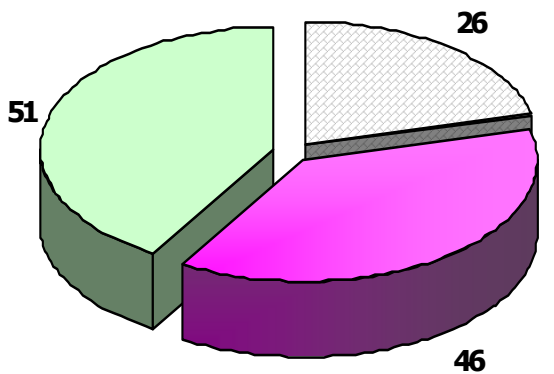

$\square$ TPODCPC $\square$ Anafilaxia $\square$ Provocação Aberta 
A Figura 2 ilustra a distribuição quanto ao início dos sintomas destacando-se que $87,7 \%$ dos pacientes apresentaram sintomas nos primeiros seis meses de vida. A idade atual dos pacientes variou entre 8,6 meses a 19,5 anos com mediana de 7,9 anos.

Figura 2 - Idade do início dos sintomas de APLV em 123 pacientes avaliados

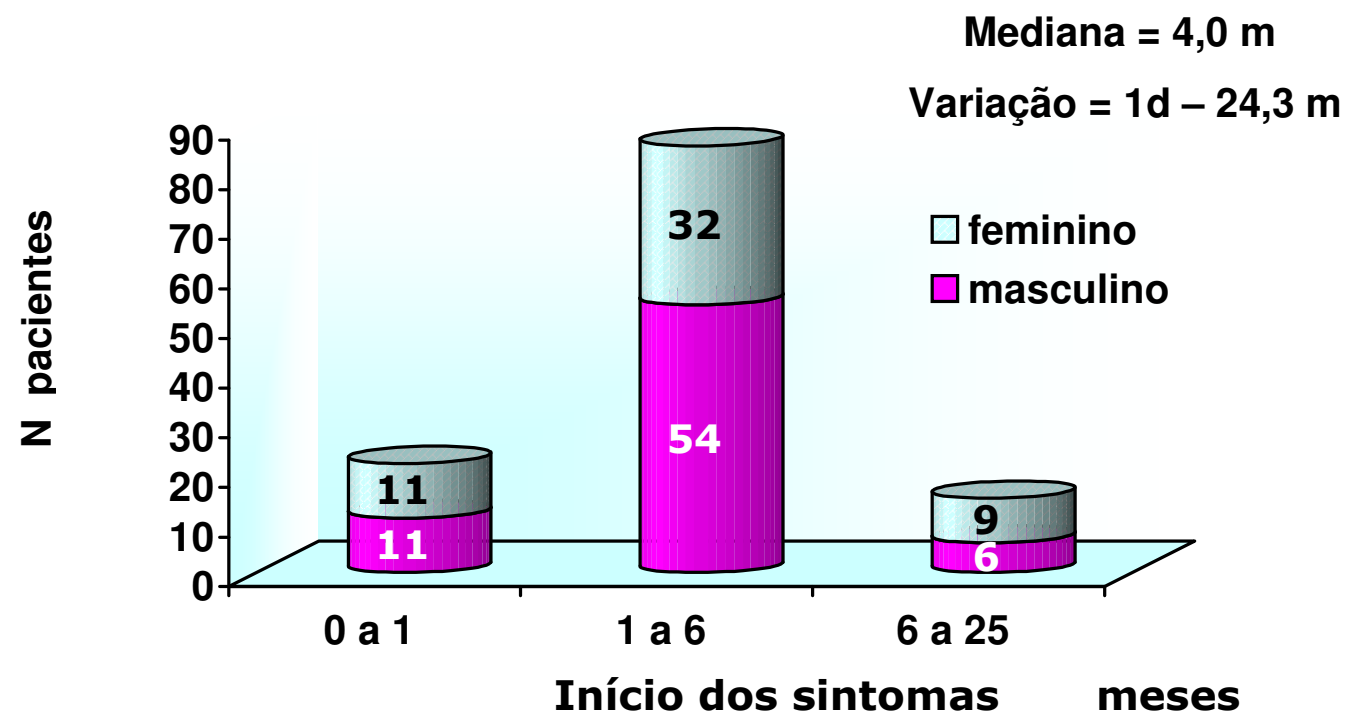

Os sintomas cutâneos e respiratórios predominaram em relação aos demais e $71,3 \%$ dos pacientes apresentaram associação de sistemas envolvidos (Figuras 3 e 4). Urticária e angioedema foram as manifestações 
mais prevalentes, seguidos de vômitos e dispnéia (Tabela 1). A associação com outras doenças alérgicas foi observada em sessenta e quatro pacientes (Figura 5). Os antecedentes familiares de atopia foram referidos em $63,4 \%$ dos pacientes sendo mais freqüente a presença de mãe atópica (Figura 7). As concentrações de $\lg \mathrm{E}$ total (mediana $=150 \mathrm{Ul} / \mathrm{mL}$ ) apresentaram grande variação $(1-12380 \mathrm{UI} / \mathrm{mL})$. Os valores de $\lg E$ total entre os 23 pacientes com dermatite atópica variaram entre 24 e $10180 \mathrm{UI} / \mathrm{mL}$, com mediana de 129 $\mathrm{UI} / \mathrm{mL}$.

Figura 3 - Distribuição das manifestações clínicas de 123 pacientes com APLV segundo os sistemas envolvidos

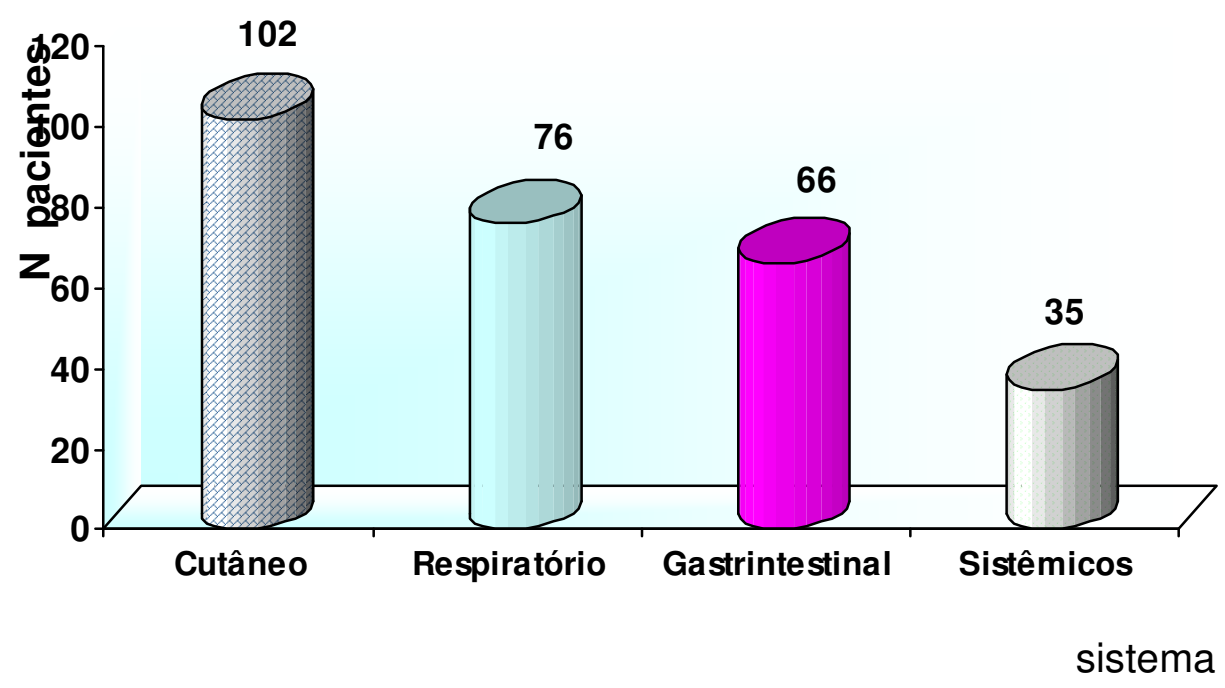


Figura 4 - Distribuição das manifestações clínicas dos 87 pacientes com APLV segundo a associação de sistemas envolvidos

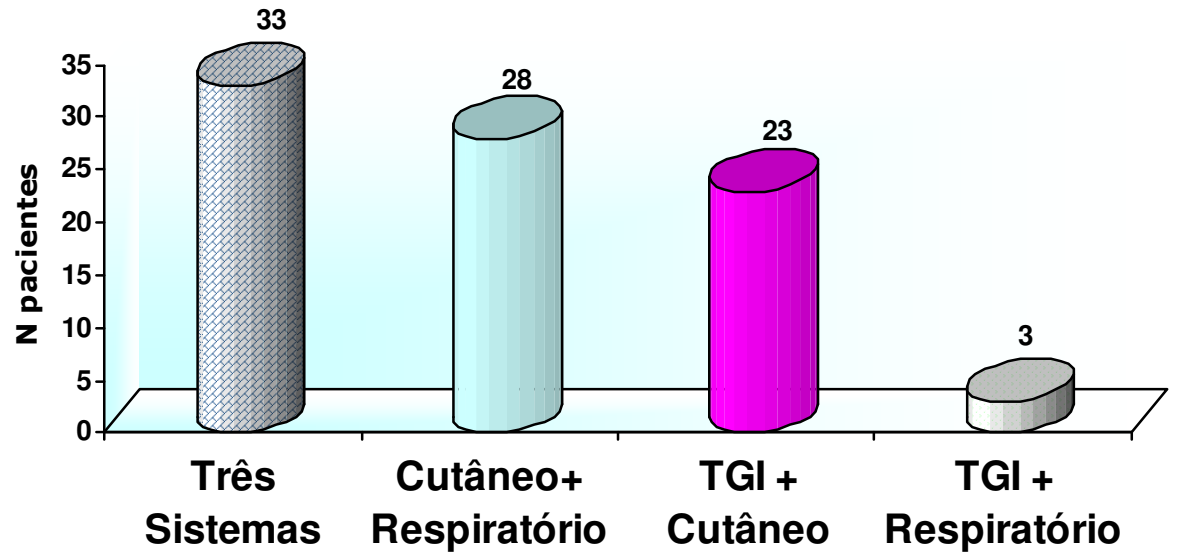


Tabela 1 - Distribuição das manifestações clínicas apresentadas pelos 123 pacientes com APLV

\begin{tabular}{|c|c|c|}
\hline Sintomas & $\begin{array}{c}\text { Manifestções } \\
\text { Clínicas }\end{array}$ & Distribuição Percentual \\
\hline \multirow{4}{*}{ Cutâneos } & Angioedema & 51,2 \\
\hline & Eritema & 19,5 \\
\hline & Urticária & 58,5 \\
\hline & $\begin{array}{l}\text { Urticária de } \\
\text { contato }\end{array}$ & 4,0 \\
\hline \multirow{4}{*}{ Gastrintestinais } & Síndrome da & 15 \\
\hline & Alergia Oral & 15,4 \\
\hline & Diarréia & 11,3 \\
\hline & Vômitos & 43,0 \\
\hline \multirow{5}{*}{ Respiratórios } & Chiado & 24,3 \\
\hline & Estridor & 17,0 \\
\hline & Rinoconjuntivite & 13,0 \\
\hline & Dispnéia & 27,6 \\
\hline & Tosse & 25,2 \\
\hline \multirow{5}{*}{ Sistêmicos } & Choque & 1,6 \\
\hline & Cianose & 16,0 \\
\hline & Hipotermia & 0,8 \\
\hline & Hipotonia & 13,8 \\
\hline & $\begin{array}{c}\text { Perda de } \\
\text { Consciência }\end{array}$ & 3,25 \\
\hline
\end{tabular}


Figura 5 - Distribuição de outras manifestações alérgicas referidas pelos 123 pacientes com APLV

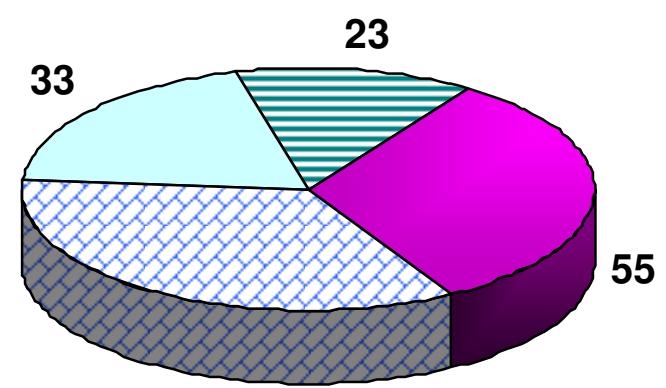

59

$\square$ Ausentes $\square$ Asma $\quad$ Dermatite Atópica $\square$ Rinite Alérgica

Figura 6 - Distribuição dos 123 pacientes com APLV segundo os antecedentes familiares de atopia

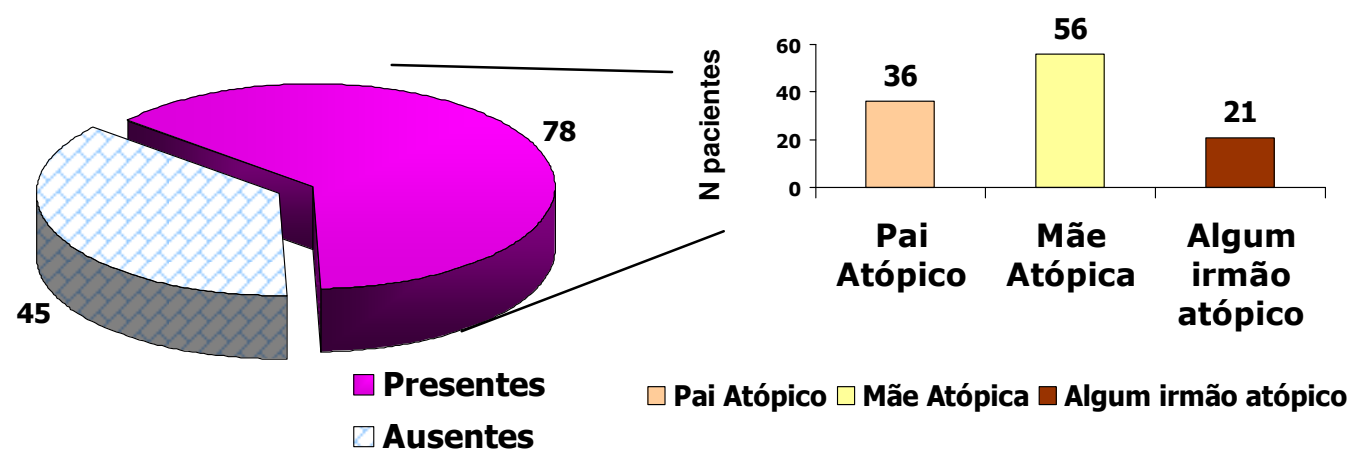


B. Concentração discriminante de IgE específica para leite de vaca e frações para o diagnóstico de alergia à proteína do leite de vaca

A idade de determinação das concentrações de IgE específica nos 123 pacientes com APLV variou entre 3,5 meses e 13,21 meses com mediana de 1,9 anos. O grupo controle foi composto por 61 pacientes $(1 \mathrm{M}: 1,1 \mathrm{~F})$ com idade variando entre 0,6 e 16,7 anos (mediana=6,83).

a. Curvas ROC para obtenção das concentrações discriminantes de IgE específica para leite de vaca e frações

As curvas ROC para concentrações de lgE específica para leite de vaca e as frações $\alpha$-lactoalbumina, $\beta$-lactoglobulina e caseína se mostraram adequadas com área sobre a curva maior que 0,8 (Figuras 7, 8, 9 e 10), sendo estabelecidas as concentrações discriminantes ou pontos de corte que conferiram elevada sensibilidade ( $\geq 95 \%$ ) e melhor VPP, sem grande prejuízo da sensibilidade e especificidade e razão de verossimilhança acima de 10 (Anexos G,H,I,J). 
Figura 7. Curva ROC para determinação de ponto de corte para valores de IgE específica para leite de vaca para o diagnóstico de APLV

\begin{tabular}{|c|c|}
\hline Características da Curva & \multicolumn{1}{|c|}{} \\
\hline Área sobre a curva & 0,929 \\
\hline EOC (AUC) & \\
\hline 95\% Intervalo de confiança & $\mathbf{0 , 0 1 8 4}$ \\
\hline
\end{tabular}

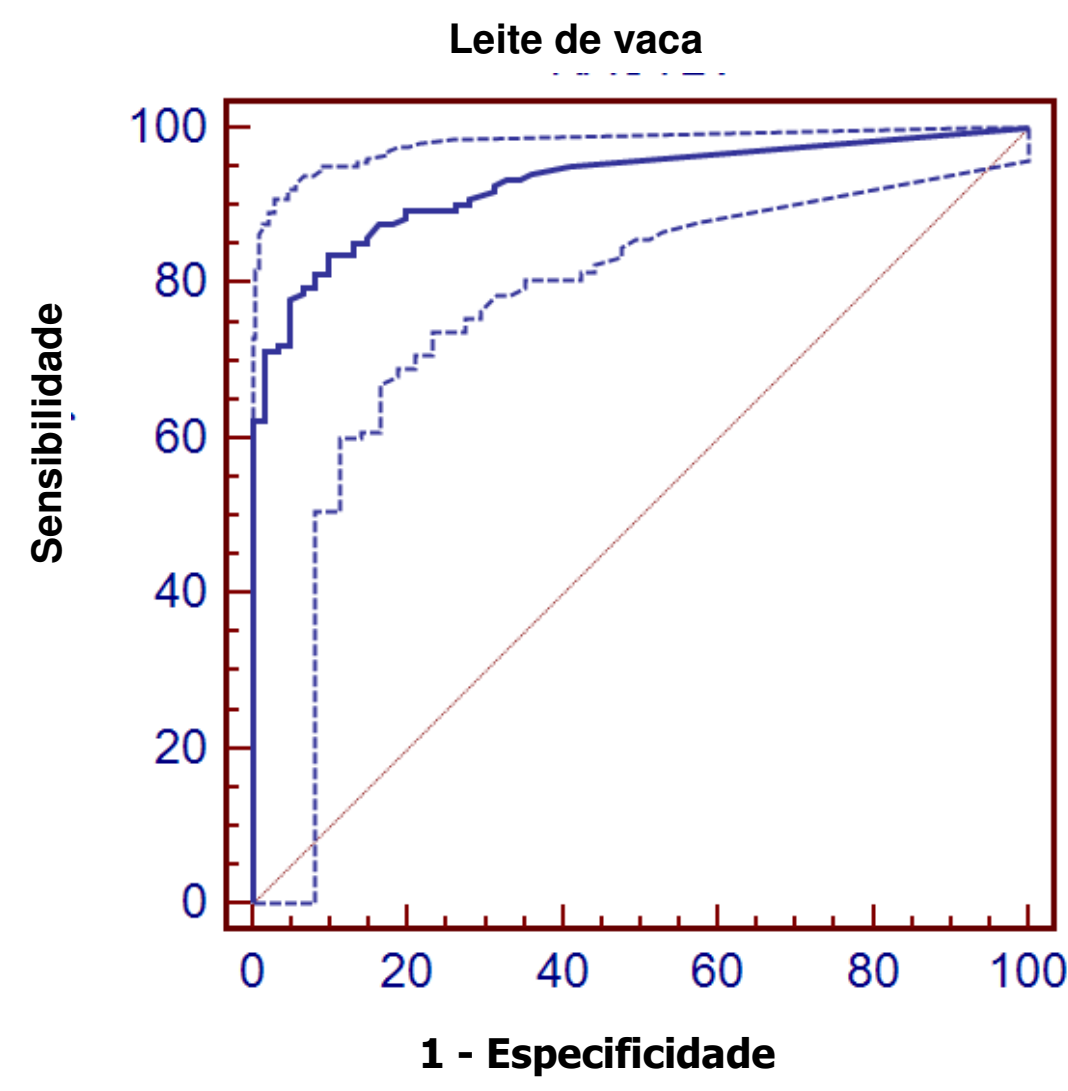


Figura 8 - Curva ROC para determinação de ponto de corte para valores de IgE específica para $\alpha$-lactoalbumina para o diagnóstico de APLV

\begin{tabular}{|c|c|}
\hline Características da Curva & \multicolumn{2}{|c}{} \\
\hline Área sobre a curva ROC (AUC) & $\mathbf{0 , 8 2 8}$ \\
\hline Erro padrão & $\mathbf{0 , 0 3 1 8}$ \\
\hline $95 \%$ Intervalo de confiança & $\mathbf{0 , 7 6 0}$ a $\mathbf{0 , 8 8 3}$ \\
\hline
\end{tabular}

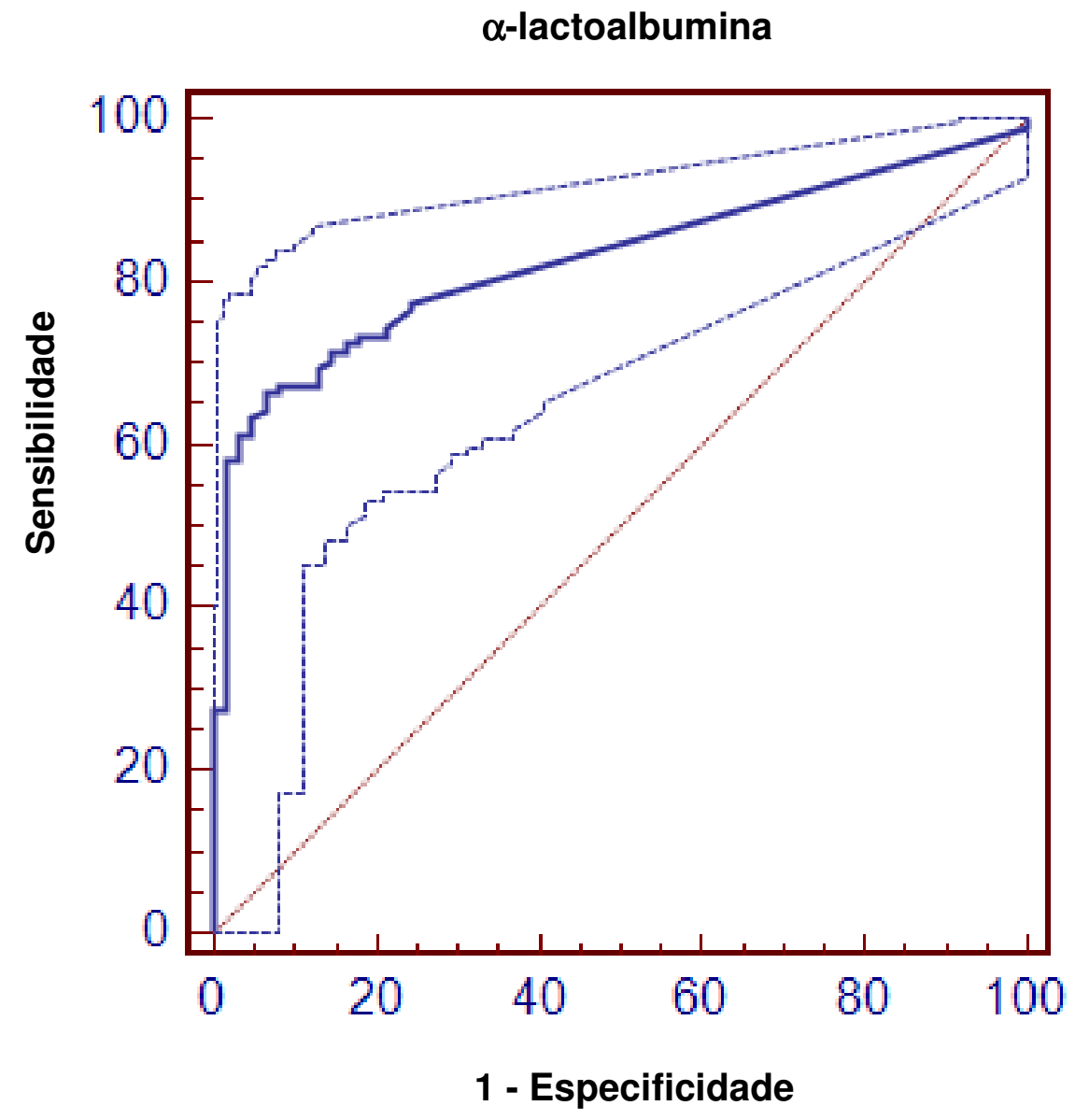


Figura 9 - Curva ROC para determinação de ponto de corte para valores de IgE específica para $\beta$-lactoglobulina para o diagnóstico de APLV

\begin{tabular}{|l|l|}
\hline \multicolumn{2}{|c|}{ Características da Curva } \\
\cline { 1 - 2 } Área sobre a curva ROC (AUC) & $\mathbf{0 , 8 5 6}$ \\
\hline Erro padrão & $\mathbf{0 , 0 2 9 2}$ \\
\hline $95 \%$ Intervalo de confiança & $\mathbf{0 , 7 9 1}$ a $\mathbf{0 , 9 0 7}$ \\
\end{tabular}

\section{$\beta$-lactoglobulina}

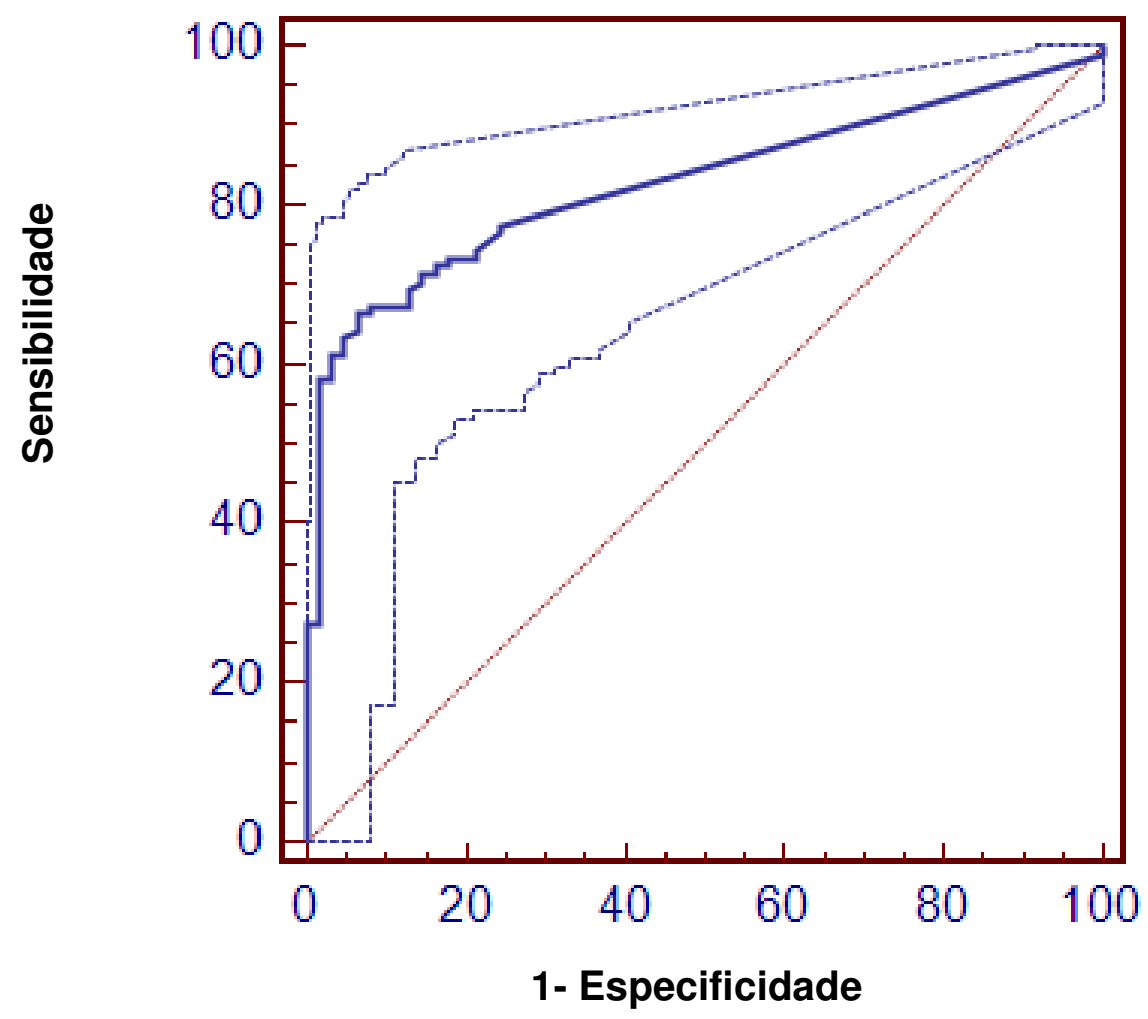


Figura 10 - Curva ROC para determinação de ponto de corte para valores de IgE específica para caseína para o diagnóstico de APLV

\begin{tabular}{|l|l|}
\hline \multicolumn{2}{|l|}{ Características da Curva } \\
\hline Área sobre a curva ROC (AUC) & $\mathbf{0 , 8 4 9}$ \\
\hline Erro padrão & $\mathbf{0 , 0 2 9 4}$ \\
\hline $95 \%$ Intervalo de confiança & $\mathbf{0 , 7 8 5}$ a 0,901 \\
\hline
\end{tabular}

\section{caseína}

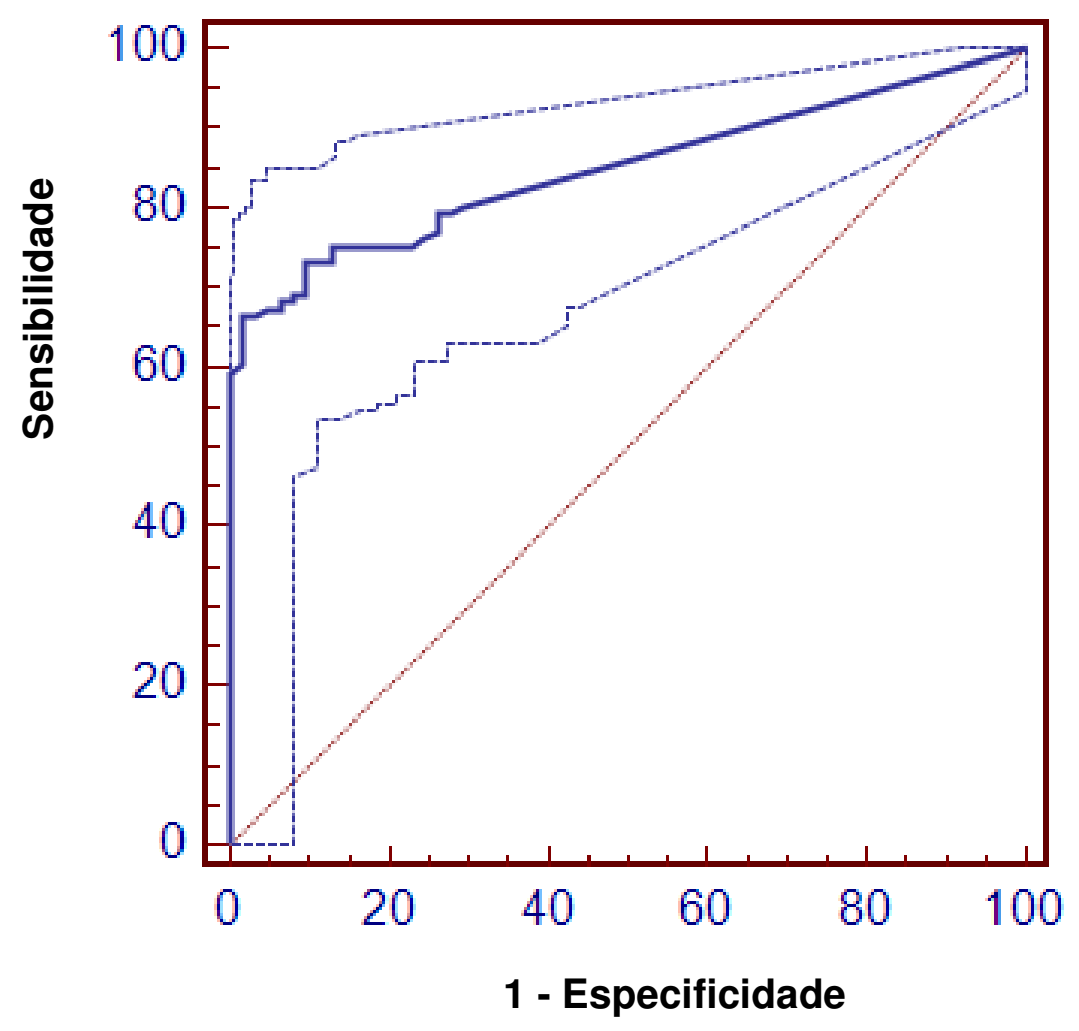


A concentração de $\lg E$ específica para proteína do leite de vaca que apresentou os critérios propostos na metodologia foi: 3,06 kUI/L. Para as frações foram considerados os seguintes valores: $2,08 \mathrm{kUl} / \mathrm{L}$ para $\alpha$ lactoalbumina, $1,85 \mathrm{kUI} / \mathrm{L}$ para $\beta$-lactoglobulina e 1,47kUI/L para caseína,.

A Tabela 2 apresenta os dados referentes à sensibilidade (Se), especificidade (Es), valor preditivo positivo (VPP), valor preditivo negativo (VPN) e razão de verossimilhança positiva (LR+). Os valores discriminantes de IgE específica para leite de vaca previamente propostos pela literatura científica (5 kU/L e $15 \mathrm{kU} / \mathrm{L}$ ) também foram avaliados na casuística do estudo (Tabela 3) 
Tabela 2 - Descrição dos Valores Preditivos Positivos (VPP), Valores Preditivos Negativos (VPN), Sensibildade (Se), Especificidade (Es) com seus respectivos intervalos de confiança (IC 95\%) para as concentrações de IgE específica para leite de vaca e suas frações obtidas através da curva ROC e consideradas determinantes para o diagnóstico de APLV.

\begin{tabular}{|c|c|c|c|c|c|c|}
\hline $\begin{array}{l}\text { Alérgeno } \\
\text { Avaliado }\end{array}$ & $\begin{array}{l}\text { Concentração de } \\
\text { lgE específica } \\
(\mathrm{kU} / \mathrm{L})\end{array}$ & $\begin{array}{l}\text { Se } \\
\text { (IC 95\%) }\end{array}$ & $\begin{array}{l}\text { Es } \\
\text { (IC 95\%) }\end{array}$ & $\begin{array}{l}\text { VPP } \\
\text { (IC 95\%) }\end{array}$ & $\begin{array}{l}\text { VPN } \\
\text { (IC 95\%) }\end{array}$ & $\begin{array}{l}\text { LR + } \\
\text { (IC 95\%) }\end{array}$ \\
\hline Leite de Vaca & 3,06 & $\begin{array}{l}71,31 \\
(62,4-79,1)\end{array}$ & $\begin{array}{l}98,36 \\
(91,2-99,7)\end{array}$ & $\begin{array}{l}98,86 \\
(93,82-99,97)\end{array}$ & $\begin{array}{l}63,16 \\
(52,7-72,79)\end{array}$ & $\begin{array}{l}43,50 \\
(38,7-48,9)\end{array}$ \\
\hline$\alpha$-lactoalbumina & 2,08 & $\begin{array}{l}58,16 \\
(47,8-68,1)\end{array}$ & $\begin{array}{l}98,36 \\
(91,2-99,7)\end{array}$ & $\begin{array}{l}100 \\
(93,74-100)\end{array}$ & $\begin{array}{l}59,80 \\
(49,65-69-35)\end{array}$ & $\begin{array}{l}35,48 \\
(29,9-42,1)\end{array}$ \\
\hline$\beta$-lactoglobulina & 1,85 & $\begin{array}{l}57,29 \\
(46,8-67,3)\end{array}$ & $\begin{array}{l}98,36 \\
(91,2-99,7)\end{array}$ & $\begin{array}{l}100 \\
(97,51-100)\end{array}$ & $\begin{array}{l}59,8 \\
(49,65-69,3)\end{array}$ & $\begin{array}{l}34,95 \\
(29,3-41,7)\end{array}$ \\
\hline Caseína & 1,47 & $\begin{array}{l}66,34 \\
(56,2-75,4)\end{array}$ & $\begin{array}{l}98,36 \\
(91,2-99,7)\end{array}$ & $\begin{array}{l}98,72 \\
(93,06-99,97)\end{array}$ & $\begin{array}{l}63,83 \\
(53,27-73,46)\end{array}$ & $\begin{array}{l}40,47 \\
(35.1-46,7)\end{array}$ \\
\hline
\end{tabular}


Tabela 3 - Descrição dos Valores Preditivos Positivos (VPP), Valores Preditivos Negativos (VPN), Sensibildade (Se), Especificidade (Es) com seus respectivos intervalos de confiança (IC 95\%) para as concentrações de lgE específica para leite de vaca propostas por Sampson et al e Garcia Ara et al como pontos de corte auxiliares ao diagnóstico de APLV aplicadas a presente casuística.

\begin{tabular}{c|c|c|c|c|c|c}
\hline $\begin{array}{c}\text { Publicação } \\
\text { selecionada }\end{array}$ & $\begin{array}{c}\text { Concentração } \\
\text { IgE específica } \\
\text { (kU/L) }\end{array}$ & $\begin{array}{c}\text { Se } \\
\text { (IC 95\%) }\end{array}$ & $\begin{array}{c}\text { Es } \\
\text { (IC 95\%) }\end{array}$ & $\begin{array}{c}\text { VPP } \\
\text { (IC 95\%) }\end{array}$ & $\begin{array}{c}\text { VPN } \\
\text { (IC 95\%) }\end{array}$ & LR + \\
\hline $\begin{array}{c}\text { Garcia Ara et al } \\
2001\end{array}$ & $\begin{array}{c}5 \\
\text { abaixo de } 2 \\
\text { anos de idade }\end{array}$ & $\begin{array}{c}56,41 \\
(44,65-67,57)\end{array}$ & $\begin{array}{c}94,44 \\
(72,70-99,86)\end{array}$ & $\begin{array}{c}97,78 \\
(88,23-99,94)\end{array}$ & $\begin{array}{c}33,33 \\
(20-75-47,92)\end{array}$ & 10,15 \\
\hline $\begin{array}{c}\text { Sampson } \\
2001\end{array}$ & 15 & $\begin{array}{c}35,25 \\
(26,84-44,40)\end{array}$ & $\begin{array}{c}100 \\
(94,13-100)\end{array}$ & $\begin{array}{c}100 \\
(91,77-100)\end{array}$ & $\begin{array}{c}43,57 \\
(35,22-52,25)\end{array}$ & $\begin{array}{c}\text { Não } \\
\text { calculado }\end{array}$ \\
\hline
\end{tabular}




\begin{abstract}
b. Curvas ROC para obtenção das concentrações discriminantes de IgE específica para leite de vaca em pacientes com anafilaxia â proteína do leite de vaca
\end{abstract}

A curva ROC que incluiu apenas pacientes que apresentaram anafilaxia comparando-se a os demais pacientes alérgicos não se apresentou adequada à obtenção de valores discriminantes para diagnóstico de alergia a proteína do leite de vaca (Fig 11). Quando se construiu uma curva comparando-se pacientes com anafilaxia versus o conjunto composto por pacientes alérgicos sem anafilaxia e grupo controle (Figura 12), a área sobre a curva foi de 0,76 e a concentração de IgE específica de acordo com os critérios propostos na metodologia foi de 39,5kUI/L. Quatro pacientes com anafilaxia confirmada à proteína do leite de vaca apresentaram pesquisa de IgE específica para leite de vaca com níveis inferiores a $0,35 \mathrm{kU} / \mathrm{L}$ e três pacientes apresentaram valores entre 035kU/L e 0,7 kU/L. 
Figura 11. Curva ROC para determinação de ponto de corte para valores de IgE específica para leite de vaca para o diagnóstico de APLV com sintomas de anafilaxia comparados a pacientes com APLV sem sintomas de anafilaxia

\begin{tabular}{|c|c|}
\hline \multicolumn{2}{|c|}{ Características da Curva } \\
\hline Área sobre a curva & 0,589 \\
ROC (AUC) & \\
\hline Erro padrão & 0,0514 \\
\hline $95 \%$ Intervalo de confiança & 0,496 a \\
& 0,677 \\
\hline
\end{tabular}

Pacientes com anafilaxia comparados aos alérgicos sem anafilaxia

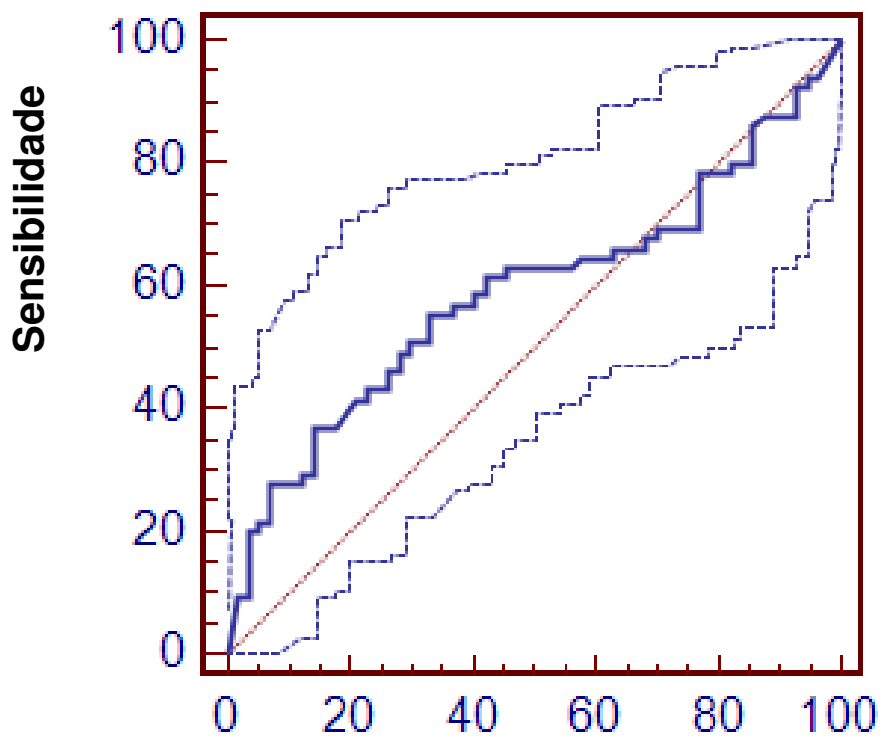

1 - Especificidade 
Figura 12 - Curva ROC para determinação de ponto de corte para valores de IgE específica para leite de vaca para o diagnóstico de APLV com sintomas de anafilaxia comparados a pacientes com APLV sem sintomas de anafilaxia e grupo controle.

\begin{tabular}{|c|c|}
\hline \multicolumn{2}{|c|}{ Características da Curva } \\
\cline { 1 - 2 } Área sobre a curva ROC (AUC) & 0,760 \\
\hline Erro padrão & 0,039 \\
\hline $95 \%$ Intervalo de confiança & $\mathbf{0 , 6 9 2}$ a 0,820 \\
\hline
\end{tabular}

Pacientes com Anafilaxia

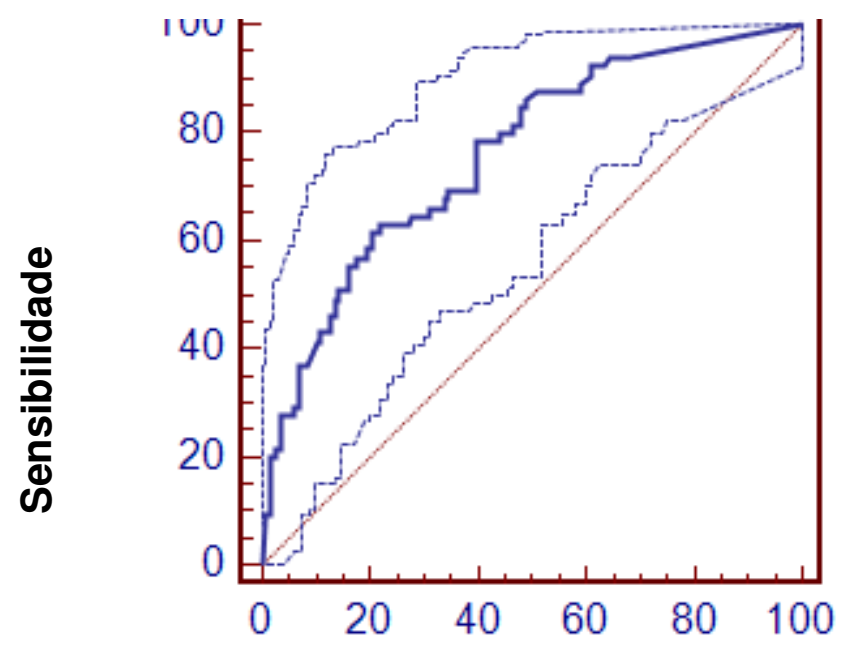

1 - Especificidade 
Discussão 


\section{DISCUSSÃO}

A prevalência de alergia alimentar varia entre $6 \%$ e $8 \%$ da população pediátrica e há evidências de seu crescimento em vários de países, nos últimos anos. (Sampson, 1999; Branun \& Lukacs, 2008). Entre os possíveis alimentos envolvidos neste processo, se destaca o leite de vaca por ser um dos primeiros a ser introduzido na dieta da criança, muitas vezes, mesmo durante o aleitamento materno (Host, 2002; Benhamou et al 2009). Trata-se de um alimento que apresenta grande importância nutricional, mas também é um dos principais alérgenos na faixa etária pediátrica, principalmente nos primeiros anos de vida, atingindo cerca de $1,5 \%$ a $5 \%$ das crianças (Bock, 1987; Sampson 1999; Nowak-Wegrzyn \& Sampson, 2006)

No Brasil, inquérito por telefone feito com gastroenterologistas pediátricos, revelou uma prevalência de alergia alimentar de $7,4 \%$, sendo 0 leite de vaca o principal alimento relatado como desencadeante (Vieira et al 2005). Entre os aspectos relevantes a serem destacados na APLV está a precocidade do início dos sintomas (Bock, 1987; Benhamou et al, 2009) Como se trata de alimento ingerido até no berçário, os sintomas de alergia podem ser observados já no primeiro ano de vida. Nos pacientes incluídos nesta casuística, destaca-se a presença de manifestações ocorridas nos primeiros 30 dias de vida. Certamente isto acrescenta gravidade ao 
processo alérgico, pois nem sempre há a percepção por parte dos pais de que se trata de um sintoma de alergia com potencial de reações graves. Estas crianças, assim como as demais alérgicas à leite, apresentam uma série de características particulares que, de certa maneira, as diferenciam dos demais pacientes com alergia alimentar, pois os sintomas são precoces. Como consequência, há dificuldades em se entender se as manifestações clínicas estão relacionadas à alergia ou um outro tipo de reação adversa aos alimentos e nem sempre se consegue aplicar a metodologia recomendada à realização do TPODCPC (Benhamou et al, 2009).

A Unidade de Alergia e Imunologia do Instituto da Criança do HCFMUSP possui um ambulatório de alergia alimentar onde estão matriculados cerca de 200 pacientes, destes, $80 \%$ receberam confirmação diagnóstica de APLV ressaltando uma vez mais a importância deste alérgeno (Jacob, 2007). Como se trata de um centro de referencia para AA, este ambulatório recebe pacientes mais graves, sendo a presença de anafilaxia, um dado relevante.

O presente estudo é o resultado da experiência e dos questionamentos que ocorreram no ambulatório de alergia alimentar desta Unidade ao longo de sete anos cuidando de pacientes com APLV. O adequado acompanhamento desses pacientes demandou a adaptação e início da realização do TPODCPC, considerado o padrão ouro para o diagnostico de alergia alimentar. Nos sete anos que se seguiram, padronizou-se 0 TPODCPC e, simultaneamente, constataram-se as dificuldades de sua 
realização, fato este já referido na literatura, por vários autores (Niggemann \& Beyer, 2007, Nowak-Wegrzyn et al, 2009).

Trata-se de exame que demanda tempo, pessoal altamente treinado em diferentes etapas de todo o processo, além de local apropriado para sua realização com capacidade para atendimento a reações adversas graves; o que restringe este procedimento aos centros de referência em alergia alimentar. Outras limitações foram sendo observadas ao longo de sua implementação e execução, incluindo-se a dificuldade de realização em crianças menores. De fato, em recente revisão na literatura, há uma tendência a dispensar pacientes da realização do TPODCPC, quando os sintomas são bastante evidentes, pelos riscos e desconfortos envolvidos na realização do procedimento (Niggemann \& Beyer, 2007; Nowak-Wegrzyn et al, 2009).

O outro aspecto que dificulta a realização deste teste é a presença de anafilaxia, muito descrita nesta casuística. Por todos estes fatores, começouse a questionar se poderiam ser definidos outros testes diagnósticos em substituição ao TPODCPC e, neste contexto, a pesquisa de IgE específica sérica ou através de testes cutâneos passou a ser uma alternativa avaliada. O incentivo a elaboração da pergunta que norteou essa tese veio do pioneirismo de Sampson et al (1997) posteriormente seguido por outros autores, para uma definição de pontos de corte em relação às concentrações IgE especifica para alguns alimentos, incluindo o leite de vaca (Roehr et al, 2001; Garcia-Ara et al, 2001; Saarinen et al, 2001; CelikBilgili et al, 2005). Houve a necessidade de reproduzir os estudos destes 
diversos autores em uma população com características clinicas diferentes, especialmente com um menor número de pacientes com dermatite atópica.

Todos os fatores acima descritos motivaram a realização desta tese, que embora representasse um desafio, poderia auxiliar no diagnóstico de pacientes brasileiros com APLV.

Um dos aspectos iniciais a ser avaliado foi a característica dos pacientes que compuseram esta casuística. As manifestações clínicas dos pacientes com APLV mediada por lgE incluídos neste trabalho não diferiram das desencadeadas pelos demais alérgenos, inclusive no que tange à gravidade e risco de morte (Sampson, 1999; Nowak-Wegrzyn \& Sampson, 2006). Nestes pacientes, houve predomínio de quadros cutâneos tal qual relatado na literatura, com destaque à presença de urticária e angioedema (Benhamou et al, 2009). Sabe-se que nos episódios de urticária aguda os alimentos são frequentemente responsáveis pelo desencadeamento de manifestações clínicas, suspeitando-se desses quando a ingestão ocorre em geral até duas horas antes do início dos sintomas (Champion, 1990). Há, entretanto, sintomas como os vômitos, muitas vezes relatados pelos pacientes incluídos nesta casuística, que são bem menos específicos para o diagnóstico de alergia alimentar e igualmente freqüentes, dificultando o diagnóstico baseado exclusivamente em manifestações clínicas (Bock,1987; Sampson 2004).

No presente estudo, a elevada presença de sintomas como broncoespasmo, dispnéia e estridor laríngeo pode se relacionar ao elevado número de pacientes com anafilaxia, o que reflete as características do 
ambulatório de onde foram selecionados, pois se trata de um serviço médico de referência terciária e especializado nos quadros mais graves. Sabe-se que sintomas respiratórios isolados relacionados à alergia alimentar não são muito comuns (James, 2003), no entanto quando são relatados em associação com envolvimento de outros sistemas, conferem maior gravidade ao processo alérgico (Clark \& Ewan, 2003).

Esta casuística viabiliza uma análise mais cuidadosa do comportamento dos valores discriminantes das concentrações séricas de IgE específica para leite de vaca, uma vez que os relatos prévios não descrevem a inclusão de pacientes com anafilaxia (Roehr et al, 2001; Garcia-Ara et al, 2001; Saarinen et al, 2001; Celik-Bilgili et al, 2005). O número elevado de pacientes com anafilaxia avaliados também explica a grande freqüência de associação de sintomas envolvendo diversos sistemas, com destaque à presença maciça de sintomas cutâneos. Isto se justifica pelas características dos critérios diagnósticos em anafilaxia, onde a associação de determinados sintomas acometendo dois sistemas diferentes define a reação anafilática (Joint Task Force on Practice Parameters, 2005).

A associação com outras doenças alérgicas é comum entre os pacientes com alergia alimentar, como o observado neste estudo. Em recente relato divulgado pelo Center of Diseases Control (CDC) observou-se que cerca de $27 \%$ das crianças com alergia alimentar desenvolveram dermatite atópica ou outra alergia cutânea enquanto que apenas $8 \%$ das crianças sem alergia alimentar apresentavam tais manifestações. Sintomas respiratórios também foram mais comuns entre os que apresentavam alergia 
alimentar (30\%) quando comparados a crianças sem alergia alimentar (9\%) (Branun \& Lukacs, 2008).

A presença de antecedentes familiares de atopia, bastante frequente entre os pacientes deste estudo, é uma característica comum em pacientes alérgicos e constitui um aspecto complementar importante quando se realiza a anamnese de pacientes com alergia alimentar (Sampson, 2004; Kumar, 2008)

Entre as doenças alérgicas associadas à alergia alimentar, a dermatite atópica merece destaque especial. Estudos que envolveram a realização de TPODCPC para diagnóstico de alergia alimentar em pacientes com DA estimaram um percentual de cerca de $30 \%$ dessa associação, certamente o grupo de maior prevalência de alergia alimentar, sendo as proteínas do ovo e leite de vaca os principais alérgenos desencadeantes dos sintomas. (Sampson \& Sicherer, 1999). Um outro aspecto relevante nos pacientes com dermatite atopia é o elevado percentual de sensibilização que estes pacientes apresentam, sendo a IgE específica por vezes bastante elevada.. Em recente estudo epidemiológico multicêntrico, que envolveu 2096 crianças com dermatite atópica de 12 países, observou-se que 54,5\% das mesmas apresentavam sensibilização a pelo menos um alérgeno, sendo $41.9 \%$ sensibilizadas a ovo e $27,4 \%$ sensibilizadas a leite (de Benedicts et al, 2009). Desta maneira, ao se eleger um grupo de pacientes com alergia alimentar para a avaliação de concentrações de lgE específica para o diagnóstico da doença, será importante considerar o número de pacientes com dermatite atópica, ponderando-se as características próprias dessa 
doença. Toda esta discussão sobre as características clinicas dos pacientes com APLV, incluindo-se os apresentados nesta casuística, são fundamentais para ressaltar que há diferenças neste grupo que podem influenciar diretamente o estabelecimento de valores determinantes das concentrações séricas de lgE específica.

O diagnóstico de alergia alimentar é baseado na anamnese, que tem como objetivos principais: definir se o sintoma pode estar relacionado á manifestação de alergia, se há relação causal com o alimento suspeito e qual o provável mecanismo envolvido, se mediado por lgE ou não. Os exames complementares podem auxiliar na confirmação diagnóstica, especialmente nos casos de alergia alimentar mediada por lgE. (Sampson, 2001; Sampson, 2004)

É importante lembrar que a dosagem de lgE total é de pouco auxílio no diagnóstico de alergia alimentar. Há um consenso na literatura de que os valores de $\lg E$ total entre os pacientes alérgicos e indivíduos sem alergia podem se sobrepor (Ahlstedt \& Murray, 2006).

Na presente casuística, as concentrações séricas de $\lg E$ total entre os pacientes alérgicos mostraram-se bastante variáveis e não apresentaram distribuição normal. Isto pode ocorrer, pois a síntese de lgE depende de uma série de fatores genéticos e a magnitude das concentrações séricas não se relaciona, na grande maioria das vezes, com a gravidade do quadro de alergia alimentar (Ahlstedt \& Murray, 2006). 
A detecção de IgE específica através de TCHI ou in vitro através do RAST pode auxiliar no estabelecimento dos alimentos suspeitos do desencadeamento das manifestações de alergia alimentar, entretanto a simples positividade dos testes indica apenas sensibilização. Estudos anteriores referem que apenas 30 a $40 \%$ dos exames positivos estavam relacionados a pacientes verdadeiramente alérgicos revelando o baixo valor preditivo positivo destes exames, especialmente quando os resultados são avaliados de maneira qualitativa. (Sampson, 1997).

A complementação da anamnese e da pesquisa de $\operatorname{lgE}$ específica ocorre através dos testes de provocação, especialmente o TPODCPC que recebe a conotação de "padrão ouro" para diagnóstico de alergia alimentar.

O TPODCPC é o método que apresenta maior sensibilidade e especificidade no diagnóstico de AA. O principal objetivo desse teste é a reprodução dos sintomas desencadeados em uma exposição natural sem a interferência da sugestão, tanto por parte do paciente quanto por parte do médico, com isto há um menor risco de resultados falso positivos. Além disso, é possível estimar a dose de alimento necessária para a indução dos sintomas. Entretanto, há uma série de desvantagens neste procedimento, destacando-se: o tempo de realização do exame, em geral um período de 8 horas para a execução completa; o adequado treinamento do corpo clínico no preparo do teste e na cuidadosa observação do paciente para detectar os eventuais efeitos adversos; a necessidade de estrutura física para receber um paciente com real risco de reação adversa e, principalmente, os riscos de desencadeamento de reações graves nos pacientes (Bock \& Atkins, 
1990; Williams \& Bock, 1999; Sicherer et al, 2000; Caffarelli \& Petroccione, 2001; Niggemann \& Beyer, 2007; Nowak-Wegrzyn et al, 2009).

Este paradigma entre ser um teste padrão ouro, mas apresentar dificuldades em sua realização que o impedem de ser amplamente aplicado, fez, nas últimas duas décadas, que se procurassem alternativas ao diagnóstico, com destaque à pesquisa de IgE específica através do TCHI ou do RAST.

Há poucos trabalhos envolvendo o $\mathrm{TCHI}$ onde são propostos pontos de corte baseados nos milímetros da pápula gerada a partir do contato do alérgeno com a pele do paciente. Sporik et al (2000) conseguiram estabelecer uma boa correlação entre o tamanho da pápula do alérgeno e a positividade do TPODCPC, em crianças abaixo de dois anos que apresentaram pápulas superiores a $6 \mathrm{~mm}$ para o leite de vaca. Nestes casos houve $100 \%$ de concordância com o teste de provocação e nas crianças acima de dois anos, este valor passou para $8 \mathrm{~mm}$. Entretanto, embora o TCHI seja prático e de fácil execução sua reprodutibilidade depende de alguns fatores como a qualidade do extrato e a uniformização da leitura de resultados. Por estas razões, no presente estudo optou-se por avaliar a pesquisa de IgE específica in vitro.

Nos últimos anos, ocorreu um aprimoramento das técnicas de pesquisa da lgE específica sérica. Desde o primeiro RAST, desenvolvido comercialmente em 1974, até os dias de hoje, houve possibilidade de uma transição efetiva entre um teste semiquantitativo (antigo RAST) e testes quantitativos como o ImmunoCAP ${ }^{\circledR}$. A escolha deste método para a 
avaliação de valores discriminantes de $\lg E$ se fundamenta nas características de elevada precisão, reprodutibilidade documentada e acurácia na determinação de lgE específica (Ahlstedt et al,2002). Desta maneira, somaram-se as dificuldades inerentes ao TPODCPC e um grande incremento na qualidade dos testes para detecção de IgE específica in vitro e, neste contexto, ocorreram uma série de estudos cujo principal objetivo foi determinar um valor de $\lg E$ específica para uma série de alimentos incluindo o leite de vaca que, por apresentar elevado valor preditivo positivo, pudesse eximir o paciente do TPODCPC (Sampson \& Ho, 1997; Sampson, 2001; Garcia-Ara et al, 2001, Boyano-Martinez et al, 2001).

Uma das principais motivações à realização deste estudo foi a observação da variedade de pontos de corte estabelecidos nos diferentes estudos realizados. Um dos relatos iniciais propostos por Sampson \& Ho (1997) sugeriram que, para a proteína do leite de vaca, a concentração de IgE específica com elevado VPP deveria ser superior a $32 \mathrm{kU} / \mathrm{L}$. Posteriormente, a mudança da característica da amostra diminuiu este ponto de corte para 15kU/L (Sampson, 2001). Garcia Ara et al (2001) sugeriram valores diferenciados para crianças baixo de 2 anos de idade. Para Celik-Bilgili S et al (2005), o ponto de corte proposto foi $88,8 \mathrm{kU} / \mathrm{L}$ e mais uma vez, boa parte da casuística apresentava dermatite atópica. A discrepância dos resultados está relacionada a diferenças em todos os passos da realização do estudo: amostra escolhida, critérios de inclusão, padronização dos testes de provocação, escolha da análise estatística a ser realizada, entre outros (Sopo et al, 2007). 
O presente estudo foi prospectivo, mesmo que esta avaliação tenha partido de dados de prontuário, pois seu desenho se baseia em uma suspeita inicial e avalia prospectivamente os resultados de exames realizados para a confirmação ou exclusão do diagnóstico e as concentrações de IgE específica obtidas. A opção por um estudo prospectivo (coorte histórica) também foi feita por Sampson \& Ho (1997) et al, mas há estudos que não mencionam esta característica da metodologia.

Quando se realiza um estudo para avaliação de um valor discriminante (ponto de corte) que possa dividir os indivíduos em dois grupos, doentes ou não, uma das opções é o estabelecimento de uma coorte de indivíduos onde pacientes com suspeita de alergia alimentar são encaminhados a um serviço e avaliados através de anamnese e testes para a confirmação ou não desta alergia, à semelhança da metodologia aplicada neste estudo (Gellerstedt et al, 2007). Neste contexto, a escolha deste grupo controle é fundamental, sendo preferencial que ele seja composto por um grupo de pacientes que apresente uma queixa possível de alergia alimentar, mas que o diagnóstico seja excluído nos passos seguintes da avaliação, incluindo o uma anamnese detalhada ou mesmo a realização do teste de provocação (Gellerstedt et al, 2007; Sopo et al 2007). O grupo controle que compôs o presente estudo apresentava sintomas ou queixas supostamente atribuídas à proteína do leite de vaca, mas que não se sustentaram após uma avaliação mais acurada. Acredita-se, então ser este um grupo melhor de indivíduos a contribuir para uma análise mais próxima do cotidiano de quem trabalha com alergia alimentar. 
A escolha do grupo controle pode ser definida de acordo com os objetivos do estudo. No trabalho inicial de Sampson \& Ho (1997), que atingiu pontos de corte bastante elevados, o objetivo foi avaliar a presença de alergia alimentar entre pacientes com dermatite atópica. Desta maneira, nada mais correto do que o grupo controle ser composto por pacientes com a dermatite, mas sem alergia alimentar. No presente estudo a escolha por pacientes com qualquer tipo de manifestação clínica foi proposital, pois a inclusão de pacientes deveria abranger quadros clínicos diversos incluindo pacientes com anafilaxia, não justificando uma seleção para um só tipo de manifestação.

Os critérios de inclusão do presente estudo contemplaram três possibilidades: TPODCPC positivo, anafilaxia ao leite de vaca ou história sugestiva de APLV seguida de resposta positiva ao teste de provocação aberta. Um dos questionamentos a ser considerado é a não uniformidade da inclusão baseada apenas no TPODCPC. Trata-se de critério difícil de ser preenchido por todos os pacientes, especialmente por aqueles que apresentaram reação anafilática recente. Este problema também ocorreu em outros estudos onde pais de pacientes se recusaram a realizar tal procedimento e acabaram sendo incluídos pelo critério "história sugestiva de alergia alimentar" (Sampson \& Ho, 1987; Sampson, 2001). Ainda é importante ressaltar que alguns autores sugerem e aceitam a realização da provocação aberta em crianças pequenas, abaixo de 2 anos de idade, pois os sinais clínicos apresentados nesta faixa etária durante o teste de 
provocação aberta são bastante evidentes e objetivos (Niggemann \& Beyer, 2007).

Os critérios de inclusão, no presente estudo, foram bastante criteriosos, incluindo-se pacientes com reações bastante evidentes de alergia alimentar com destaque para a presença de urticária, angioedema e anafilaxia. A discussão, se pacientes com anafilaxia devem ou não realizar testes de provocação, especialmente para diagnóstico e não para avaliação de aquisição de tolerância, foi bem sustentada em alguns trabalhos na literatura. Para alguns autores o teste de provocação em pacientes com anafilaxia é "desnecessário, indesejável e pouco seguro" (Eigenmann \& Sampson, 1998; Perry et al, 2004). Em 2007, Niggemann \& Beyer revisaram os métodos diagnósticos em alergia alimentar e sugeriram indicações clínicas para a realização do TPODCPC. Nesta revisão, propôs-se que pacientes com história clínica de anafilaxia associada a uma detecção positiva de IgE específica (TCHI ou RAST), como o que ocorreu com os pacientes incluídos nesta casuística, não necessitariam nenhum tipo de teste de provocação. A indicação da provocação ocorreria em casos duvidosos de reação anafilática com ou sem confirmação através da IgE específica, mesmo assim sugeriu-se a provocação aberta.

Outro aspecto a ser abordado na determinação dos valores discriminantes de IgE específica é a decisão da metodologia estatística a ser empregada. A construção de curva ROC foi a escolha feita em diversos trabalhos onde o objetivo foi a avaliação de pontos de corte em alergia alimentar, sendo bastante utilizada em vários setores da medicina para 
estabelecimento de pontos de decisão de procedimentos clínicos ou laboratoriais que auxiliem no diagnóstico (Hatanaka \& Benseñor, 2005). A distribuição dos pontos ao longo da curva delimita uma área sob a mesma que representa a acurácia do método avaliado (Hatanaka \& Benseñor, 2005). No presente estudo os resultados foram excelentes na determinação da área sobre a curva com os valores de IgE para a proteína do leite de vaca e bons para as frações $\alpha$-lactoalbumina, $\beta$-lactoglobulina e caseína. Consideram-se excelentes as áreas entre 0,9 e 1, boas as áreas entre 0,8 e 0,9 ; regulares entre $0,7-0,8$ e, abaixo destas, os pontos de corte sugeridos não são confiáveis, pois incluem muitos resultados falsos positivos (Hatanaka \& Benseñor, 2005).

A obtenção de uma concentração de IgE específica que possa substituir um teste considerado padrão ouro requer um elevado valor preditivo positivo, pois valores acima do ponto de corte garantem chances reais do paciente ser alérgico a proteína do leite de vaca. Também é importante não incluir neste grupo, pessoas não alérgicas que apresentam valores acima dos pontos de corte obtidos, ou seja, pacientes que não são alérgicos a esta proteína. Neste caso busca-se um ponto de corte que apresente elevada especificidade. No presente estudo após a construção das curvas ROC, observou-se que os pontos de corte que melhor atenderam às exigências de uma especificidade adequada foram os valores cuja especificidade foi $98 \%$, pois o intervalo de confiança foi bastante estreito. Obviamente toda vez que se eleva a especificidade, perde-se em sensibilidade. Tomando-se o valor proposto para a proteína do leite e vaca, 
observa-se que a sensibilidade foi de $73,31 \%$, o que significa que quase $30 \%$ dos pacientes com APLV não atingiram os valores propostos para eximi-los do TPODCPC, portanto nestes pacientes seria interessante a realização dos testes de provocação.

Toda esta discussão sobre os aspectos estatísticos do presente estudo e dos demais estudos publicados é fundamental para que entenda e avalie criticamente o que realmente se espera dos pontos de corte obtidos. Nos trabalhos que já propuseram a determinação de análise destes valores discriminantes, os valores de especificidade e sensibilidade foram bastante variados. Ao avaliar o valor discriminante proposto por Garcia Ara et al (2001) observa-se que para valores acima de $5 \mathrm{kU} / \mathrm{L}$ a sensibilidade esperada foi de $30 \%$, ou seja muitos pacientes deveriam ser submetidos aos testes de provocação para estabelecimento do diagnóstico. Assim é necessário um olhar cuidadoso sobre os valores propostos e se eles realmente atendem à demanda da população avaliada.

No presente estudo, os valores preditivos positivos e negativos calculados a partir dos pontos de corte sugeridos foram adequados e atingiram os objetivos propostos. O que se faz necessário discutir é a valorização destes dados sem o conhecimento da prevalência de alergia alimentar da população estudada. Pode-se calcular o VPP e o VPN em uma população fechada, como a amostra adotada, mas a inclusão da variável prevalência faz com que haja mudanças nos resultados obtidos. Desta maneira, situações onde a prevalência de alergia alimentar é elevada, como por exemplo, na dermatite atópica, aplicando-se o dado de prevalência para 
o cálculo do VPP este permanece elevado, já em locais com baixa prevalência de alergia alimentar, para o mesmo ponto de corte selecionado haverá uma redução do VPP (Sopo et al , 2007). No estudo aqui descrito não houve possibilidade de aplicação desta fórmula, pois não há no Brasil estudos populacionais de avaliação da prevalência de alergia alimentar, mas talvez esta seja próxima ao proposto nos demais estudos. Esta inferência é baseada no único estudo, previamente citado, de avaliação de prevalência de alergia alimentar realizado no Brasil, com prevalência obtida de aproximadamente 7\% (Vieira et al, 2005). Já é bastante conhecido que a metodologia de inquéritos por telefone com a população apresentam muitas limitações, geralmente superestimando os valores de prevalência. Neste caso, a população consultada foram médicos gastroenterologistas, o que pode ter maior valor em relação à qualidade da informação prestada, mas certamente foram subestimados os casos de alergia alimentar IgE mediada, já que a maioria dos casos gastrintestinais não apresentam este mecanismo fisiopatológico (Vieira et al, 2005).

Uma alternativa à escolha dos valores discriminantes baseados nos resultados de VPP é a adoção da razão de verossimilhança que, se for acima de 10, confere uma forte evidência da correlação entre presença de alergia alimentar e a positividade do exame (Deeks \& Altman, 2004). Neste estudo os pontos de corte escolhidos apresentaram elevada razão de verossimilhança, embasando ainda mais a escolha das concentrações determinantes de $\lg E$ específica. 
Não há na literatura, avaliação de valores discriminantes para as frações do leite de vaca, embora estes alérgenos sejam importantes para a sensibilização e desenvolvimento de APLV. Estudos realizados na Unidade de Alergia e Imunologia do ICr HCFMUSP avaliando pacientes com APLV mostraram que a pesquisa de IgE específica para as frações $\alpha$ lactoalbumina, $\beta$-lactoglobulina e caseína, através do $\mathrm{TCHI}$, contribuiu para o incremento diagnóstico em pacientes que apresentavam o teste cutâneo negativo para o alérgeno de leite (Higa et al 2007). Isto motivou a realização da pesquisa da IgE sérica para estas frações do leite de vaca, com o objetivo de determinar valores de corte para o diagnóstico de alergia ao leite de vaca. Entretanto este estudo mostrou que esta avaliação em nada acrescentaria a este diagnóstico, pois as áreas sobre as curvas ROC para as frações apresentaram pior acurácia que para o leite total. Além disto, os valores de sensibilidade foram menores do que os obtidos para o leite de vaca como um todo. Um aspecto que pode justificar tais resultados é a boa qualidade da fase sólida deste alérgeno no ImmunoCAP que atende as necessidades para diagnóstico de APLV e a representatividade das frações no RAST de leite total (Ahlstedt \& Murray , 2006). A combinação de resultados do leite de vaca com as frações, provavelmente, nada acrescentaria aos resultados obtidos com o leite total, representando ainda um custo maior ao paciente. Portanto o exame mais recomendado ainda é a dosagem de lgE específica para as proteínas do leite de vaca. Estudos envolvendo a fração caseína estão mais associados a aspectos relacionados 
à gravidade e desenvolvimento de tolerância, objetivos não abordados neste estudo (Vila et al, 2001).

No presente estudo, realizou-se o cálculo da sensibilidade, especificidade, VPP e VPN para os valores previamente propostos nos estudos realizados por Sampson (2001) e Garcia Ara et al (2001). Esta análise ilustrou a dificuldade em se adaptar valores obtidos em diferentes populações. Os valores propostos foram nitidamente menos adequados do que os calculados pela curva ROC, embora tenha havido um ganho pequeno na especificidade, houve uma queda muito importante na sensibilidade e VPN, desta forma muitos pacientes seriam submetidos ao TPODCPC.

A avaliação em separado dos pacientes com anafilaxia trouxe contribuições interessantes ao diagnóstico na APLV. A impossibilidade de construir uma curva ROC de acurácia aceitável, envolvendo pacientes alérgicos com anafilaxia e sem anafilaxia, corrobora com dados da literatura que afirmam que valores mais elevados de IgE específica podem não estar relacionados a maior gravidade da manifestação clínica, entretanto há estudos recentes que tentam estabelecer esta relação considerando os alérgenos do amendoim e ovo. Tais estudos necessitam ser reproduzidos considerando-se outros alimentos (Benhamou et al, 2008; Vlieg-Boerstra et al, 2008).

Em uma análise subseqüente, quando se reformulou a curva incluindo entre os não anafiláticos, pacientes alérgicos e grupo controle, a área sobre a curva revelou-se de fraca acurácia e o ponto de corte obtido para distinguir 
entre anafiláticos e não anafiláticos foi bastante alto, especialmente se comparado ao valor obtido considerando-se o conjunto de alérgicos como um todo. Algumas inferências são possíveis: primeiro, este resultado ressalta mais uma vez as informações da literatura relacionadas aos valores de IgE específica e gravidade e, segundo, considerando a intensidade das manifestações clínicas de um paciente com anafilaxia, pode-se concluir que uma adequada anamnese pode ser suficiente para seu diagnóstico na maior parte dos casos, sendo a lgE específica útil para a confirmação do alérgeno. Esta observação é corroborada pelos próprios critérios propostos de anafilaxia que incluem informações obtidas exclusivamente através de anamnese e exame físico (Joint Task Force on Practice Parameters, 2005). Então, não há necessidade de se discriminar esta população, elevando-se de maneira importante o ponto de corte.

Ainda com relação á anafilaxia, um outro ponto a ser destacado entre os pacientes anafiláticos foi percentual pequeno, mas, importante, de crianças que apresentaram pesquisa de IgE específica negativa, valores inferiores à capacidade de detecção do método. Estes pacientes apresentaram história muito sugestiva de anafilaxia desencadeada pelo leite de vaca e confirmação diagnóstica através do TCHI. Na literatura existem relatos semelhantes de ausência de positividade de lgE específica em alguns pacientes com anafilaxia (Vlieg-Boerstra et al, 2008), gerando uma preocupação com a necessidade de desenvolvimento de outras metodologias diagnósticas. Trata-se de um aspecto relevante, pois, neste 
contexto, não há necessidade de segmentação de mais subgrupos além da dermatite atópica.

Desta maneira o presente estudo contribuiu para uma série de aspectos no diagnóstico de alergia a proteína do leite de vaca. Com o estabelecimento de um valor determinante de $\lg E$ específica para diagnóstico de APLV adequado para a população avaliada, pode-se demonstrar que diferentes populações de pacientes com alergia alimentar podem apresentar diferentes valores discriminantes de lgE específica tornando-se difícil estabelecer um ponto de corte que possa ser universalmente adotado. Entretanto a adequada qualidade dos dados obtidos, considerando-se a área sobre a curva e razão de verossimilhança obtida, permitiu demonstrar que, em um grupo de paciente com APLV com baixa frequência de indivíduos com dermatite atópica, as sugestões de valores discriminantes são bastante inferiores às propostas em grupos com grande representatividade de pacientes com dermatite atópica, reforçando mais uma vez a necessidade de uma avaliação em separado dos dois grupos: alergia alimentar associada à dermatite atópica ou não.

O estudo da alergia alimentar é amplo, incluindo diversos aspectos da doença, mas o diagnóstico adequado é fundamental para iniciar o manejo da doença e as técnicas laboratoriais disponíveis contribuem para cumprir este objetivo. Embora novas técnicas laboratoriais venham surgindo, a pesquisa de IgE sérica específica é um exame bastante utilizado na prática clínica, portanto é importante um amplo conhecimento sobre as possibilidades a serem exploradas para o aprimoramento diagnóstico. 
Produzir resultados locais é fundamental para se estabelecer um posicionamento que pode ou não concordar com propostas já préestabelecidas na literatura médica. Há necessidade de busca de parâmetros diagnósticos próprios da população brasileira e a ampliação dos conhecimentos regionais em alergia alimentar deve ser estimulada para que se possa produzir um volume grande de estudos, permitindo um olhar mais realístico sobre esta doença. 
Conclusões 


\section{CONCLUSÕES}

1. Na população avaliada no estudo, foi possível estabelecer uma concentração de lgE sérica específica para leite de vaca acima da qual se dispensa a necessidade da realização do teste de provocação oral duplo cego placebo controlado para diagnóstico de alergia alimentar.

2. A concentração determinante de $\lg E$ específica para o leite de vaca foi inferior às previamente apresentadas em outros estudos, provavelmente em decorrência das características peculiares de cada população, destacando-se o pequeno número de pacientes com dermatite atópica nesta casuística.

3. Para o diagnóstico de alergia ao leite de vaca, a avaliação das concentrações determinantes de IgE específica para as frações do leite de vaca não acrescentou valor diagnóstico à concentração discriminante de lgE específica para leite de vaca

4. Nos pacientes com anafilaxia desta casuística, a concentração 
discriminante de IgE específica para leite de vaca mostrou-se muito elevada e com sensibilidade muito baixa, mostrando-se inadequada para o diagnóstico da alergia ao leite de vaca, Nestes pacientes, este diagnóstico deve considerar a anamnese e a concentração de $\lg E$ específica determinante para leite de vaca. 
Anexos 
Anexo A. Aprovação do estudo pela Comissão de Ética para Análise de Projetos de Pesquisa da Diretoria Clínica do Hospital das Clínicas

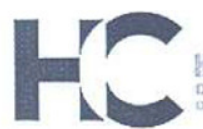

HOSPITAL DAS CLIMICAS

\section{APROVAÇÃO}

A Comissāo de Ética para Análise de Projetos de Pesquisa - CAPPesq da Diretoria Clínica do Hospital das Clínicas e da Faculdade de Medicina da Universidade de São Paulo, em sessão de 14/03/2007, APROVOU ○ Protocolo de Pesquisa $n^{\circ} 1375 / 06$, intitulado: "AVALIAÇÃO DA CONTRIBUIÇĀO DA PESQUISA DE IGE ESPECÍFICA PARA A PROTEÍNA DO LEITE DE VACA E SUAS FRAÇÕES PARA DIAGNÓSTICO DE ALERGIA A PROTEÍNA DO LEITE DE VACA MEDIADA POR IGE" apresentado pelo Departamento de Pediatria, inclusive o Termo de Consentimento Livre e Esclarecido.

Cabe ao pesquisador elaborar e apresentar à CAPPesq, os relatórios parciais e final sobre a pesquisa (Resoluçāo do Conselho Nacional de Saúde n 196, de 10.10.1996, inciso IX. 2, letra "c")

Pesquisador(a) Responsável: Dra . Cristina Miuki Abe Jacob

Pesquisador (a) Executante: Ana Paula B. Moschione Castro

CAPPesq, 14 de março de 2007.

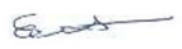

PROF. DR. EDUARDO MASSAD

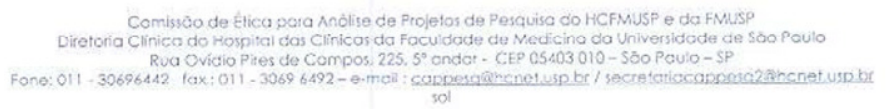

Em novembro de 2009 houve submissão à CAPpesq da mudança do título da tese para: "Determinação das concentrações séricas de $\lg E$ específica para o leite de vaca e suas frações no diagnóstico de alergia ao leite de vaca" com o aceite desta comissão. 
Anexo B. Declaraçao de não aplicaçao de termo de consentimento livre e esclarecido para todos os dados coletados

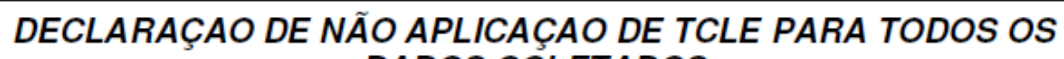

À CAPPesq

DECLARAÇÃO

Declaro, para os devidos fins, que para o estudo: Título ".. Avaliação da contribuição da pesquisa de IgE específica para a proteína do leite de vaca e suas frações para diagnóstico de alergia a proteína do leite de vaca mediada por IgE." não será utilizado para alguns dados coletados, o formulário do Termo de Consentimento Livre e Esclarecido (Anexo I), pelo fato de utilizar apenas os dados dos prontuários de pacientes.

Os pesquisadores comprometem-se a manter absoluto sigilo acerca da identidade dos mesmos.

São Paulo, de de 
Anexo C. Protocolo padronizado para atendimento a pacientes com alergia a proteína do leite de vaca

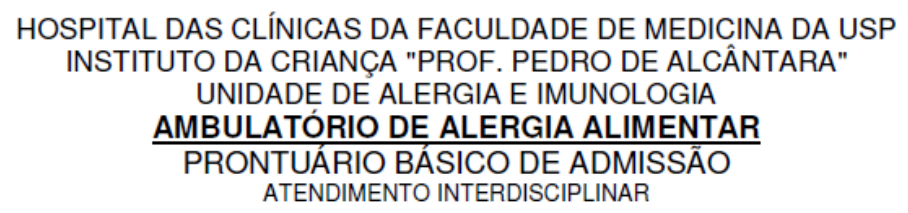

5-DATA: 6-IDADE:

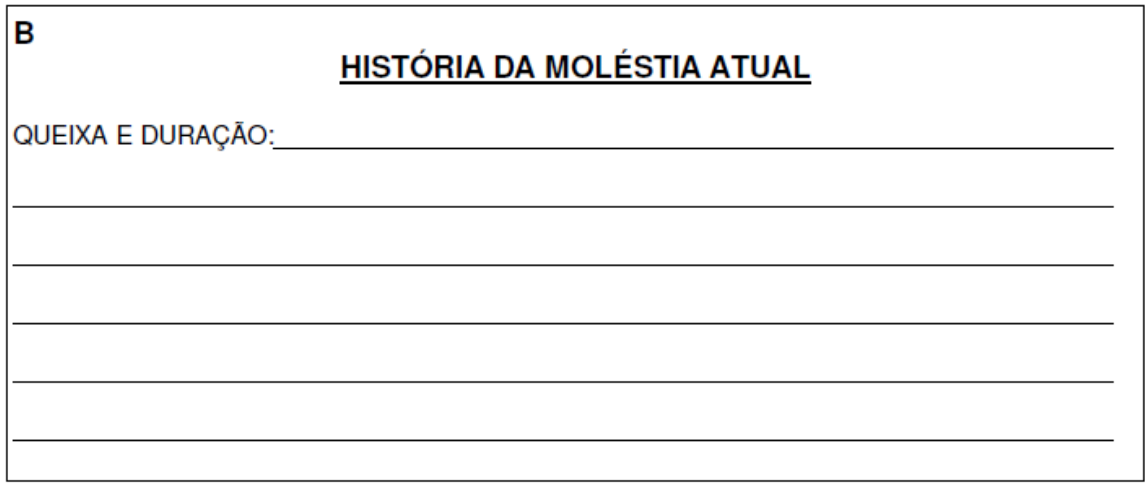

\section{MANIFESTACÕES CLÍNICAS DA ALERGIA ALIMENTAR}

IDADE DE INÍCIO DAS PRIMEIRAS MANIFESTAÇŌES:

QUAIS AS PRIMEIRAS MANIFESTAÇŌES:

INTERVALO DE TEMPO DE INGESTÃO DO LV E O APARECIMENTO DOS $1^{\text {os }}$ SINTOMAS:

$$
<2 \text { horas } \square>2 \text { horas }
$$

4 QUANTIDADE DO ALIMENTO E FORMA DE APRESENTAÇÃO:
FATORES ASSOCIADOS:
EXERCÍCIO $\square$
OUTROS

MANIFESTAÇÕES CLÍNICAS (anotar na frente de cada manifestação qtos episódios e a idade) :

6 DERMATOLÓGICAS: Eritema Urticária $\square$ Angioedema, Dermatite Atópica $\square$ Sd.AlergiaOral, Urticária de Contato $\square$

7 GASTRO-INTESTINAIS: Vômitos $\square \quad$ Diarréia $\square$ Dor Abdominal $\square \quad$ Distensão abdominal $\square$

Cólica do Lactente $\square$ Flatulência $\square$ Outros

8. RESPIRATÓRIAS: Chiado $\square$ Estridor $\square$ Tosse $\square$ Rinoconjuntivite $\square$

9. CARDIOVASCULAR: Choque Anafilático $\bar{E}$ Edema de Laringe $\square$ Dispnéia $\square$

Cianose $\square \quad$ Hipotensão $\square \quad$ Perda de consciência $\square$

10. ARTICULARES: $\quad$ Artrite $\square$ Artralgia $\square$

11. GERAIS: Défict de ganho P/E $\square$ Palidez $\square$ 

Anexo C. Protocolo padronizado para atendimento a pacientes com alergia a
proteína do leite de vaca (cont.)

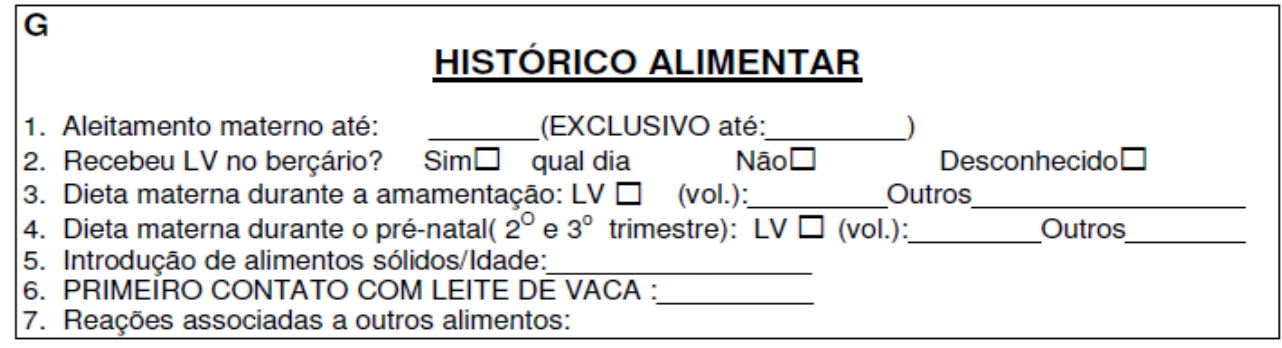

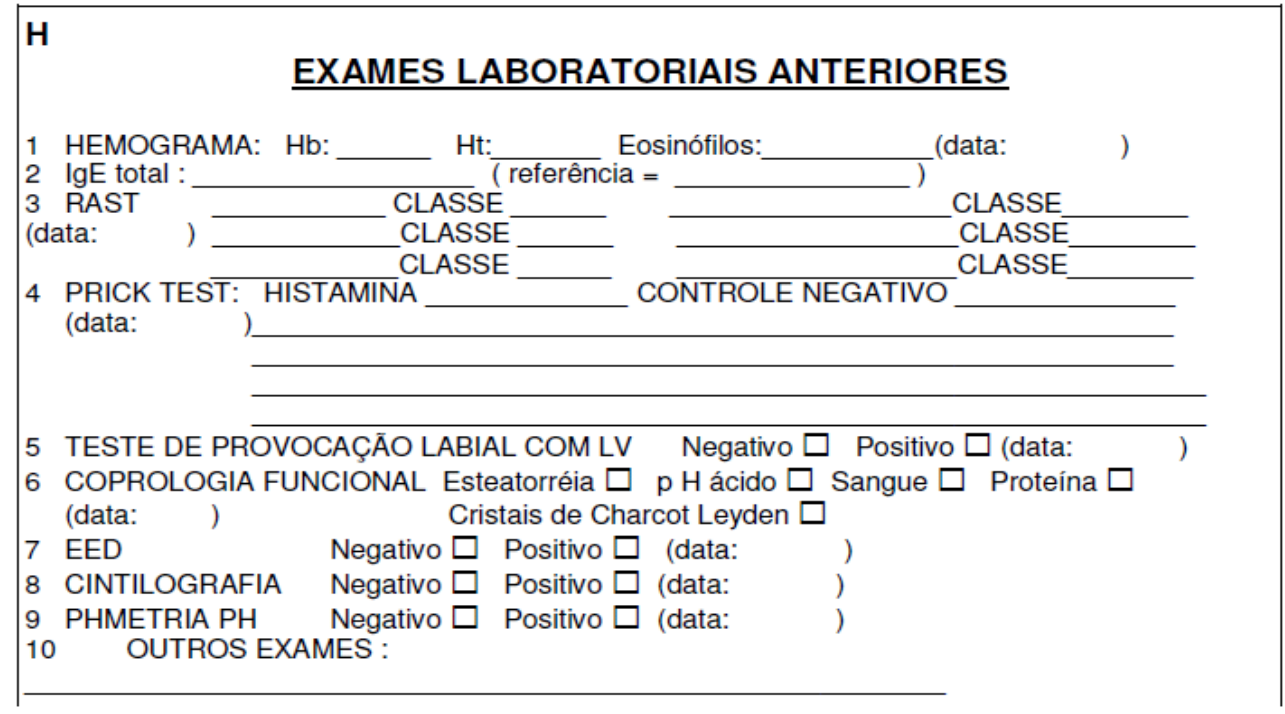

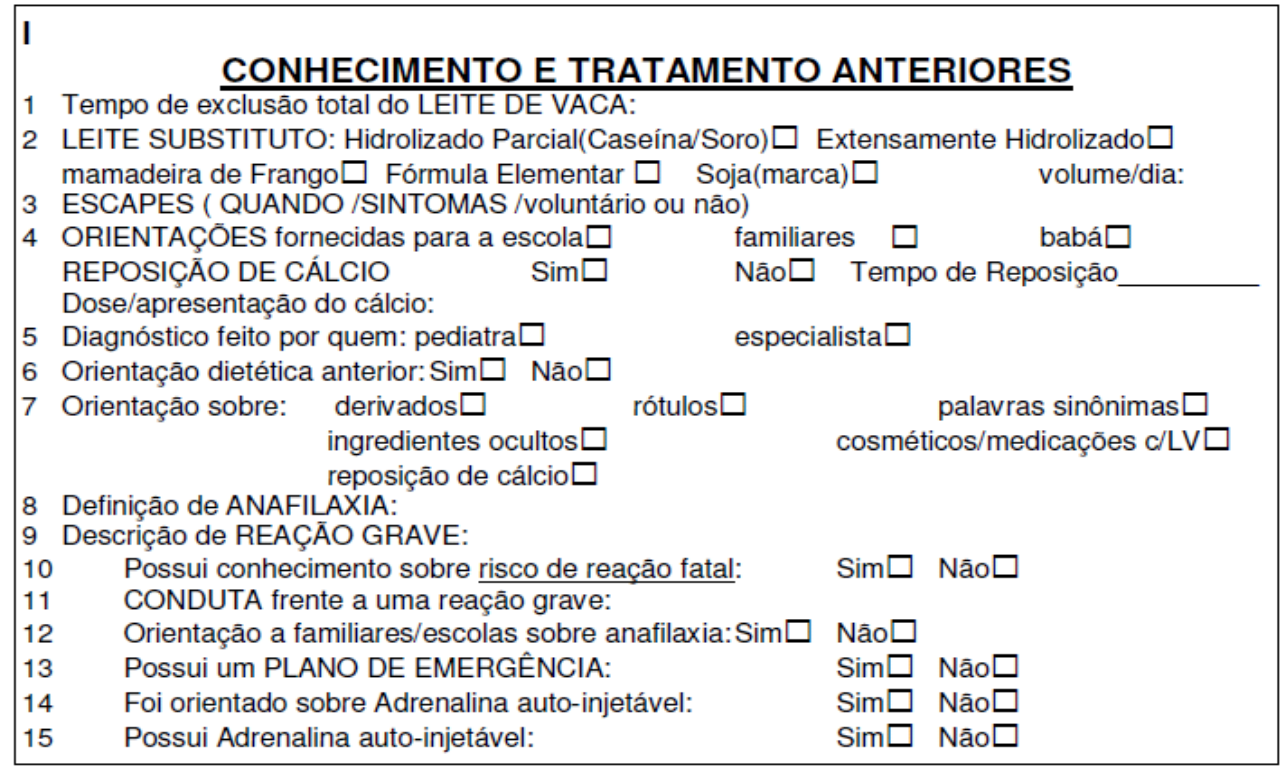


Anexo C. Protocolo padronizado para atendimento a pacientes com alergia a proteína do leite de vaca (cont.)

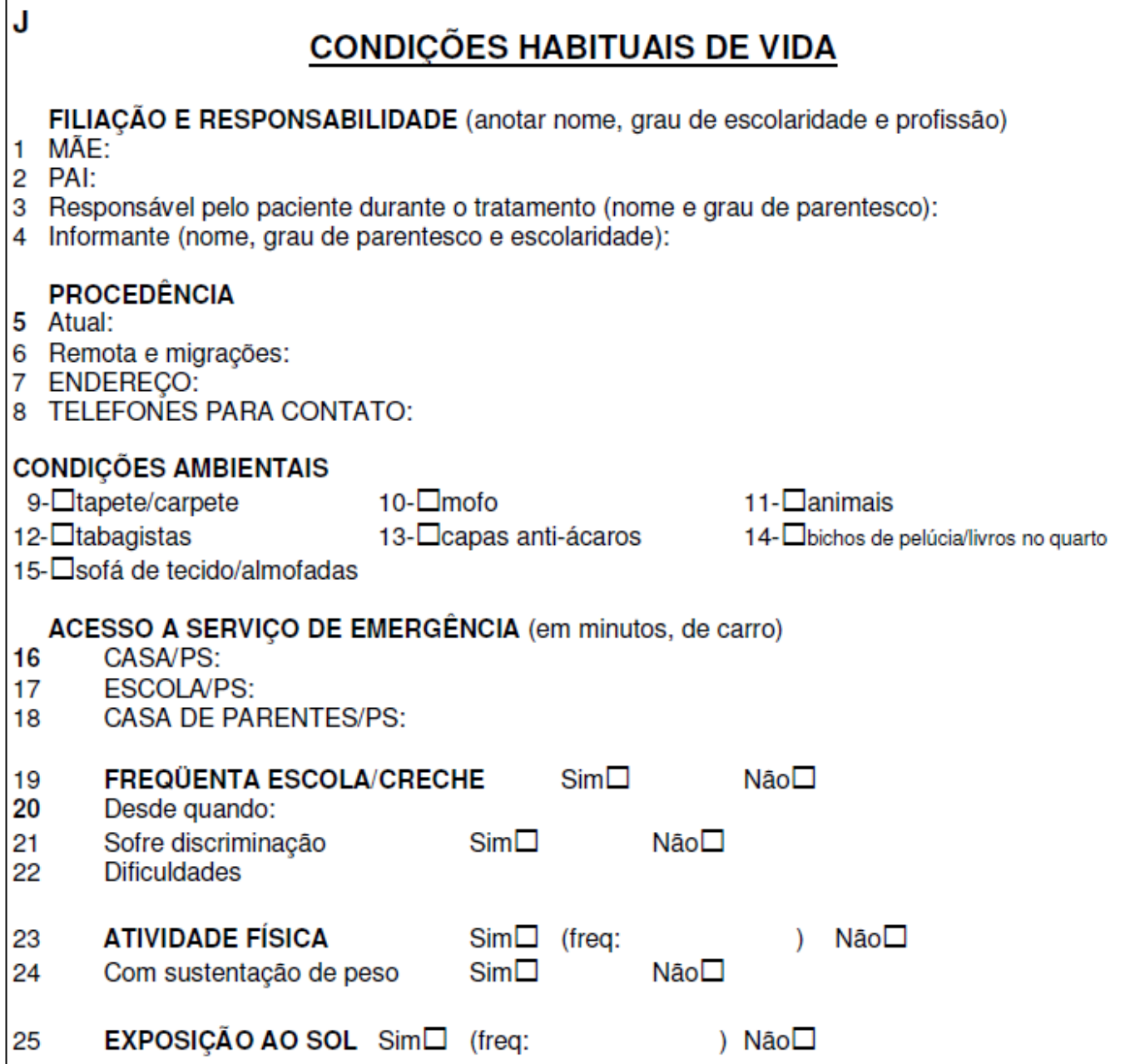

\section{CONDICÕ̃ES HABITUAIS DE VIDA}

FILIAÇÃO E RESPONSABILIDADE (anotar nome, grau de escolaridade e profissão)

1 MÃE:

PAI:

3 Responsável pelo paciente durante o tratamento (nome e grau de parentesco):

4 Informante (nome, grau de parentesco e escolaridade):

\section{PROCEDÊNCIA}

5 Atual:

6 Remota e migraçōes:

7 ENDEREÇO:

8 TELEFONES PARA CONTATO:

\section{CONDIÇÕES AMBIENTAIS}

$\begin{array}{lll}9-\square \text { tapete/carpete } & 10-\square \text { mofo } & 11-\square \text { animais } \\ 12-\square \text { tabagistas } & 13-\square \text { capas anti-ácaros } & 14-\square \text { bichos de pelúciallivros no quarto } \\ 15-\square \text { sofá de tecido/almofadas } & & \end{array}$

ACESSO A SERVIÇO DE EMERGÊNCIA (em minutos, de carro)

16 CASAIPS:

17 ESCOLA/PS:

18 CASA DE PARENTES/PS:

19 FREQÜENTA ESCOLA/CRECHE Sim $\square \quad$ Nâo $\square$

20 Desde quando:

21 Sofre discriminação $\quad \operatorname{Sim} \square \quad$ Nâo $\square$

22 Dificuldades

23 ATIVIDADE FÍSICA $\quad \operatorname{Sim} \square$ (freq: Nâo $\square$

24 Com sustentação de peso $\quad \operatorname{Sim} \square \quad$ Não $\square$

25 EXPOSIÇÃO AO SOL Sim $\square$ (freq: Nâo $\square$

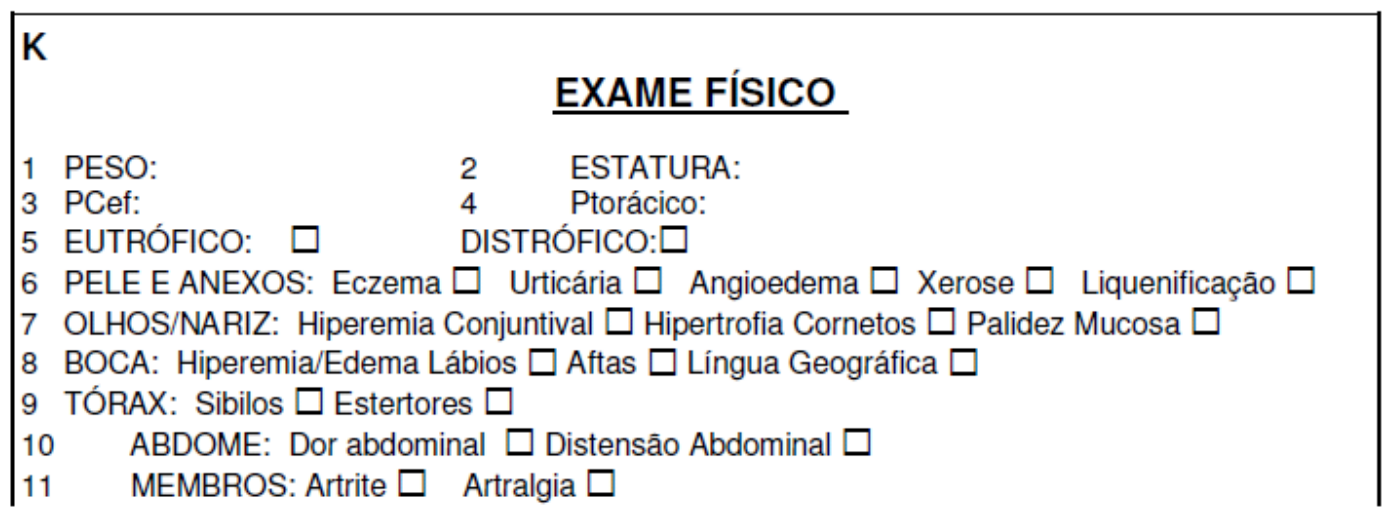


Anexo C. Protocolo padronizado para atendimento a pacientes com alergia a proteína do leite de vaca (cont.)
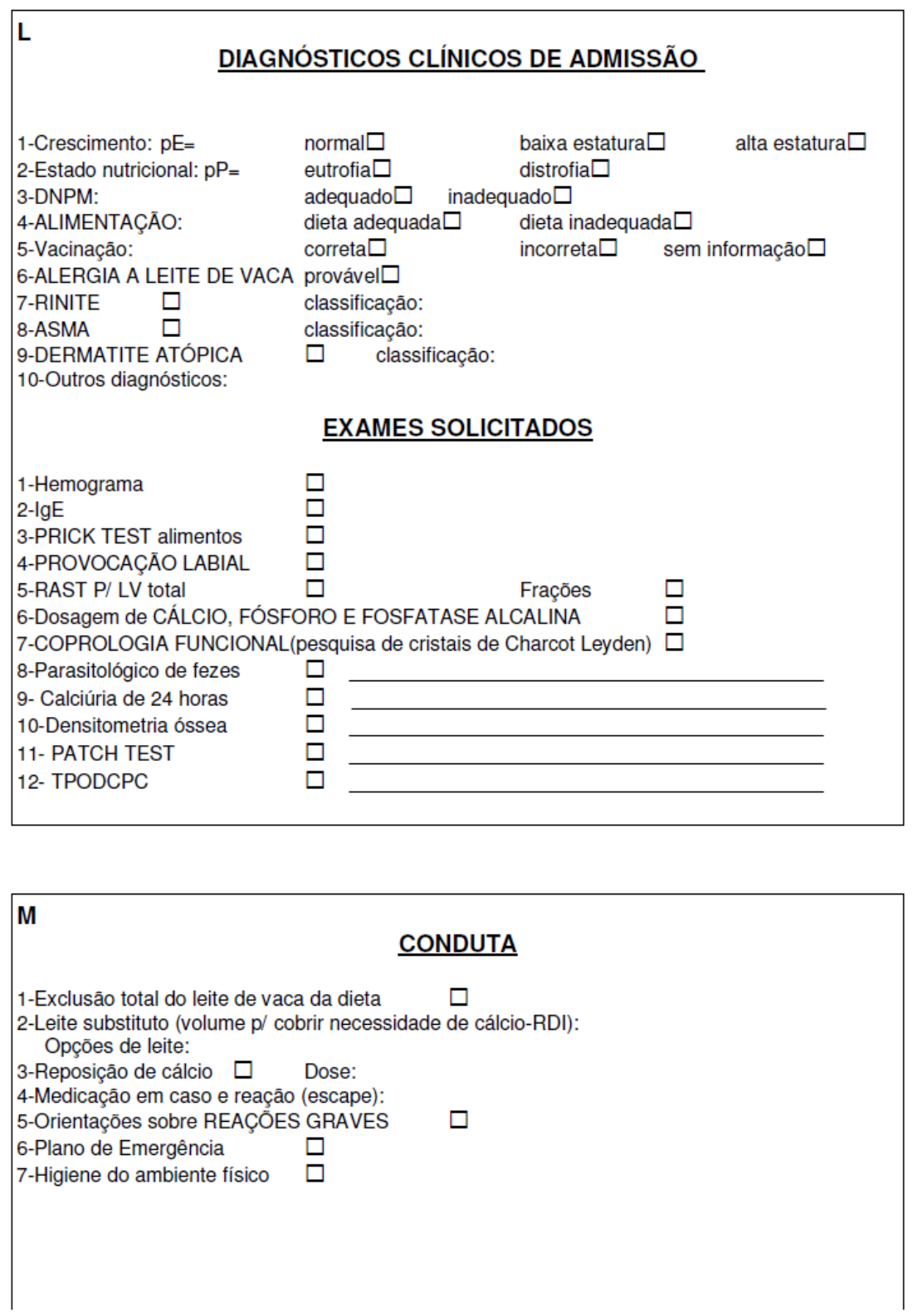
Anexo D. Valores de lgE específica para leite de vaca, $\alpha$-lactoalbumina, $\beta$ lactoglobulina e caseína em pacientes com alergia a proteína do leite de vaca sem manifestações de anafilaxia.

\begin{tabular}{|c|c|c|c|c|c|c|c|c|c|}
\hline Paciente & LV & ALFA & BETA & CASEINA & Paciente & LV & ALFA & BETA & CASEINA \\
\hline 1 & 3,50 & 3,00 & 3,00 & 4,10 & 45 & 24,80 & 10,10 & 9,44 & 24,70 \\
\hline 2 & 2,70 & 0,35 & 0,35 & 0,35 & 46 & 9,70 & 14,10 & 1,33 & 0,37 \\
\hline 3 & 8,70 & 7,01 & 0,35 & 0,46 & 47 & 6,20 & 6,20 & 0,31 & 3,04 \\
\hline 4 & 12,70 & & & & 48 & 98,30 & 44,90 & & 100,00 \\
\hline 5 & 17,50 & 0,35 & 0,35 & 1,80 & 49 & 18,60 & 6,67 & 4,04 & 18,20 \\
\hline 6 & 17,50 & 17,50 & 17,50 & 17,50 & 50 & 11,60 & 0,37 & 1,69 & 21,00 \\
\hline 7 & 14,00 & & & & 51 & 39,50 & 4,70 & 5,13 & 9,15 \\
\hline 8 & 22,20 & & & & 52 & 0,76 & 0,35 & 1,10 & 0,35 \\
\hline 9 & 4,26 & & & 0,69 & 53 & 3,98 & 5,37 & 0,89 & 2,29 \\
\hline 10 & 1,37 & 0,00 & 1,10 & 1,18 & 54 & 1,58 & 0,35 & 5,05 & 0,84 \\
\hline 11 & 0,36 & 0,35 & 0,40 & 0,35 & 55 & 10,60 & 9,32 & 6,86 & 2,26 \\
\hline 12 & 24,10 & 0,35 & 5,38 & 32,40 & 56 & 38,20 & 10,70 & 16,40 & 22,40 \\
\hline 13 & 12,50 & & & & 57 & 13,20 & 10,10 & 12,90 & 10,70 \\
\hline 14 & 26,10 & 2,69 & 1,60 & 20,00 & & & & & \\
\hline 15 & 15,70 & 2,47 & 21,40 & 15,20 & & & & & \\
\hline 16 & 0,35 & & & & & & & & \\
\hline 17 & 5,39 & 3,47 & 0,88 & 4,62 & & & & & \\
\hline 18 & 0,60 & 0,35 & 0,86 & 0,35 & & & & & \\
\hline 19 & 100,00 & & & & & & & & \\
\hline 20 & 1,35 & 5,20 & 5,20 & 2,30 & & & & & \\
\hline 21 & 0,74 & & & & & & & & \\
\hline 22 & 0,86 & 0,35 & 0,94 & 0,35 & & & & & \\
\hline 23 & 3,44 & 0,73 & 1,01 & 3,32 & & & & & \\
\hline 24 & 11,30 & 16,20 & 0,35 & 0,35 & & & & & \\
\hline 25 & 3,04 & 3,51 & 0,94 & 0,35 & & & & & \\
\hline 26 & 17,90 & 3,66 & 0,66 & 12,20 & & & & & \\
\hline 27 & 4,00 & & & & & & & & \\
\hline 28 & 1,83 & 0,40 & 1,37 & 1,41 & & & & & \\
\hline 29 & 17,40 & 0,90 & 0,91 & 5,04 & & & & & \\
\hline 30 & 7,30 & 5,13 & 4,18 & 7,97 & & & & & \\
\hline 31 & 6,00 & 1,71 & 3,00 & 3,78 & & & & & \\
\hline 32 & 3,57 & 5,31 & 3,80 & 0,80 & & & & & \\
\hline 33 & 5,66 & & & & & & & & \\
\hline 34 & 4,84 & 4,68 & 0,41 & 1,07 & & & & & \\
\hline 35 & 6,62 & 2,27 & & 1,54 & & & & & \\
\hline 36 & 1,67 & 0,35 & 1,70 & 0,35 & & & & & \\
\hline 37 & 5,87 & 5,86 & 2,16 & 5,13 & & & & & \\
\hline 38 & 6,57 & 0,35 & 2,07 & 2,89 & & & & & \\
\hline 39 & 6,31 & 3,51 & 3,66 & 5,35 & & & & & \\
\hline 40 & 4,46 & 0,35 & 8,04 & 0,35 & & & & & \\
\hline 41 & 0,35 & 0,35 & 0,35 & 0,35 & & & & & \\
\hline 42 & 0,46 & 0,35 & 0,49 & 0,35 & & & & & \\
\hline 43 & 15,30 & 4,05 & 7,37 & 14,80 & & & & & \\
\hline 44 & 7,23 & 1,19 & 1,31 & 7,98 & & & & & \\
\hline
\end{tabular}


Anexo E. Valores de IgE específica para leite de vaca, $\alpha$-lactoalbumina, $\beta$ lactoglobulina e caseína em pacientes com alergia a proteína do leite de vaca com manifestações de anafilaxia anafilaxia

\begin{tabular}{|c|c|c|c|c|c|c|c|c|c|}
\hline Paciente & LV & ALFA & BETA & CASEINA & Paciente & LV & ALFA & BETA & CASEINA \\
\hline 1 & 17,50 & 17,50 & 9,80 & 17,50 & 45 & 20,40 & 13,30 & 6,24 & 14,30 \\
\hline 2 & 10,80 & 6,90 & 1,60 & 10,40 & 46 & 100,00 & 18,70 & 5,72 & 68,90 \\
\hline 3 & 4,38 & 0,55 & 5,40 & 0,35 & 47 & 63,30 & 4,04 & 14,00 & 49,40 \\
\hline 4 & 13,78 & & & 9,02 & 48 & & 7,43 & 3,62 & 48,50 \\
\hline 5 & 27,90 & & & 6,00 & 49 & 0,94 & 1,22 & 0,93 & 0,35 \\
\hline 6 & 34,20 & 10,80 & 4,18 & 40,40 & 50 & 35,00 & 23,50 & 5,57 & 37,70 \\
\hline 7 & 0,35 & 0,35 & 0,35 & 0,35 & 51 & 5,66 & & & \\
\hline 8 & 3,60 & 1,00 & 2,50 & 2,40 & 52 & 12,30 & 7,16 & 2,65 & 3,86 \\
\hline 9 & 17,50 & 8,70 & 11,70 & 17,50 & 53 & 0,49 & 9,51 & 9,28 & \\
\hline 10 & 14,20 & 3,90 & 11,00 & 5,30 & 54 & 70,10 & 8,32 & 23,40 & 39,80 \\
\hline 11 & 12,20 & 0,66 & 2,74 & 12,40 & 55 & 100,00 & 54,60 & & 100,00 \\
\hline 12 & 1,02 & & & & 56 & 22,10 & 7,60 & 4,28 & 11,90 \\
\hline 13 & 3,51 & & & & 57 & 8,50 & & & \\
\hline 14 & 1,87 & & & 1,87 & 58 & 0,51 & 0,42 & 0,35 & 0,35 \\
\hline 15 & 2,29 & 3,81 & 0,35 & 0,90 & 59 & 0,50 & 0,35 & 0,35 & 0,35 \\
\hline 16 & 22,40 & 6,18 & 8,81 & 20,10 & 50 & 14,40 & 10,20 & 5,20 & 7,98 \\
\hline 17 & 40,70 & & & & 61 & 100,00 & 1,68 & 10,70 & 100,00 \\
\hline 18 & 2,18 & & & & 62 & 0,39 & 0,35 & 0,35 & 0,44 \\
\hline 19 & 12,90 & & & & 63 & 100,00 & 50,50 & 12,30 & 63,50 \\
\hline 20 & 0,35 & 0,35 & 0,35 & 0,35 & 64 & 21,20 & 0,99 & 0,84 & 17,30 \\
\hline 21 & 100,00 & 73,40 & 63,10 & 100,00 & 65 & 2,58 & 0,35 & 2,80 & 0,35 \\
\hline 22 & 7,90 & & & & 66 & 16,60 & 16,30 & 4,60 & 9,31 \\
\hline 23 & 17,50 & & & & & & & & \\
\hline 24 & 41,60 & 0,86 & 0,84 & 2,93 & & & & & \\
\hline 25 & 65,00 & 8,00 & 27,00 & 44,00 & & & & & \\
\hline 26 & 8,78 & & & 11,00 & & & & & \\
\hline 27 & 6,64 & 1,73 & 4,97 & 3,06 & & & & & \\
\hline 28 & 22,10 & 7,60 & 4,28 & 11,90 & & & & & \\
\hline 29 & 0,86 & 0,69 & 0,44 & 0,51 & & & & & \\
\hline 30 & 2,51 & 6,99 & 3,08 & 2,14 & & & & & \\
\hline 31 & 1,04 & & 0,78 & & & & & & \\
\hline 32 & 38,60 & 0,51 & 2,88 & 44,10 & & & & & \\
\hline 33 & 27,40 & 14,20 & 2,24 & 34,40 & & & & & \\
\hline 34 & 20,60 & 3,20 & 2,25 & 18,60 & & & & & \\
\hline 35 & 1,34 & 0,35 & 0,61 & 0,90 & & & & & \\
\hline 36 & 86,90 & 0,70 & 2,87 & & & & & & \\
\hline 37 & 2,28 & 2,59 & 2,59 & 0,70 & & & & & \\
\hline 38 & 13,40 & & & & & & & & \\
\hline 39 & 12,30 & 9,48 & 11,70 & 20,10 & & & & & \\
\hline 40 & 1,54 & 0,39 & 0,50 & 0,48 & & & & & \\
\hline 41 & 73,20 & 24,40 & 21,40 & 66,90 & & & & & \\
\hline 42 & 0,35 & 0,35 & 0,35 & 0,35 & & & & & \\
\hline 43 & 0,35 & 0,35 & 0,35 & 0,35 & & & & & \\
\hline 44 & 100,00 & 3,75 & 24,50 & 100,00 & & & & & \\
\hline
\end{tabular}


Anexo $\mathrm{F}$ Valores de IgE específica para leite de vaca, $\alpha$-lactoalbumina, $\beta$ lactoglobulina e caseína entre as crianças que integraram o grupo controle

\begin{tabular}{|c|c|c|c|c|c|c|c|c|c|}
\hline Controle & LV & ALFA & BETA & CASEINA & Controle & LV & ALFA & BETA & CASEINA \\
\hline 1 & 0,35 & 0,35 & 0,35 & 0,35 & 46 & 0,35 & 0,35 & 0,35 & 0,35 \\
\hline 2 & 0,35 & 0,35 & 0,35 & 0,35 & 47 & 0,35 & 0,35 & 0,35 & 0,35 \\
\hline 3 & 0,80 & 1,40 & 0,98 & 1,33 & 48 & 0,35 & 0,35 & 0,35 & 0,35 \\
\hline 4 & 0,35 & 0,35 & 0,35 & 0,35 & 49 & 0,50 & 0,75 & 0,77 & 0,56 \\
\hline 5 & 0,35 & 0,35 & 0,35 & 0,35 & 50 & 0,50 & 0,46 & 0,55 & 0,37 \\
\hline 6 & 0,35 & 0,35 & 0,35 & 0,35 & 51 & 0,35 & 0,35 & 0,35 & 0,35 \\
\hline 7 & 0,73 & 0,35 & 0,94 & 0,66 & 52 & 0,35 & 0,35 & 0,35 & 0,35 \\
\hline 8 & 1,10 & 0,44 & 0,35 & 1,08 & 53 & 0,35 & 0,35 & 0,35 & 0,35 \\
\hline 9 & 0,39 & 0,52 & 0,62 & 0,40 & 54 & 0,35 & 0,35 & 0,35 & 0,35 \\
\hline 10 & 0,35 & 0,35 & 0,35 & 0,35 & 55 & 0,35 & 0,35 & 0,35 & 0,35 \\
\hline 11 & 0,96 & 0,87 & 0,46 & 0,63 & 56 & 0,35 & 0,35 & 0,91 & 0,35 \\
\hline 12 & 0,35 & 0,35 & 0,35 & 0,35 & 57 & 0,35 & 0,35 & 0,35 & 0,35 \\
\hline 13 & 0,35 & 0,35 & 0,35 & 0,35 & 58 & 0,35 & 0,35 & 0,35 & 0,35 \\
\hline 14 & 1,30 & 0,35 & 2,31 & 0,66 & 59 & 0,35 & 0,35 & 0,35 & 0,35 \\
\hline 15 & 0,35 & 0,35 & 0,35 & 0,35 & 50 & 0,35 & 0,35 & 0,35 & 0,35 \\
\hline 16 & 0,46 & 0,35 & 0,49 & 0,35 & 61 & 0,64 & 0,61 & 0,35 & 0,35 \\
\hline 17 & 2,87 & 0,77 & 1,70 & 1,02 & & & & & \\
\hline 18 & 0,54 & 0,35 & 0,79 & 0,35 & & & & & \\
\hline 19 & 0,68 & 1,00 & 0,58 & 0,35 & & & & & \\
\hline 20 & 0,40 & 0,35 & 0,50 & 0,35 & & & & & \\
\hline 21 & 0,35 & 0,35 & 0,35 & 0,35 & & & & & \\
\hline 22 & 0,35 & 0,35 & 0,35 & 0,35 & & & & & \\
\hline 23 & 1,64 & 0,35 & 1,18 & 0,48 & & & & & \\
\hline 24 & 0,35 & 0,35 & 0,35 & 0,35 & & & & & \\
\hline 25 & 0,65 & 0,35 & 0,63 & 0,65 & & & & & \\
\hline 26 & 0,35 & 0,35 & 0,35 & 0,35 & & & & & \\
\hline 27 & 0,35 & 0,35 & 0,35 & 0,35 & & & & & \\
\hline 28 & 1,83 & 0,40 & 1,37 & 1,41 & & & & & \\
\hline 29 & 0,76 & 0,35 & 0,43 & 0,56 & & & & & \\
\hline 30 & 0,35 & 0,35 & 0,35 & 0,35 & & & & & \\
\hline 31 & 1,45 & 0,35 & 0,85 & 0,76 & & & & & \\
\hline 32 & 0,35 & 0,35 & 0,35 & 0,35 & & & & & \\
\hline 33 & 0,35 & 0,35 & 0,35 & 0,35 & & & & & \\
\hline 34 & 0,35 & 0,35 & 0,35 & 0,35 & & & & & \\
\hline 35 & 0,36 & 0,35 & 0,40 & 0,35 & & & & & \\
\hline 36 & 0,36 & 0,77 & 0,35 & 0,71 & & & & & \\
\hline 37 & 0,86 & 0,69 & 0,44 & 0,51 & & & & & \\
\hline 38 & 0,35 & 0,35 & 0,35 & 0,35 & & & & & \\
\hline 39 & 0,35 & 0,35 & 0,35 & 0,35 & & & & & \\
\hline 40 & 0,35 & 0,39 & 0,35 & 0,35 & & & & & \\
\hline 41 & 0,35 & 0,35 & 0,35 & 0,35 & & & & & \\
\hline 42 & 0,36 & 0,35 & 0,35 & 0,35 & & & & & \\
\hline 43 & 0,35 & 0,35 & 0,35 & 0,35 & & & & & \\
\hline 44 & 3,06 & 2,08 & 1,85 & 2,30 & & & & & \\
\hline 45 & 5,11 & 7,58 & 0,64 & 1,47 & & & & & \\
\hline
\end{tabular}




\section{Anexo G. Valores de IgE específica para leite de vaca que compuseram a curva ROC (pacientes e grupo controle)}

\begin{tabular}{|c|c|c|}
\hline \multicolumn{3}{|l|}{ ROC curve } \\
\hline Variable & \multicolumn{2}{|c|}{ RASTLV } \\
\hline Classification variable & \multicolumn{2}{|l|}{ grupo } \\
\hline \multicolumn{3}{|l|}{ Positive group } \\
\hline grupo & \multicolumn{2}{|l|}{$=1$} \\
\hline Sample size & \multicolumn{2}{|l|}{122} \\
\hline \multicolumn{3}{|l|}{ Negative group } \\
\hline grupo & \multicolumn{2}{|l|}{$=0$} \\
\hline Sample size & \multicolumn{2}{|l|}{61} \\
\hline \multicolumn{2}{|l|}{ Disease prevalence (\%) } & unknown \\
\hline \multicolumn{2}{|c|}{ Area under the ROC curve (AUC) } & 0,929 \\
\hline \multicolumn{2}{|l|}{ Standard Error } & 0,0184 \\
\hline \multicolumn{2}{|l|}{$95 \%$ Confidence Interval } & 0,881 to 0,962 \\
\hline \multicolumn{2}{|l|}{ z statistic } & 23,367 \\
\hline \multicolumn{2}{|c|}{ Significance level P (Area=0.5) } & 0,0001 \\
\hline
\end{tabular}

Criterion values and coordinates of the ROC curve [Hide]

\begin{tabular}{|c|c|c|c|c|c|c|c|c|}
\hline Criterion & Sensitivity & $95 \% \mathrm{Cl}$ & Specificity & $95 \% \mathrm{Cl}$ & $+\mathrm{LR}$ & $95 \% \mathrm{Cl}$ & -LR & $95 \% \mathrm{Cl}$ \\
\hline$>=0,35$ & 100,00 & $97,0-100,0$ & 0,00 & $0,0-5,9$ & 1,00 & & & \\
\hline$>0,35$ & 95,08 & $89,6-98,2$ & 59,02 & $45,7-71,4$ & 2,32 & $1,9-2,9$ & 0,083 & $0,04-0,2$ \\
\hline$>0,36$ & 94,26 & $88,5-97,7$ & 63,93 & $50,6-75,8$ & 2,61 & $2,2-3,2$ & 0,09 & $0,04-0,2$ \\
\hline$>0,39$ & 93,44 & $87,5-97,1$ & 65,57 & $52,3-77,3$ & 2,71 & $2,2-3,3$ & 0,10 & $0,05-0,2$ \\
\hline$>0,4$ & 93,44 & $87,5-97,1$ & 67,21 & $54,0-78,7$ & 2,85 & $2,4-3,4$ & 0,098 & $0,05-0,2$ \\
\hline$>0,46$ & 92,62 & $86,5-96,6$ & 68,85 & $55,7-80,1$ & 2,97 & $2,5-3,5$ & 0,11 & $0,05-0,2$ \\
\hline$>0,49$ & 91,80 & $85,4-96,0$ & 68,85 & $55,7-80,1$ & 2,95 & $2,5-3,5$ & 0,12 & $0,06-0,2$ \\
\hline$>0,5$ & 90,98 & $84,4-95,4$ & 72,13 & $59,2-82,8$ & 3,26 & $2,8-3,9$ & 0,12 & $0,06-0,3$ \\
\hline$>0,51$ & 90,16 & $83,4-94,8$ & 72,13 & $59,2-82,8$ & 3,24 & $2,7-3,8$ & 0,14 & $0,07-0,3$ \\
\hline$>0,54$ & 90,16 & $83,4-94,8$ & 73,77 & $60,9-84,2$ & 3,44 & $2,9-4,0$ & 0,13 & $0,07-0,3$ \\
\hline$>0,6$ & 89,34 & $82,5-94,2$ & 73,77 & $60,9-84,2$ & 3,41 & $2,9-4,0$ & 0,14 & $0,07-0,3$ \\
\hline$>0,64$ & 89,34 & $82,5-94,2$ & 75,41 & $62,7-85,5$ & 3,63 & $3,1-4,2$ & 0,14 & $0,07-0,3$ \\
\hline$>0,65$ & 89,34 & $82,5-94,2$ & 77,05 & $64,5-86,8$ & 3,89 & $3,4-4,5$ & 0,14 & $0,07-0,3$ \\
\hline$>0,68$ & 89,34 & $82,5-94,2$ & 78,69 & $66,3-88,1$ & 4,19 & $3,6-4,8$ & 0,14 & $0,07-0,3$ \\
\hline$>0,73$ & 89,34 & $82,5-94,2$ & 80,33 & $68,2-89,4$ & 4,54 & $4,0-5,2$ & 0,13 & $0,06-0,3$ \\
\hline$>0,74$ & 88,52 & $81,5-93,6$ & 80,33 & $68,2-89,4$ & 4,50 & $3,9-5,2$ & 0,14 & $0,07-0,3$ \\
\hline$>0,76$ & 87,70 & $80,5-92,9$ & 81,97 & $70,0-90,6$ & 4,86 & $4,2-5,6$ & 0,15 & $0,07-0,3$ \\
\hline$>0,8$ & 87,70 & $80,5-92,9$ & 83,61 & $71,9-91,8$ & 5,35 & $4,7-6,1$ & 0,15 & $0,07-0,3$ \\
\hline$>0,86$ & 86,07 & $78,6-91,7$ & 85,25 & $73,8-93,0$ & 5,83 & $5,1-6,6$ & 0,16 & $0,08-0,3$ \\
\hline$>0,94$ & 85,25 & $77,7-91,0$ & 85,25 & $73,8-93,0$ & 5,78 & $5,1-6,6$ & 0,17 & $0,08-0,4$ \\
\hline$>0,96$ & 85,25 & $77,7-91,0$ & 86,89 & $75,8-94,1$ & 6,50 & $5,8-7,3$ & 0,17 & $0,08-0,4$ \\
\hline$>1,02$ & 84,43 & $76,8-90,4$ & 86,89 & $75,8-94,1$ & 6,44 & $5,7-7,3$ & 0,18 & $0,08-0,4$ \\
\hline$>1,04$ & 83,61 & $75,8-89,7$ & 86,89 & $75,8-94,1$ & 6,37 & $5,6-7,2$ & 0,19 & $0,09-0,4$ \\
\hline$>1,1$ & 83,61 & $75,8-89,7$ & 88,52 & $77,8-95,2$ & 7,29 & $6,5-8,2$ & 0,19 & $0,08-0,4$ \\
\hline$>1,3$ * & 83,61 & $75,8-89,7$ & 90,16 & $79,8-96,3$ & 8,50 & $7,6-9,5$ & 0,18 & $0,08-0,4$ \\
\hline$>1,34$ & 82,79 & $74,9-89,0$ & 90,16 & $79,8-96,3$ & 8,42 & $7,5-9,5$ & 0,19 & $0,08-0,4$ \\
\hline$>1,35$ & 81,97 & $74,0-88,3$ & 90,16 & $79,8-96,3$ & 8,33 & $7,4-9,4$ & 0,20 & $0,09-0,5$ \\
\hline$>1,37$ & 81,15 & $73,1-87,7$ & 90,16 & $79,8-96,3$ & 8,25 & $7,3-9,3$ & 0,21 & $0,09-0,5$ \\
\hline$>1,45$ & 81,15 & $73,1-87,7$ & 91,80 & $81,9-97,3$ & 9,90 & $8,8-11,1$ & " 0,21 & $0,08-0,5$ \\
\hline$>1,54$ & 80,33 & $72,2-87,0$ & 91,80 & $81,9-97,3$ & 9,80 & $8,7-11,0$ & 0,21 & $0,09-0,5$ \\
\hline$>1,58$ & 79,51 & $71,3-86,3$ & 91,80 & $81,9-97,3$ & 9,70 & $8,6-10,9$ & 0,22 & $0,09-0,6$ \\
\hline
\end{tabular}


Anexo G. Valores de IgE específica para leite de vaca que compuseram a curva ROC (pacientes e grupo controle)

\begin{tabular}{|c|c|c|c|c|c|c|c|c|}
\hline$>1,64$ & 79,51 & $71,3-86,3$ & 93,44 & $84,0-98,1$ & 12,13 & $10,8-13,6$ & 0,22 & $0,08-0,6$ \\
\hline$>1,67$ & 78,69 & $70,4-85,6$ & 93,44 & $84,0-98,1$ & 12,00 & $10,7-13,4$ & 0,23 & $0,08-0,6$ \\
\hline$>1,83$ & 77,87 & $69,5-84,9$ & 95,08 & $86,3-98,9$ & 15,83 & $14,2-17,7$ & 0,23 & $0,07-0,7$ \\
\hline$>1,87$ & 77,05 & $68,6-84,2$ & 95,08 & $86,3-98,9$ & 15,67 & $14,0-17,5$ & 0,24 & $0,08-0,8$ \\
\hline$>2,18$ & 76,23 & $67,7-83,5$ & 95,08 & $86,3-98,9$ & 15,50 & $13,8-17,4$ & 0,25 & $0,08-0,8$ \\
\hline$>2,28$ & 75,41 & $66,8-82,8$ & 95,08 & $86,3-98,9$ & 15,33 & $13,6-17,2$ & 0,26 & $0,08-0,8$ \\
\hline$>2,29$ & 74,59 & $65,9-82,0$ & 95,08 & $86,3-98,9$ & 15,17 & $13,5-17,1$ & 0,27 & $0,09-0,8$ \\
\hline$>2,51$ & 73,77 & $65,0-81,3$ & 95,08 & $86,3-98,9$ & 15,00 & $13,3-16,9$ & 0,28 & $0,09-0,9$ \\
\hline$>2,58$ & 72,95 & $64,2-80,6$ & 95,08 & $86,3-98,9$ & 14,83 & $13,1-16,8$ & 0,28 & $0,09-0,9$ \\
\hline$>2,7$ & 72,13 & $63,3-79,9$ & 95,08 & $86,3-98,9$ & 14,67 & $13,0-16,6$ & 0,29 & $0,09-0,9$ \\
\hline$>2,87$ & 72,13 & $63,3-79,9$ & 96,72 & $88,6-99,5$ & 22,00 & $19,5-24,8$ & 0,29 & $0,07-1,2$ \\
\hline$>3,04$ & 71,31 & $62,4-79,1$ & 96,72 & $88,6-99,5$ & 21,75 & $19,3-24,6$ & 0,30 & $0,07-1,2$ \\
\hline$>3,06$ & 71,31 & $62,4-79,1$ & 98,36 & $91,2-99,7$ & 43,50 & $38,7-48,9$ & 0,29 & $0,04-2,1$ \\
\hline$>3,44$ & 70,49 & $61,6-78,4$ & 98,36 & $91,2-99,7$ & 43,00 & $38,2-48,4$ & 0,30 & $0,04-2,1$ \\
\hline$>3,5$ & 69,67 & $60,7-77,7$ & 98,36 & $91,2-99,7$ & 42,50 & $37,6-48,0$ & 0,31 & $0,04-2,2$ \\
\hline$>3,51$ & 68,85 & $59,8-76,9$ & 98,36 & $91,2-99,7$ & 42,00 & $37,1-47,5$ & 0,32 & $0,04-2,3$ \\
\hline$>3,57$ & 68,03 & $59,0-76,2$ & 98,36 & $91,2-99,7$ & 41,50 & $36,6-47,1$ & 0,33 & $0,05-2,3$ \\
\hline$>3,6$ & 67,21 & $58,1-75,4$ & 98,36 & $91,2-99,7$ & 41,00 & $36,1-46,6$ & 0,33 & $0,05-2,4$ \\
\hline$>3,98$ & 66,39 & $57,3-74,7$ & 98,36 & $91,2-99,7$ & 40,50 & $35,6-46,1$ & 0,34 & $0,05-2,4$ \\
\hline$>4$ & 65,57 & $56,4-73,9$ & 98,36 & $91,2-99,7$ & 40,00 & $35,0-45,7$ & 0,35 & $0,05-2,5$ \\
\hline$>4,26$ & 64,75 & $55,6-73,2$ & 98,36 & $91,2-99,7$ & 39,50 & $34,5-45,2$ & 0,36 & $0,05-2,5$ \\
\hline$>4,38$ & 63,93 & $54,7-72,4$ & 98,36 & $91,2-99,7$ & 39,00 & $34,0-44,7$ & 0,37 & $0,05-2,6$ \\
\hline$>4,46$ & 63,11 & $53,9-71,7$ & 98,36 & $91,2-99,7$ & 38,50 & $33,5-44,3$ & 0,37 & $0,05-2,7$ \\
\hline$>4,84$ & 62,30 & $53,1-70,9$ & 98,36 & $91,2-99,7$ & 38,00 & $33,0-43,8$ & 0,38 & $0,05-2,7$ \\
\hline$>5,11$ & 62,30 & $53,1-70,9$ & 100,00 & $94,1-100,0$ & & & 0,38 & \\
\hline$>5,39$ & 61,48 & $52,2-70,1$ & 100,00 & $94,1-100,0$ & & & 0,39 & \\
\hline$>5,66$ & 59,84 & $50,6-68,6$ & 100,00 & $94,1-100,0$ & & & 0,40 & \\
\hline$>5,87$ & 59,02 & $49,7-67,8$ & 100,00 & $94,1-100,0$ & & & 0,41 & \\
\hline$>6$ & 58,20 & $48,9-67,1$ & 100,00 & $94,1-100,0$ & & & 0,42 & \\
\hline$>6,2$ & 57,38 & $48,1-66,3$ & 100,00 & $94,1-100,0$ & & & 0,43 & \\
\hline$>6,31$ & 56,56 & $47,3-65,5$ & 100,00 & $94,1-100,0$ & & & 0,43 & \\
\hline$>6,57$ & 55,74 & $46,5-64,7$ & 100,00 & $94,1-100,0$ & & & 0,44 & \\
\hline$>6,62$ & 54,92 & $45,7-63,9$ & 100,00 & $94,1-100,0$ & & & 0,45 & \\
\hline$>6,64$ & 54,10 & $44,8-63,2$ & 100,00 & $94,1-100,0$ & & & 0,46 & \\
\hline$>7,23$ & 53,28 & $44,0-62,4$ & 100,00 & $94,1-100,0$ & & & 0,47 & \\
\hline$>7,3$ & 52,46 & $43,2-61,6$ & 100,00 & $94,1-100,0$ & & & 0,48 & \\
\hline$>7,9$ & 51,64 & $42,4-60,8$ & 100,00 & $94,1-100,0$ & & & 0,48 & \\
\hline$>8,5$ & 50,82 & $41,6-60,0$ & 100,00 & $94,1-100,0$ & & & 0,49 & \\
\hline$>8,7$ & 50,00 & $40,8-59,2$ & 100,00 & $94,1-100,0$ & & & 0,50 & \\
\hline$>8,78$ & 49,18 & $40,0-58,4$ & 100,00 & $94,1-100,0$ & & & 0,51 & \\
\hline$>9,7$ & 48,36 & $39,2-57,6$ & 100,00 & $94,1-100,0$ & & & 0,52 & \\
\hline$>10,6$ & 47,54 & $38,4-56,8$ & 100,00 & $94,1-100,0$ & & & 0,52 & \\
\hline$>10,8$ & 46,72 & $37,6-56,0$ & 100,00 & $94,1-100,0$ & & & 0,53 & \\
\hline$>11,3$ & 45,90 & $36,8-55,2$ & 100,00 & $94,1-100,0$ & & & 0,54 & \\
\hline$>11,6$ & 45,08 & $36,1-54,3$ & 100,00 & $94,1-100,0$ & & & 0,55 & \\
\hline$>12,2$ & 44,26 & $35,3-53,5$ & 100,00 & $94,1-100,0$ & & & 0,56 & \\
\hline$>12,3$ & 42,62 & $33,7-51,9$ & 100,00 & $94,1-100,0$ & & & 0,57 & \\
\hline$>12,5$ & 41,80 & $32,9-51,1$ & 100,00 & $94,1-100,0$ & & & 0,58 & \\
\hline$>12,7$ & 40,98 & $32,2-50,3$ & 100,00 & $94,1-100,0$ & & & 0,59 & \\
\hline$>12,9$ & 40,16 & $31,4-49,4$ & 100,00 & $94,1-100,0$ & & & 0,60 & \\
\hline$>13,2$ & 39,34 & $30,6-48,6$ & 100,00 & $94,1-100,0$ & & & 0,61 & \\
\hline$>13,4$ & 38,52 & $29,9-47,8$ & 100,00 & $94,1-100,0$ & & & 0,61 & \\
\hline$>13,78$ & 37,70 & $29,1-46,9$ & 100,00 & $94,1-100,0$ & & & 0,62 & \\
\hline$>14$ & 36,89 & $28,3-46,1$ & 100,00 & $94,1-100,0$ & & & 0,63 & \\
\hline
\end{tabular}




\section{Anexo G. Valores de IgE específica para leite de vaca que compuseram a curva ROC (pacientes e grupo controle)}

\begin{tabular}{|c|c|c|c|c|c|}
\hline$>14,2$ & 36,07 & $27,6-45,3$ & 100,00 & $94,1-100,0$ & 0,64 \\
\hline$>14,4$ & 35,25 & $26,8-44,4$ & 100,00 & $94,1-100,0$ & 0,65 \\
\hline$>15,3$ & 34,43 & $26,1-43,6$ & 100,00 & $94,1-100,0$ & 0,66 \\
\hline$>15,7$ & 33,61 & $25,3-42,7$ & 100,00 & $94,1-100,0$ & 0,66 \\
\hline$>16,6$ & 32,79 & $24,6-41,9$ & 100,00 & $94,1-100,0$ & 0,67 \\
\hline$>17,4$ & 31,97 & $23,8-41,0$ & 100,00 & $94,1-100,0$ & 0,68 \\
\hline$>17,5$ & 27,87 & $20,1-36,7$ & 100,00 & $94,1-100,0$ & 0,72 \\
\hline$>17,9$ & 27,05 & $19,4-35,8$ & 100,00 & $94,1-100,0$ & 0,73 \\
\hline$>18,6$ & 26,23 & $18,7-35,0$ & 100,00 & $94,1-100,0$ & 0,74 \\
\hline$>20,4$ & 25,41 & $18,0-34,1$ & 100,00 & $94,1-100,0$ & 0,75 \\
\hline$>20,6$ & 24,59 & $17,2-33,2$ & 100,00 & $94,1-100,0$ & 0,75 \\
\hline$>21,2$ & 23,77 & $16,5-32,3$ & 100,00 & $94,1-100,0$ & 0,76 \\
\hline$>22,1$ & 22,13 & $15,1-30,5$ & 100,00 & $94,1-100,0$ & 0,78 \\
\hline$>22,2$ & 21,31 & $14,4-29,6$ & 100,00 & $94,1-100,0$ & 0,79 \\
\hline$>22,4$ & 20,49 & $13,7-28,7$ & 100,00 & $94,1-100,0$ & 0,80 \\
\hline$>24,1$ & 19,67 & $13,0-27,8$ & 100,00 & $94,1-100,0$ & 0,80 \\
\hline$>24,8$ & 18,85 & $12,3-26,9$ & 100,00 & $94,1-100,0$ & 0,81 \\
\hline$>26,1$ & 18,03 & $11,7-26,0$ & 100,00 & $94,1-100,0$ & 0,82 \\
\hline$>27,4$ & 17,21 & $11,0-25,1$ & 100,00 & $94,1-100,0$ & 0,83 \\
\hline$>27,9$ & 16,39 & $10,3-24,2$ & 100,00 & $94,1-100,0$ & 0,84 \\
\hline$>34,2$ & 15,57 & $9,6-23,2$ & 100,00 & $94,1-100,0$ & 0,84 \\
\hline$>35$ & 14,75 & $9,0-22,3$ & 100,00 & $94,1-100,0$ & 0,85 \\
\hline$>38,2$ & 13,93 & $8,3-21,4$ & 100,00 & $94,1-100,0$ & 0,86 \\
\hline$>38,6$ & 13,11 & $7,7-20,4$ & 100,00 & $94,1-100,0$ & 0,87 \\
\hline$>39,5$ & 12,30 & $7,1-19,5$ & 100,00 & $94,1-100,0$ & 0,88 \\
\hline$>40,7$ & 11,48 & $6,4-18,5$ & 100,00 & $94,1-100,0$ & 0,89 \\
\hline$>41,6$ & 10,66 & $5,8-17,5$ & 100,00 & $94,1-100,0$ & 0,89 \\
\hline$>63,3$ & 9,84 & $5,2-16,6$ & 100,00 & $94,1-100,0$ & 0,90 \\
\hline$>65$ & 9,02 & $4,6-15,6$ & 100,00 & $94,1-100,0$ & 0,91 \\
\hline$>70,1$ & 8,20 & $4,0-14,6$ & 100,00 & $94,1-100,0$ & 0,92 \\
\hline$>73,2$ & 7,38 & $3,4-13,5$ & 100,00 & $94,1-100,0$ & 0,93 \\
\hline$>86,9$ & 6,56 & $2,9-12,5$ & 100,00 & $94,1-100,0$ & 0,93 \\
\hline$>98,3$ & 5,74 & $2,3-11,5$ & 100,00 & $94,1-100,0$ & 0,94 \\
\hline$>100$ & 0,00 & $0,0-3,0$ & 100,00 & $94,1-100,0$ & 1,00 \\
\hline
\end{tabular}


Anexo $\mathrm{H}$. Valores de IgE específica para $\alpha$-lactoalbumina que compuseram a curva ROC (pacientes e grupo controle)

\begin{tabular}{|c|c|c|}
\hline \multicolumn{3}{|l|}{ ROC curve } \\
\hline Variable & \multicolumn{2}{|c|}{ RASTALFA } \\
\hline Classification variable & \multicolumn{2}{|l|}{ grupo } \\
\hline \multicolumn{3}{|l|}{ Positive group } \\
\hline grupo & \multicolumn{2}{|l|}{-1} \\
\hline Sample size & \multicolumn{2}{|l|}{98} \\
\hline \multicolumn{3}{|l|}{ Negative group } \\
\hline grupo & \multicolumn{2}{|l|}{-0} \\
\hline Sample size & \multicolumn{2}{|l|}{61} \\
\hline \multicolumn{2}{|l|}{ Disease prevalence $(\%)$} & unknown \\
\hline \multicolumn{2}{|c|}{ Area under the ROC curve (AUC) } & 0,828 \\
\hline \multicolumn{2}{|l|}{ Standard Error } & 0,0318 \\
\hline \multicolumn{2}{|l|}{$95 \%$ Confidence Interval } & 0,760 to 0,883 \\
\hline \multicolumn{2}{|l|}{$\mathrm{z}$ statistic } & 10,321 \\
\hline \multicolumn{2}{|c|}{ Signiticance level P (Area-0.5) } & 0,0001 \\
\hline
\end{tabular}

Criterion values and coordinates of the ROC curve [Hide]

\begin{tabular}{|c|c|c|c|c|c|c|c|c|}
\hline Criterion & Sensitivity & $95 \% \mathrm{Cl}$ & Specificity & $95 \% \mathrm{Cl}$ & +LA & $95 \% \mathrm{Cl}$ & -LR & $95 \% \mathrm{Cl}$ \\
\hline $2=0$ & 100,00 & $96,3-100,0$ & 0,00 & $0,0-5,9$ & 1,00 & & & \\
\hline$>0$ & $98, \overline{98}$ & $94,4-99,8$ & 0,00 & $0,0-5,9$ & 0,99 & & & \\
\hline$>0,35$ & 77,55 & $68,0-85,4$ & 75,41 & $62,7-85,5$ & $3,15^{\prime}$ & $2,6-3,8$ & 0,30 & $0,2-0,5$ \\
\hline$>0,37$ & 76,53 & $66,9-84,5$ & 75,41 & $62,7-85,5$ & $3,11^{\prime \prime}$ & $2,6-3,7$ & 0,31 & $0,2-0,5$ \\
\hline$>0,39$ & 75,51 & $65,8-83,6$ & 77,05 & $64,5-86,8$ & 3,29 & $2,8-3,9$ & 0,32 & $0,2-0,6$ \\
\hline$>0,4$ & $74, \overline{49}$ & $64,7-82,8$ & 78,69 & $66,3-88,1$ & 3,50 & $2,9-4,2$ & 0,32 & $0,2-0,6$ \\
\hline$>0,42$ & 73,47 & $63,6-81,9$ & 78,69 & $66,3-88,1$ & $3,45^{\prime}$ & $2,9-4,1$ & 0,34 & $0,2-0,6$ \\
\hline$>0,44$ & 73,47 & $63,6-81,9$ & 80,33 & $68,2-89,4$ & $3,73^{\prime}$ & $3,1-4,4$ & 0,33 & $0,2-0,6$ \\
\hline$>0,46$ & 73,47 & $63,6-81,9$ & 81,97 & $70,0-90,6$ & 4,07 & $3,4-4,8$ & 0,32 & $0,2-0,6$ \\
\hline$>0,51$ & 72,45 & $62,5-81,0$ & 81,97 & $70,0-90,6$ & 4,02 & $3,4-4,8$ & 0,34 & $0,2-0,6$ \\
\hline$>0,52$ & 72,45 & $62,5-81,0$ & 83,61 & $71,9-91,8$ & 4,42 & $3,7-5,2$ & 0,33 & $0,2-0,6$ \\
\hline$>0,55$ & 71,43 & $61,4-80,1$ & 83,61 & $71,9-91,8$ & 4,36 & $3,7-5,2$ & 0,34 & $0,2-0,7$ \\
\hline$>0,61$ & 71,43 & $61,4-80,1$ & 85,25 & $-73,8-93,0$ & 4,84 & $4,1-5,7$ & 0,34 & $0,2-0,7$ \\
\hline$>0,66$ & $70, \overline{4}$ & $60,3-79,2$ & 85,25 & $73,8-93,0$ & 4,77 & $4,0-5,6$ & 0,35 & $0,2-0,7$ \\
\hline$>0,69$ & 69,39 & $59,3-78,3$ & 86,89 & $75,8-94,1$ & $5,29^{\prime}$ & $4,5-6,2$ & 0,35 & $0,2-0,7$ \\
\hline$>0,7$ & 68,37 & $58,2-77,4$ & 86,89 & $75,8-94,1$ & 5,21 & $4,4-6,2$ & 0,36 & $0,2-0,7$ \\
\hline$>0,73$ & 67,35 & $57,1-76,5$ & 86,89 & $75,8-94,1$ & 5,14 & $4,3-6,1$ & 0,38 & $0,2-0,8$ \\
\hline$>0,75$ & $67, \overline{35}$ & $57,1-76,5$ & 88,52 & $77,8-95,2$ & 5,87 & $5,0-6,9$ & 0,37 & $0,2-0,8$ \\
\hline$>0,77$ & 67,35 & $57,1-76,5$ & 91,80 & $81,9-97,3$ & 8,22 & $7,0-9,6$ & 0,36 & $0,1-0,9$ \\
\hline$>0,86$ & 66,33 & $56,1-75,6$ & 91,80 & $81,9-97,3$ & 8,09 & $6,9-9,5$ & 0,37 & $0,2-0,9$ \\
\hline$>0,87^{\circ}$ & 66,33 & $56,1-75,6$ & 93,44 & $84,0-98,1$ & 10,11 & $8,7-11,8$ & 0,36 & $0,1-1,0$ \\
\hline$>0,9$ & 65,31 & $55,0-74,6$ & 93,44 & $84,0-98,1$ & 9,96 & $8,5-11,7$ & 0,37 & $0,1-1,0$ \\
\hline$>0,99$ & 64.29 & $54,0-73,7$ & 93,44 & $84,0-98,1$ & $9,80^{\circ}$ & $8,3-11,5$ & 0,38 & $0,1-1,0$ \\
\hline$>1$ & 63,27 & $52,9-72,8$ & 95,08 & $86,3-98,9$ & $12,86^{\prime}$ & $10,9-15,1$ & 0,39 & $0,1-1,2$ \\
\hline$>1,19$ & 62,24 & $51,9-71,8$ & 95,08 & $86,3-98,9$ & $12,66^{\prime}$ & $10,7-14,9$ & 0,40 & $0,1-1,2$ \\
\hline$>1,22$ & 61,22 & $50,8-70,9$ & 95,08 & $86,3-98,9$ & 12,45 & $10,5-14,7$ & 0,41 & $0,1-1,3$ \\
\hline$>1,4$ & 61,22 & $50,8-70,9$ & 96,72 & $88,6-99,5$ & 18,67 & $15,8-22,0$ & 0,40 & $0,1-1,6$ \\
\hline$>1,68$ & 60,20 & $49,8-70,0$ & 96,72 & $88,6-99,5$ & 18,36 & $15,5-21,7$ & 0,41 & $0,1-1,6$ \\
\hline$>1,71$ & 59,18 & $48,8-69,0$ & 96,72 & $88,6-99,5$ & 18,05 & $15,2-21,4$ & 0,42 & $0,1-1,7$ \\
\hline$>1,73$ & 58,16 & $47,8-68,1$ & 96,72 & $88,6-99,5$ & 17,74 & $14,9-21,1$ & 0,43 & $0,1-1,7$ \\
\hline$>2,08$ & 58,16 & $47,8-68,1$ & 98,36 & $91,2-99,7$ & 35,48 & $29,9-42,1$ & 0,43 & $0,06-3,0$ \\
\hline
\end{tabular}




\section{Anexo $\mathrm{H}$. Valores de IgE específica para $\alpha$-lactoalbumina que compuseram} a curva ROC (pacientes e grupo controle)

\begin{tabular}{|c|c|c|c|c|c|c|c|c|}
\hline$>2,27$ & 57,14 & $46,7-67,1$ & 98,36 & $91,2-99,7$ & 34,86 & $29,3-41,5$ & 0,44 & $0,06-3,1$ \\
\hline$>2,47$ & 56,12 & $45,7-66,1$ & 98,36 & $91,2-99,7$ & 34,23 & $28,7-40,9$ & 0,45 & $0,06-3,2$ \\
\hline$>2,59$ & 55,10 & $44,7-65,2$ & 98,36 & $91,2-99,7$ & 33,61 & $28,0-40,3$ & 0,46 & $0,06-3,2$ \\
\hline$>2,69$ & 54,08 & $43,7-64,2$ & 98,36 & $91,2-99,7$ & 32,99 & $27,4-39,7$ & 0,47 & $0,07-3,3$ \\
\hline$>3$ & 53,06 & $42,7-63,2$ & 98,36 & $91,2-99,7$ & 32,37 & $26,8-39,1$ & 0,48 & $0,07-3,4$ \\
\hline$>3,2$ & 52,04 & $41,7-62,2$ & 98,36 & $91,2-99,7$ & 31,74 & $26,2-38,5$ & 0,49 & $0,07-3,4$ \\
\hline$>3,47$ & 51,02 & $40,7-61,3$ & 98,36 & $91, \overline{2}-99,7$ & 31,12 & $25,6-37,9$ & 0,50 & $0,07-3,5$ \\
\hline$>3,51$ & 48,98 & $38,7-59,3$ & 98,36 & $91,2-99,7$ & 29,88 & $24,3-36,7$ & 0,52 & $0,07-3,7$ \\
\hline$>3,66$ & 47,96 & $37,8-58,3$ & 98,36 & $91,2-99,7$ & 29,26 & $23,7-36,0$ & 0,53 & $0,08-3,7$ \\
\hline$>3,75$ & 46,94 & $36,8-57,3$ & 98,36 & $91,2-99,7$ & 28,63 & $23,1-35,4$ & 0,54 & $0,08-3,8$ \\
\hline$>3,81$ & 45,92 & $35,8-56,3$ & 98,36 & $91,2-99,7$ & 28,01 & $22,5-34,8$ & 0,55 & $0,08-3,9$ \\
\hline$>3,9$ & 44,90 & $34,8-55,3$ & 98,36 & $91,2-99,7$ & 27,39 & $21,9-34,2$ & 0,56 & $0,08-3,9$ \\
\hline$>4,04$ & 43,88 & $33,9-54,3$ & 98,36 & $91,2-99,7$ & 26,77 & $21,3-33,6$ & 0,57 & $0,08-4,0$ \\
\hline$>4,05$ & 42,86 & $32,9-53,3$ & 98,36 & $91,2-99,7$ & 26,14 & $20,8-32,9$ & 0,58 & $0,08-4,1$ \\
\hline$>4,68$ & 41,84 & $31,9-52,2$ & 98,36 & $91,2-99,7$ & 25,52 & $20,2-32,3$ & 0,59 & $0,0 B-4,2$ \\
\hline$>4,7$ & 40,82 & $31,0-51,2$ & 98,36 & $91,2-99,7$ & 24,90 & $19,6-31,7$ & 0,60 & $0,09-4,2$ \\
\hline$>5,13$ & 39.80 & $30,0-50,2$ & 98,36 & $91,2-99,7$ & 24,28 & $19,0-31,0$ & 0,61 & $0,09-4,3$ \\
\hline$>5,2$ & 38,78 & $29,1-49,2$ & 98,36 & $91,2-99,7$ & 23,65 & $18,4-30,4$ & 0,62 & $0,09-4,4$ \\
\hline$>5,31$ & 37,76 & $28,2-48,1$ & 98,36 & $91,2-99,7$ & 23,03 & $17,8-29,8$ & 0,63 & $0,09-4,4$ \\
\hline$>5,37$ & 36,73 & $27,2-47,1$ & 98,36 & $91,2-99,7$ & 22,41 & $17,2-29,1$ & 0,64 & $0,09-4,5$ \\
\hline$>5,86$ & 35,71 & $26,3-46,0$ & 98,36 & $91,2-99,7$ & 21,79 & $16,7-28,5$ & 0,65 & $0,09-4,6$ \\
\hline$>6,18$ & 34,69 & $25,4-45,0$ & 98,36 & $91,2-99,7$ & 21,16 & $16,1-27,8$ & 0,66 & $0,09-4,7$ \\
\hline$>6,2$ & 33,67 & $24,4-43,9$ & 98,36 & $91,2-99,7$ & 20,54 & $15,5-27,2$ & 0,67 & $0,1-4,7$ \\
\hline$>6,67$ & 32,65 & $23,5-42,9$ & 98,36 & $91,2-99,7$ & 19,92 & $15,0-26,5$ & 0,68 & $0,1-4,8$ \\
\hline$>6,9$ & 31,63 & $22,6-41,8$ & 98,36 & $91,2-99,7$ & $19,30^{\circ}$ & $14,4-25,9$ & 0,70 & $0,1-4,9$ \\
\hline$>6,99$ & 30,61 & $21,7-40,7$ & 98,36 & $91,2-99,7$ & 18,67 & $13,8-25,2$ & 0,71 & $0,1-4,9$ \\
\hline$>7,01$ & 29,59 & $20,8-39,7$ & 98,36 & $91,2-99,7$ & 18,05 & $13,3-24,5$ & 0,72 & $0,1-5,0$ \\
\hline$>7,16$ & 28,57 & $19,9-38,6$ & 98,36 & $91,2-99,7$ & 17,43 & $12,7-23,9$ & 0,73 & $0,1-5,1$ \\
\hline$>7,43$ & 27,55 & $19,0-37,5$ & 98,36 & $91,2-99,7$ & 16,81 & $12,2-23,2$ & 0,74 & $0,1-5,2$ \\
\hline$>7,58$ & 27,55 & $19,0-37,5$ & 100,00 & $94,1-100,0$ & & & 0,72 & \\
\hline$>7,6$ & 25,51 & $17,2-35,3$ & 100,00 & $94,1-100,0$ & & & 0,74 & \\
\hline$>8$ & 24,49 & $16,4-34,2$ & 100,00 & $94,1-100,0$ & & & 0,76 & \\
\hline$>8,32$ & 23,47 & $15,5-33,1$ & 100,00 & $94,1-100,0$ & & & 0,77 & \\
\hline$>8,7$ & 22,45 & $14,6-32,0$ & 100,00 & $94,1-100,0$ & & & 0,78 & \\
\hline$>9,32$ & 21,43 & $13,8-30,9$ & 100,00 & $94,1-100,0$ & & & 0,79 & \\
\hline$>9,48$ & 20,41 & $12,9-29,7$ & 100,00 & $94,1-100,0$ & & & 0,80 & \\
\hline$>9,51$ & 19.39 & $12,1-28,6$ & 100,00 & $94,1-100,0$ & & & 0,81 & \\
\hline$>10,1$ & 17,35 & $10,4-26,3$ & 100,00 & $94,1-100,0$ & & & 0,83 & \\
\hline$>10.2$ & 16,33 & $9,6-25,2$ & 100,00 & $94,1-100,0$ & & & 0,84 & \\
\hline$>10,7$ & 15,31 & $8,8-24,0$ & 100,00 & $94,1-100,0$ & & & 0,85 & \\
\hline$>10,8$ & 14,29 & $8,0-22,8$ & 100,00 & $94,1-100,0$ & & & 0,86 & \\
\hline$>13,3$ & 13,27 & $7,3-21,6$ & 100,00 & $94,1-100,0$ & & & 0,87 & \\
\hline$>14,1$ & 12,24 & $6,5-20,4$ & 100,00 & $94,1-100,0$ & & & 0,88 & \\
\hline$>14.2$ & 11,22 & $5,7-19,2$ & 100,00 & $94,1-100,0$ & & & 0,89 & \\
\hline$>16,2$ & 10,20 & $5,0-18,0$ & 100,00 & $94,1-100,0$ & & & 0,90 & \\
\hline$>16,3$ & 9,18 & $4,3-16,7$ & 100,00 & $94,1-100,0$ & & & 0,91 & \\
\hline$>17,5$ & 7,14 & $2,9-14,2$ & 100,00 & $94,1-100,0$ & & & 0,93 & \\
\hline$>18,7$ & 6,12 & $2,3-12,9$ & 100,00 & $94,1-100,0$ & & & 0,94 & \\
\hline$>23,5$ & 5,10 & $1,7-11,5$ & 100,00 & $94,1-100,0$ & & & 0,95 & \\
\hline$>24,4$ & $4,0 \mathrm{~B}$ & $1,1-10,1$ & 100,00 & $94,1-100,0$ & & & 0,96 & \\
\hline$>44,9$ & 3,06 & $0,7-8,7$ & 100,00 & $94,1-100,0$ & & & 0,97 & \\
\hline$>50,5$ & 2,04 & $0,3-7,2$ & 100,00 & $94,1-100,0$ & & & 0,98 & \\
\hline$>54,6$ & 1,02 & $0,2-5,6$ & 100,00 & $94,1-100,0$ & & & 0,99 & \\
\hline$>73,4$ & 0,00 & $0,0-3,7$ & 100,00 & $94,1-100,0$ & & & 1,00 & \\
\hline
\end{tabular}




\section{Anexo I. Valores de IgE específica para $\beta$-lactoglobulina que compuseram a curva ROC (pacientes e grupo controle)}

\begin{tabular}{|c|c|c|}
\hline \multicolumn{3}{|l|}{ ROC curve } \\
\hline Variable & \multicolumn{2}{|c|}{ RASTBETA } \\
\hline Classification variable & \multicolumn{2}{|l|}{ grupo } \\
\hline \multicolumn{3}{|l|}{ Positive group } \\
\hline grupo & \multicolumn{2}{|l|}{-1} \\
\hline Sample size & \multicolumn{2}{|l|}{96} \\
\hline \multicolumn{3}{|l|}{ Negative group } \\
\hline grupo & \multicolumn{2}{|l|}{-0} \\
\hline Sample size & \multicolumn{2}{|l|}{61} \\
\hline \multicolumn{2}{|l|}{ Disease prevalence $(\%)$} & unknown \\
\hline \multicolumn{2}{|c|}{ Area under the ROC curve (AUC) } & 0,856 \\
\hline \multicolumn{2}{|c|}{ Standard Error } & 0,0292 \\
\hline \multicolumn{2}{|l|}{$95 \%$ Confidence Interval } & 0,791 to 0,907 \\
\hline \multicolumn{2}{|l|}{$z$ statistic } & 12,177 \\
\hline \multicolumn{2}{|c|}{ Significance level P (Area-0.5) } & 0,0001 \\
\hline
\end{tabular}

Criterion values and coordinates of the ROC curve [Hide]

\begin{tabular}{|c|c|c|c|c|c|c|c|c|}
\hline Criterion & Sensitivity & $95 \% \mathrm{Cl}$ & Specificity & $95 \% \mathrm{Cl}$ & + LA & $95 \% \mathrm{Cl}$ & -LR & $95 \% \mathrm{Cl}$ \\
\hline $2=0,31$ & 100,00 & $96,2-100,0$ & 0,00 & $0,0-5,9$ & 1,00 & & & \\
\hline$>0,31$ & 98,96 & $94,3-99,8$ & 0,00 & $0,0-5,9$ & 0,99 & & & \\
\hline$>0,35$ & 85,42 & $76,7-91,8$ & 63,93 & $50,6-75,8$ & 2,37 & $1,9-2,9$ & 0,23 & $0,1-0,4$ \\
\hline$>0,4$ & 84,37 & $75,5-91,0$ & 65,57 & $52,3-77,3$ & 2,45 & $2,0-3,0$ & 0,24 & $0,1-0,4$ \\
\hline$>0,41$ & 83,33 & $74,3-90,2$ & 65,57 & $52,3-77,3$ & 2,42 & $2,0-3,0$ & 0,25 & $0,1-0,4$ \\
\hline$>0.43$ & 83,33 & $74,3-90,2$ & 67,21 & $54,0-78,7$ & 2,54 & $2,1-3,1$ & 0.25 & $0,1-0,4$ \\
\hline$>0,44$ & 82,29 & $73,2-89,3$ & 68,85 & $55,7-80,1$ & 2,64 & $2,2-3,2$ & 0.26 & $0,1-0,5$ \\
\hline$>0.46$ & 82,29 & $73,2-89,3$ & 70,49 & $57,4-81,5$ & 2,79 & $2,3-3,4$ & 0.25 & $0,1-0,4$ \\
\hline$>0,49$ & 81,25 & $72,0-88,5$ & 72,13 & $59, \frac{1}{2}-82,8$ & 2,92 & $2,4-3,5$ & 0.26 & $0,1-0,5$ \\
\hline$>0,5$ & 80,21 & $70,8-87,6$ & 73,77 & $60,9-84,2$ & 3,06 & $2,6-3,7$ & 0,27 & $0,1-0,5$ \\
\hline$>0,55$ & 80,21 & $70,8-87,6$ & 75,41 & $62,7-85,5$ & 3,26 & $2,7-3,9$ & 0.26 & $0,1-0,5$ \\
\hline$>0,58$ & 80,21 & $70,8-87,6$ & 77,05 & $64,5-86,8$ & 3,49 & $3,0-4,1$ & 0.26 & $0,1-0.5$ \\
\hline$>0,61$ & 79,17 & $69,7-86,8$ & 77,05 & $64,5-86,8$ & 3,45 & $2,9-4,1$ & 0,27 & $0,1-0,5$ \\
\hline$>0,62$ & 79,17 & $69,7-86,8$ & 78,69 & $66,3-88,1$ & 3,71 & $3,1-4,4$ & 0.26 & $0,1-0,5$ \\
\hline$>0,63$ & 79,17 & $69,7-86,8$ & 80,33 & $68,2-89,4$ & 4,02 & $3,4-4,7$ & 0,26 & $0,1-0,5$ \\
\hline$>0.64$ & 79.17 & $69,7-86,8$ & 81,97 & $70,0-90,6$ & 4.39 & $3.8-5.1$ & 0.25 & $0,1-0.5$ \\
\hline$>0,66$ & 78,12 & $68,5-85,9$ & 81,97 & $70,0-90,6$ & 4,33 & $3,7-5,1$ & 0,27 & $0,1-0,5$ \\
\hline$>0,77$ & 78,12 & $68,5-85,9$ & 83,61 & $71,9-91,8$ & 4,77 & $4,1-5,6$ & 0.26 & $0,1-0,5$ \\
\hline$>0,78$ & 77,08 & $67,4-85,0$ & 83,61 & $71,9-91,8$ & 4,70 & $4,0-5,5$ & 0,27 & $0,1-0,5$ \\
\hline$>0,79^{\circ}$ & 77,08 & $67,4-85,0$ & 85,25 & $73,8-93,0$ & 5,22 & $4,5-6,1$ & 0.27 & $0,1-0,5$ \\
\hline$>0,84$ & 75,00 & $65,1-83,3$ & 85,25 & $73,8-93,0$ & 5,08 & $4,4-5,9$ & 0.29 & $0,1-0,6$ \\
\hline$>0,85$ & 75,00 & $65,1-83,3$ & 86,89 & $75,8-94,1$ & 5,72 & $4,9-6,7$ & 0.29 & $0,1-0,6$ \\
\hline$>0,86$ & 73,96 & $64,0-82,4$ & 86,89 & $75,8-94,1$ & 5,64 & $4,8-6,6$ & 0.30 & $0,1-0,6$ \\
\hline$>0,88$ & 72,92 & $62,9-81,5$ & 86,89 & $75,8-94,1$ & 5,56 & $4,8-6,5$ & 0,31 & $0,2-0,6$ \\
\hline$>0,89$ & 71,87 & $61,8-80,6$ & 86,89 & $75,8-84,1$ & 5,48 & $4,7-6,4$ & 0,32 & $0,2-0,7$ \\
\hline$>0,91$ & 70,83 & $60,7-79,7$ & 88,52 & $77,8-95,2$ & 6,17 & $5,3-7,2$ & 0,33 & $0,2-0,7$ \\
\hline$>0,93$ & 69,79 & $59,6-78,7$ & 88,52 & $77,8-95,2$ & 6,08 & $5,2-7,1$ & 0,34 & $0,2-0,7$ \\
\hline$>0,94$ & 67,71 & $57,4-76,9$ & 90,16 & $79,8-96,3$ & 6,88 & $5,9-8,1$ & 0,36 & $0,2-0,8$ \\
\hline$>0,98$ & 67,71 & $57,4-76,9$ & 91,80 & $81, \overline{9}-97,3$ & 8,26 & $7,1-9,7$ & 0,35 & $0,1-0,9$ \\
\hline$>1,01$ & 66,67 & $56,3-76,0$ & 91,80 & $81,9-97,3$ & 8,13 & $6,9-9,5$ & 0,36 & $0,1-0,9$ \\
\hline$>1,1$ & 64,58 & $54,2-74,1$ & 91,80 & $81,9-97,3$ & 7,88 & $6,7-9,3$ & 0,39 & $0,2-0,9$ \\
\hline
\end{tabular}




\section{Anexo I. Valores de IgE específica para $\beta$-lactoglobulina que compuseram a curva ROC (pacientes e grupo controle)}

\begin{tabular}{|c|c|c|c|c|c|c|c|c|}
\hline$>1,18$ & 64,58 & $54,2-74,1$ & 93,44 & $84,0-98,1$ & 9,85 & $8,4-11,6$ & 0,38 & $0,1-1,0$ \\
\hline$>1,31$ & 63,54 & $53,1-73,1$ & 93,44 & $84,0-98,1$ & 9,69 & $8,2-11,4$ & 0,39 & $0,1-1,0$ \\
\hline$>1,33$ & 62,50 & $52,0-72,2$ & 93,44 & $84,0-98,1$ & 9,53 & $8,1-11,3$ & 0,40 & $0,2-1,1$ \\
\hline$>1,37$ & 61,46 & $51,0-71,2$ & 95,08 & $86,3-98,9$ & 12,50 & $10,6-14,8$ & 0,41 & $0,1-1,3$ \\
\hline$>1,6$ & 59,38 & $48,9-69,3$ & 95,08 & $86,3-98,9$ & 12,07 & $10,1-14,4$ & 0,43 & $0,1-1,3$ \\
\hline$>1,69$ & 58,33 & $47,8-68,3$ & 95,08 & $86,3-98,9$ & ' 11,86 & $9,9-14,2$ & 0,44 & $0,1-1,4$ \\
\hline$>1,7$ & 57,29 & $46,8-67,3$ & 96,72 & $88,6-99,5$ & 17,47 & $14,6-20,9$ & 0,44 & $0,1-1,8$ \\
\hline$>1,85$ & 57,29 & $46,8-67,3$ & 98,36 & $91,2-99,7$ & 34,95 & $29,3-41,7$ & 0,43 & $0,06-3,1$ \\
\hline$>2,07$ & 56,25 & $45,7-66,4$ & 98,36 & $91,2-99,7$ & 34,31 & $28,7-41,1$ & 0,44 & $0,06-3,1$ \\
\hline$>2,16$ & 55,21 & $44,7-65,4$ & 98,36 & $91,2-99,7$ & 33,68 & $28,0-40,4$ & 0,46 & $0,06-3,2$ \\
\hline$>2,24$ & $54,1 \overline{7}$ & $43,7-64,4$ & 98,36 & $91,2-99,7$ & 33,04 & $27,4-39,8$ & 0,47 & $0,07-3,3$ \\
\hline$>2,25$ & 53,13 & $42,7-63,4$ & 98,36 & $91,2-99,7$ & 32,41 & $26,8-39,2$ & 0,48 & $0,07-3,4$ \\
\hline$>2,31$ & 53,13 & $42,7-63,4$ & 100,00 & $94,1-100,0$ & & & 0,47 & \\
\hline$>2,5$ & 52,08 & $41,6-62,4$ & 100,00 & $94,1-100,0$ & & & 0,48 & \\
\hline$>2,59$ & 51,04 & $40,6-61,4$ & 100,00 & $94,1-100,0$ & & & 0,49 & \\
\hline$>2,65$ & 50,00 & $39,6-60,4$ & 100,00 & $94,1-100,0$ & & & 0,50 & \\
\hline$>2,74$ & 48,96 & $38,6-59,4$ & 100,00 & $94,1-100,0$ & & & 0,51 & \\
\hline$>2,8$ & 47,92 & $37,6-58,4$ & 100,00 & $94,1-100,0$ & & & 0,52 & \\
\hline$>2,87$ & 46,88 & $36,6-57,3$ & 100,00 & $94,1-100,0$ & & & 0,53 & \\
\hline$>2,88$ & 45,83 & $35,6-56,3$ & 100,00 & $94,1-100,0$ & & & 0,54 & \\
\hline$>3$ & 43,75 & $33,6-54,3$ & 100,00 & $94,1-100,0$ & & & 0,56 & \\
\hline$>3,08$ & 42,71 & $32,7-53,2$ & 100,00 & $94,1-100,0$ & & & 0,57 & \\
\hline$>3,62$ & 41,67 & $31,7-52,2$ & 100,00 & $94,1-100,0$ & & & 0,58 & \\
\hline$>3,66$ & 40,63 & $30,7-51,1$ & 100,00 & $94,1-100,0$ & & & 0,59 & \\
\hline$>3,8$ & 39,58 & $29,7-50,1$ & 100,00 & $94,1-100,0$ & & & 0,60 & \\
\hline$>4,04$ & 38,54 & $28,8-49,0$ & 100,00 & $94,1-100,0$ & & & 0,61 & \\
\hline$>4,18$ & 36,46 & $26,9-46,9$ & 100,00 & $94,1-100,0$ & & & 0,64 & \\
\hline$>4.28$ & 34,38 & $25,0-44,8$ & 100,00 & $94,1-100,0$ & & & 0,66 & \\
\hline$>4,6$ & 33,33 & $24,0-43,7$ & 100,00 & $94,1-100,0$ & & & 0,67 & \\
\hline$>4,97$ & 32,29 & $23,1-42,6$ & 100,00 & $94,1-100,0$ & & & 0,68 & \\
\hline$>5,05$ & 31,25 & $22,2-41,5$ & 100,00 & $94,1-100,0$ & & & 0,69 & \\
\hline$>5,13$ & 30,21 & $21,3-40,4$ & 100,00 & $94,1-100,0$ & & & 0,70 & \\
\hline$>5,2$ & 28,12 & $19,4-38,2$ & 100,00 & $94,1-100,0$ & & & 0,72 & \\
\hline$>5,38$ & 27,08 & $18,5-37,1$ & 100,00 & $94,1-100,0$ & & & 0,73 & \\
\hline$>5,4$ & 26,04 & $17,6-36,0$ & 100,00 & $94,1-100,0$ & & & 0,74 & \\
\hline$>5,57$ & 25,00 & $16,7-34,9$ & 100,00 & $94,1-100,0$ & & & 0,75 & \\
\hline$>5,72$ & 23,96 & $15,8-33,8$ & 100,00 & $94,1-100,0$ & & & 0,76 & \\
\hline$>6,24$ & 22,92 & $15,0-32,6$ & 100,00 & $94,1-100,0$ & & & 0,77 & \\
\hline$>6,86$ & 21,87 & $14,1-31,5$ & 100,00 & $94,1-100,0$ & & & 0,78 & \\
\hline$>7,37$ & 20,83 & $13,2-30,3$ & 100,00 & $94,1-100,0$ & & & 0,79 & \\
\hline$>8,04$ & 19,79 & $12,4-29,2$ & 100,00 & $94,1-100,0$ & & & 0,80 & \\
\hline$>8,81$ & 18,75 & $11,5-28,0$ & 100,00 & $94,1-100,0$ & & & 0,81 & \\
\hline$>9,28$ & $17, \overline{7} 1$ & $10,7-26,8$ & 100,00 & $94,1-100,0$ & & & 0,82 & \\
\hline$>9,44$ & 16,67 & $9,8-25,7$ & 100,00 & $94,1-100,0$ & & & 0,83 & \\
\hline$>9,8$ & 15,63 & $9,0-24,5$ & 100,00 & $94,1-100,0$ & & & 0,84 & \\
\hline$>10,7$ & 14,58 & $8,2-23,3$ & 100,00 & $94,1-100,0$ & & & 0,85 & \\
\hline$>11$ & 13,54 & $7,4-22,0$ & 100,00 & $94,1-100,0$ & & & 0,86 & \\
\hline$>11,7$ & 11,46 & $5,9-19,6$ & 100,00 & $94,1-100,0$ & & & 0,89 & \\
\hline$>12,3$ & 10,42 & $5,1-18,3$ & 100,00 & $94,1-100,0$ & & & 0,90 & \\
\hline$>12,9$ & $9,3 \overline{8}$ & $4,4-17,1$ & 100,00 & $94,1-100,0$ & & & 0,91 & \\
\hline$>14$ & 8,33 & $3,7-15,8$ & 100,00 & $94,1-100,0$ & & & 0,92 & \\
\hline$>16,4$ & 7,29 & $3,0-14,5$ & 100,00 & $94,1-100,0$ & & & 0,93 & \\
\hline$>17,5$ & 6,25 & $2,3-13,1$ & 100,00 & $94,1-100,0$ & & & 0,94 & \\
\hline$>21,4$ & 4,17 & $1,2-10,3$ & 100,00 & $94,1-100,0$ & & & 0,96 & \\
\hline & & 0,7 - & & $94,1-10$ & & & 0,9 & \\
\hline & & 0,3 & 10 & $94,1-10$ & & & 0,9 & \\
\hline & & 0,2 & 10 & $94,1-10$ & & & 0,9 & \\
\hline & & 0,0 & 10 & $94,1-10$ & & & 1,0 & \\
\hline
\end{tabular}




\section{Anexo J. Valores de IgE específica para caseína que compuseram a curva ROC (pacientes e grupo controle)}

\begin{tabular}{|c|c|c|}
\hline \multicolumn{3}{|l|}{ ROC curve } \\
\hline Variable & \multicolumn{2}{|c|}{ RASTCASEINA } \\
\hline Classification variable & \multicolumn{2}{|c|}{ grupo } \\
\hline \multicolumn{3}{|l|}{ Positive group } \\
\hline grupo & \multicolumn{2}{|l|}{$=1$} \\
\hline Sample size & \multicolumn{2}{|l|}{101} \\
\hline \multicolumn{3}{|l|}{ Negative group } \\
\hline grupo & \multicolumn{2}{|l|}{$=0$} \\
\hline Sample size & \multicolumn{2}{|l|}{61} \\
\hline \multicolumn{2}{|l|}{ Disease prevalence $(\%)$} & unknown \\
\hline \multicolumn{2}{|c|}{ Area under the ROC curve (AUC) } & 0,849 \\
\hline \multicolumn{2}{|c|}{ Standard Error } & 0,0294 \\
\hline \multicolumn{2}{|l|}{$95 \%$ Confidence Interval } & 0,785 to 0,901 \\
\hline \multicolumn{2}{|l|}{ z statistic } & 11,886 \\
\hline \multicolumn{2}{|c|}{ Significance level P (Area=0.5) } & 0,0001 \\
\hline
\end{tabular}

Criterion values and coordinates of the ROC curve [Hide]

\begin{tabular}{|c|c|c|c|c|c|c|c|c|}
\hline Criterion & Sensitivity & $95 \% \mathrm{Cl}$ & Specificity & $95 \% \mathrm{Cl}$ & $+\mathrm{LR}$ & $95 \% \mathrm{Cl}$ & -LR & $95 \% \mathrm{Cl}$ \\
\hline$>=0,35$ & 100,00 & $96,4-100,0$ & 0,00 & $0,0-5,9$ & 1,00 & & & \\
\hline$>0,35$ & 80,20 & $71,1-87,5$ & 70,49 & $57,4-81,5$ & 2,72 & $2,2-3,3$ & 0,28 & $0,2-0,5$ \\
\hline$>0,37$ & 79,21 & $70,0-86,6$ & 72,13 & $59,2-82,8$ & 2,84 & $2,4-3,4$ & 0,29 & $0,2-0,5$ \\
\hline$>0,4$ & 79,21 & $70,0-86,6$ & 73,77 & $60,9-84,2$ & 3,02 & $2,5-3,6$ & 0,28 & $0,2-0,5$ \\
\hline$>0,44$ & 78,22 & $68,9-85,8$ & 73,77 & $60,9-84,2$ & 2,98 & $2,5-3,6$ & 0,30 & $0,2-0,5$ \\
\hline$>0,46$ & 77,23 & $67,8-85,0$ & 73,77 & $60,9-84,2$ & 2,94 & $2,5-3,5$ & 0,31 & $0,2-0,5$ \\
\hline$>0,48$ & 76,24 & $66,7-84,1$ & 75,41 & $62,7-85,5$ & 3,10 & $2,6-3,7$ & 0,32 & $0,2-0,6$ \\
\hline$>0,51$ & 75,25 & $65,7-83,3$ & 77,05 & $64,5-86,8$ & 3,28 & $2,7-3,9$ & 0,32 & $0,2-0,6$ \\
\hline$>0,56$ & 75,25 & $65,7-83,3$ & 80,33 & $68,2-89,4$ & 3,83 & $3,2-4,5$ & 0,31 & $0,2-0,6$ \\
\hline$>0,63$ & 75,25 & $65,7-83,3$ & 81,97 & $70,0-90,6$ & 4,17 & $3,5-4,9$ & 0,30 & $0,2-0,6$ \\
\hline$>0,65$ & 75,25 & $65,7-83,3$ & 83,61 & $71,9-91,8$ & 4,59 & $3,9-5,4$ & 0,30 & $0,2-0,6$ \\
\hline$>0,66$ & 75,25 & $65,7-83,3$ & 86,89 & $75,8-94,1$ & 5,74 & $4,9-6,7$ & 0,28 & $0,1-0,6$ \\
\hline$>0,69$ & 74,26 & $64,6-82,4$ & 86,89 & $75,8-94,1$ & 5,66 & $4,9-6,6$ & 0,30 & $0,1-0,6$ \\
\hline$>0,7$ & 73,27 & $63,5-81,6$ & 86,89 & $75,8-94,1$ & $5,59^{\prime}$ & $4,8-6,5$ & 0,31 & $0,1-0,6$ \\
\hline$>0,71$ & 73,27 & $63,5-81,6$ & 88,52 & $77,8-95,2$ & 6,38 & $5,5-7,4$ & 0,30 & $0,1-0,7$ \\
\hline$>0,76$ & 73,27 & $63,5-81,6$ & 90,16 & $79,8-96,3$ & 7,45 & $6,4-8,6$ & 0,30 & $0,1-0,7$ \\
\hline$>0,8$ & 72,28 & $62,5-80,7$ & 90,16 & $79,8-96,3$ & 7,35 & $6,3-8,5$ & 0,31 & $0,1-0,7$ \\
\hline$>0,84$ & 71,29 & $61,4-79,9$ & 90,16 & $79,8-96,3$ & 7,25 & $6,2-8,4$ & 0,32 & $0,1-0,7$ \\
\hline$>0,9$ & 69,31 & $59,3-78,1$ & 90,16 & $79,8-96,3$ & 7,05 & $6,0-8,2$ & 0,34 & $0,2-0,8$ \\
\hline$>1,02$ & 69,31 & $59,3-78,1$ & 91,80 & $81,9-97,3$ & 8,46 & $7,3-9,8$ & 0,33 & $0,1-0,8$ \\
\hline$>1,07$ & 68,32 & $58,3-77,2$ & 91,80 & $81,9-97,3$ & 8,33 & $7,2-9,7$ & 0,35 & $0,1-0,8$ \\
\hline$>1,08$ & 68,32 & $58,3-77,2$ & 93,44 & $84,0-98,1$ & 10,42 & $9,0-12,1$ & 0,34 & $0,1-0,9$ \\
\hline$>1,18$ & 67,33 & $57,3-76,3$ & 93,44 & $84,0-98,1$ & 10,27 & $8,8-11,9$ & 0,35 & $0,1-0,9$ \\
\hline$>1,33$ & 67,33 & $57,3-76,3$ & 95,08 & $86,3-98,9$ & $13,69^{\prime}$ & $11,8-15,9$ & 0,34 & $0,1-1,1$ \\
\hline$>1,41$ & 66,34 & $56,2-75,4$ & 96,72 & $88,6-99,5$ & 20,23 & $17,5-23,4$ & 0,35 & $0,09-1,4$ \\
\hline$>1,47^{\circ}$ & 66,34 & $56,2-75,4$ & 98,36 & $91,2-99,7$ & 40,47 & $35,1-46,7$ & 0,34 & $0,05-2,4$ \\
\hline$>1,54$ & 65,35 & $55,2-74,5$ & 98,36 & $91,2-99,7$ & 39,86 & $34,5-46,1$ & 0,35 & $0,05-2,5$ \\
\hline$>1,8$ & 64,36 & $54,2-73,6$ & 98,36 & $91,2-99,7$ & 39,26 & $33,8-45,6$ & 0,36 & $0,05-2,6$ \\
\hline$>1,87$ & 63,37 & $53,2-72,7$ & 98,36 & $91,2-99,7$ & 38,65 & $33,2-45,0$ & 0,37 & $0,05-2,6$ \\
\hline$>2,14$ & 62,38 & $52,2-71,8$ & 98,36 & $91,2-99,7$ & 38,05 & $32,6-44,4$ & 0,38 & $0,05-2,7$ \\
\hline$>2,26$ & 61,39 & $51,2-70,9$ & 98,36 & $91,2-99,7$ & 37,45 & $32,0-43,9$ & 0,39 & $0,06-2,8$ \\
\hline
\end{tabular}




\section{Anexo J. Valores de IgE específica para caseína que compuseram a curva $\mathrm{ROC}$ (pacientes e grupo controle)}

\begin{tabular}{|c|c|c|c|c|c|c|c|c|}
\hline$>2,29$ & 60,40 & $50,2-70,0$ & 98,36 & $91,2-99,7$ & 36,84 & $31,4-43,3$ & 0,40 & $0,06-2,9$ \\
\hline$>2,3$ & 59,41 & $49,2-69,1$ & 100,00 & $94,1-100,0$ & & & 0,41 & \\
\hline$>2,4$ & 58,42 & $48,2-68,1$ & 100,00 & $94,1-100,0$ & & & 0,42 & \\
\hline$>2,89$ & 57,43 & $47,2-67,2$ & 100,00 & $94,1-100,0$ & & & 0,43 & \\
\hline$>2,93$ & 56,44 & $46,2-66,3$ & 100,00 & $94,1-100,0$ & & & 0,44 & \\
\hline$>3,04$ & 55,45 & $45,2-65,3$ & 100,00 & $94,1-100,0$ & & & 0,45 & \\
\hline$>3,06$ & $54, \overline{46}$ & $44,2-64,4$ & 100,00 & $94,1-100,0$ & & & 0,46 & \\
\hline$>3,32$ & 53,47 & $43,3-63,5$ & 100,00 & $94,1-100,0$ & & & 0,47 & \\
\hline$>3,78$ & 52,48 & $42,3-62,5$ & 100,00 & $94,1-100,0$ & & & 0,48 & \\
\hline$>3,86$ & 51,49 & $41,3-61,6$ & 100,00 & $94,1-100,0$ & & & 0,49 & \\
\hline$>4,1$ & 50,50 & $40,4-60,6$ & 100,00 & $94,1-100,0$ & & & 0,50 & \\
\hline$>4,62$ & 49,50 & $39,4-59,6$ & 100,00 & $94,1-100,0$ & & & 0,50 & \\
\hline$>5,04$ & 48,51 & $38,4-58,7$ & 100,00 & $94,1-100,0$ & & & 0,51 & \\
\hline$>5,13$ & 47,52 & $37,5-57,7$ & 100,00 & $94,1-100,0$ & & & 0,52 & \\
\hline$>5,3$ & 46,53 & $36,5-56,7$ & 100,00 & $94,1-100,0$ & & & 0,53 & \\
\hline$>5,35$ & 45,54 & $35,6-55,8$ & 100,00 & $94,1-100,0$ & & & 0,54 & \\
\hline$>6$ & 44,55 & $34,7-54,8$ & 100,00 & $94,1-100,0$ & & & 0,55 & \\
\hline$>7,97$ & 43,56 & $33,7-53,8$ & 100,00 & $94,1-100,0$ & & & 0,56 & \\
\hline$>7,98$ & 41,58 & $31,9-51,8$ & 100,00 & $94,1-100,0$ & & & 0,58 & \\
\hline$>9,02$ & 40,59 & $30,9-50,8$ & 100,00 & $94,1-100,0$ & & & 0,59 & \\
\hline$>9,15$ & 39,60 & $30,0-49,8$ & 100,00 & $94,1-100,0$ & & & 0,60 & \\
\hline$>9,31$ & 38,61 & $29,1-48,8$ & 100,00 & $94,1-100,0$ & & & 0,61 & \\
\hline$>10,4$ & 37,62 & $28,2-47,8$ & 100,00 & $94,1-100,0$ & & & 0,62 & \\
\hline$>10,7$ & 36,63 & $27,3-46,8$ & 100,00 & $94,1-100,0$ & & & 0,63 & \\
\hline$>11$ & 35,64 & $26,4-45,8$ & 100,00 & $94,1-100,0$ & & & 0,64 & \\
\hline$>11,9$ & 33,66 & $24,6-43,8$ & 100,00 & $94,1-100,0$ & & & 0,66 & \\
\hline$>12,2$ & 32,67 & $23,7-42,7$ & 100,00 & $94,1-100,0$ & & & 0,67 & \\
\hline$>12,4$ & 31,68 & $22,8-41,7$ & 100,00 & $94,1-100,0$ & & & 0,68 & \\
\hline$>14,3$ & 30,69 & $21,9-40,7$ & 100,00 & $94,1-100,0$ & & & 0,69 & \\
\hline$>14,8$ & 29,70 & $21,0-39,6$ & 100,00 & $94,1-100,0$ & & & 0,70 & \\
\hline$>15,2$ & 28,71 & $20,1-38,6$ & 100,00 & $94,1-100,0$ & & & 0,71 & \\
\hline$>17,3$ & 27,72 & $19,3-37,5$ & 100,00 & $94,1-100,0$ & & & 0,72 & \\
\hline$>17,5$ & 24,75 & $16,7-34,3$ & 100,00 & $94,1-100,0$ & & & 0,75 & \\
\hline$>18,2$ & 23,76 & $15,9-33,3$ & 100,00 & $94,1-100,0$ & & & 0,76 & \\
\hline$>18,6$ & 22,77 & $15,0-32,2$ & 100,00 & $94,1-100,0$ & & & 0,77 & \\
\hline$>20$ & 21,78 & $14,2-31,1$ & 100,00 & $94,1-100,0$ & & & 0,78 & \\
\hline$>20,1$ & 19,80 & $12,5-28,9$ & 100,00 & $94,1-100,0$ & & & 0,80 & \\
\hline$>21$ & 18,81 & $11,7-27,8$ & 100,00 & $94,1-100,0$ & & & 0,81 & \\
\hline$>22,4$ & 17,82 & $10,9-26,7$ & 100,00 & $94,1-100,0$ & & & 0,82 & \\
\hline$>24,7$ & 16,83 & $10,1-25,6$ & 100,00 & $94,1-100,0$ & & & 0,83 & \\
\hline$>32,4$ & 15,84 & $9,3-24,4$ & 100,00 & $94,1-100,0$ & & & 0,84 & \\
\hline$>34,4$ & 14,85 & $8,6-23,3$ & 100,00 & $94,1-100,0$ & & & 0,85 & \\
\hline$>37,7$ & 13,86 & $7,8-22,2$ & 100,00 & $94,1-100,0$ & & & 0,86 & \\
\hline$>39,8$ & 12,87 & $7,0-21,0$ & 100,00 & $94,1-100,0$ & & & 0,87 & \\
\hline$>40,4$ & 11,88 & $6,3-19,8$ & 100,00 & $94,1-100,0$ & & & 0,88 & \\
\hline$>44$ & 10,89 & $5,6-18,7$ & 100,00 & $94,1-100,0$ & & & 0,89 & \\
\hline$>44,1$ & 9,90 & $4,9-17,5$ & 100,00 & $94,1-100,0$ & & & 0,90 & \\
\hline$>48,5$ & 8,91 & $4,2-16,2$ & 100,00 & $94,1-100,0$ & & & 0,91 & \\
\hline$>49,4$ & 7,92 & $3,5-15,0$ & 100,00 & $94,1-100,0$ & & & 0,92 & \\
\hline$>63,5$ & 6,93 & $2,8-13,8$ & 100,00 & $94,1-100,0$ & & & 0,93 & \\
\hline$>66,9$ & 5,94 & $2,2-12,5$ & 100,00 & $94,1-100,0$ & & & 0,94 & \\
\hline$>68,9$ & 4,95 & $1,6-11,2$ & 100,00 & $94,1-100,0$ & & & 0,95 & \\
\hline$>100$ & 0,00 & $0,0-3,6$ & 100,00 & $94,1-100,0$ & & & 1,00 & \\
\hline
\end{tabular}


Anexo K. Valores de IgE específica para leite que compuseram a curva ROC (pacientes anafiláticos e não anafiláticos)

\section{ROC curve}

\begin{tabular}{|l|l|}
\hline Variable & RASTLV \\
\hline Classification variable & anafilaxia \\
\hline
\end{tabular}

\begin{tabular}{|c|c|}
\hline Disease prevalence (\%) & unknown \\
\hline Area under the ROC curve (AUC) & 0,589 \\
\hline Standard Error & 0,0514 \\
\hline $95 \%$ Confidence Interval & 0,496 to 0,677 \\
\hline z statistic & 1,725 \\
\hline Significance level P (Area=0.5) & 0,0844 \\
\hline
\end{tabular}

\begin{tabular}{|c|c|c|c|c|c|c|c|c|}
\hline Criterion & Sensitivity & $95 \% \mathrm{Cl}$ & Specificity & $95 \% \mathrm{Cl}$ & $+L R$ & $95 \% \mathrm{Cl}$ & -LR & $95 \% \mathrm{Cl}$ \\
\hline$x=0,35$ & 100,00 & $94,4-100,0$ & 0,00 & $0,0-6,3$ & 1,00 & & & \\
\hline$>0,35$ & 93,85 & $85,0-98,3$ & 3,51 & $0,5-12,1$ & 0,97 & $0,2-3,8$ & 1,75 & $0,7-4,5$ \\
\hline$>0,36$ & 93,85 & $85,0-98,3$ & 5,26 & $1,2-14,6$ & 0,99 & $0,3-3,0$ & 1,17 & $0,5-3,0$ \\
\hline$>0,39$ & 92,31 & $82,9-97,4$ & 5,26 & $1,2-14,6$ & 0,97 & $0,3-2,9$ & 1,46 & $0,6-3,4$ \\
\hline$>0,46$ & 92,31 & $82,9-97,4$ & 7,02 & $2,0-17,0$ & 0,99 & $0,4-2,6$ & 1,10 & $0,5-2,6$ \\
\hline$>0,49$ & 90,77 & $81,0-96,5$ & 7,02 & $2,0-17,0$ & 0,98 & $0,4-2,5$ & 1,32 & $0,6-2,8$ \\
\hline$>0,5$ & 89,23 & $79,1-95,5$ & 7,02 & $2,0-17,0$ & 0,96 & $0,4-2,5$ & 1,53 & $0,8-3,1$ \\
\hline$>0,51$ & 87,69 & $77,2-94,5$ & 7,02 & $2,0-17,0$ & 0,94 & $0,4-2,4$ & 1,75 & $0,9-3,4$ \\
\hline$>0,6$ & 87,69 & $77,2-94,5$ & 8,77 & $2,9-19,3$ & 0,96 & $0,4-2,2$ & 1,40 & $0,7-2,7$ \\
\hline$>0,74$ & 87,69 & $77,2-94,5$ & 10,53 & $4,0-21,5$ & 0,98 & $0,5-2,1$ & 1,17 & $0,6-2,3$ \\
\hline$>0,76$ & 87,69 & $77,2-94,5$ & 12,28 & $5,1-23,7$ & 1,00 & $0,5-2,0$ & 1,00 & $0,5-1,9$ \\
\hline$>0,86$ & 86,15 & $75,3-93,5$ & 14,04 & $6,3-25,8$ & 1,00 & $0,5-1,9$ & 0,99 & $0,5-1,8$ \\
\hline$>0,94$ & 84,62 & $73,5-92,4$ & 14,04 & $6,3-25,8$ & 0,98 & $0,5-1,9$ & 1,10 & $0,6-2,0$ \\
\hline$>1,02$ & 83,08 & $71,7-91,2$ & 14,04 & $6,3-25,8$ & 0,97 & $0,5-1,9$ & 1,21 & $0,7-2,1$ \\
\hline$>1,04$ & 81,54 & $70,0-90,1$ & 14,04 & $6,3-25,8$ & 0,95 & $0,5-1,8$ & 1,32 & $0,8-2,2$ \\
\hline$>1,34$ & 80,00 & $68,2-88,9$ & 14,04 & $6,3-25,8$ & 0,93 & $0,5-1,8$ & 1,42 & $0,9-2,3$ \\
\hline$>1,35$ & 80,00 & $68,2-88,9$ & 15,79 & $7,5-27,9$ & 0,95 & $0,5-1,8$ & 1,27 & $0,8-2,1$ \\
\hline$>1,37$ & 80,00 & $68,2-88,9$ & 17,54 & $8,8-29,9$ & 0,97 & $0,5-1,7$ & 1,14 & $0,7-1,9$ \\
\hline$>1,54$ & 78,46 & $66,5-87,7$ & 17,54 & $8,8-29,9$ & 0,95 & $0,5-1,7$ & 1,23 & $0,8-2,0$ \\
\hline$>1,58$ & 78,46 & $66,5-87,7$ & 19,30 & $10,1-31,9$ & 0,97 & $0,6-1,7$ & 1,12 & $0,7-1,8$ \\
\hline$>1,67$ & 78,46 & $66,5-87,7$ & 21,05 & $11,4-33,9$ & 0,99 & $0,6-1,7$ & 1,02 & $0,6-1,7$ \\
\hline$>1,83$ & 78,46 & $66,5-87,7$ & 22,81 & $12,8-35,8$ & 1,02 & $0,6-1,7$ & 0,94 & $0,6-1,5$ \\
\hline$>1,87$ & 76,92 & $64,8-86,5$ & 22,81 & $12,8-35,8$ & 1,00 & $0,6-1,6$ & 1,01 & $0,6-1,6$ \\
\hline$>2,18$ & 75,38 & $63,1-85,2$ & 22,81 & $12,8-35,8$ & 0,98 & $0,6-1,6$ & 1,08 & $0,7-1,7$ \\
\hline$>2,28$ & 73,85 & $61,5-84,0$ & 22,81 & $12,8-35,8$ & 0,96 & $0,6-1,6$ & 1,15 & $0,7-1,8$ \\
\hline$>2,29$ & 72,31 & $59,8-82,7$ & 22,81 & $12,8-35,8$ & 0,94 & $0,6-1,5$ & 1,21 & $0,8-1,8$ \\
\hline$>2,51$ & 70,77 & $58,2-81,4$ & 22,81 & $12,8-35,8$ & 0,92 & $0,6-1,5$ & 1,28 & $0,9-1,9$ \\
\hline$>2,58$ & 69,23 & $56,6-80,1$ & 22,81 & $12,8-35,8$ & 0,90 & $0,5-1,5$ & 1,35 & $0,9-2,0$ \\
\hline$>2,7$ & 69,23 & $56,6-80,1$ & 24,56 & $14,1-37,8$ & 0,92 & $0,6-1,5$ & 1,25 & $0,8-1,9$ \\
\hline$>3,04$ & 69,23 & $56,6-80,1$ & 26,32 & $15,5-39,7$ & 0,94 & $0,6-1,5$ & 1,17 & $0,8-1,7$ \\
\hline$>3,44$ & 69,23 & $56,6-80,1$ & 28,07 & $17,0-41,5$ & 0,96 & $0,6-1,5$ & 1,10 & $0,7-1,6$ \\
\hline
\end{tabular}


Anexo K. Valores de IgE específica para leite que compuseram a curva ROC (pacientes anafiláticos e não anafiláticos)

\begin{tabular}{|c|c|c|c|c|c|c|c|c|}
\hline$>3,5$ & 69,23 & $56,6-80,1$ & 29,82 & $18,4-43,4$ & 0,99 & $0,6-1,5$ & 1,03 & $0,7-1,5$ \\
\hline$>3,51$ & 67,69 & $54,9-78,8$ & 29,82 & $18,4-43,4$ & 0,96 & $0,6-1,5$ & 1,08 & $0,7-1,6$ \\
\hline$>3.57$ & 67,69 & $54,9-78,8$ & 31,58 & $19,9-45,2$ & 0,99 & $0,7-1,5$ & 1,02 & $0,7-1,5$ \\
\hline$>3,6$ & 66,15 & $53,4-77,4$ & 31,58 & $19,9-45,2$ & 0,97 & $0,6-1,5$ & 1,07 & $0,7-1,6$ \\
\hline$>3,98$ & 66,15 & $53,4-77,4$ & 33,33 & $21,4-47,1$ & 0,99 & $0,7-1,5$ & 1,02 & $0,7-1,5$ \\
\hline$>4$ & 66,15 & $53,4-77,4$ & 35,09 & $22,9-48,9$ & 1,02 & $0,7-1,5$ & 0,96 & $0,7-1,4$ \\
\hline$>4,26$ & 66,15 & $53,4-77,4$ & 36,84 & $24,5-50,7$ & 1,05 & $0,7-1,5$ & 0,92 & $0,6-1,4$ \\
\hline$>4,38$ & 64,62 & $51,8-76,1$ & 36,84 & $24,5-50,7$ & 1,02 & $0,7-1,5$ & 0,96 & $0,7-1,4$ \\
\hline$>4,46$ & 64,62 & $51,8-76,1$ & 38,60 & $26,0-52,4$ & 1,05 & $0,7-1,5$ & 0,92 & $0,6-1,4$ \\
\hline$>4,84$ & 64,62 & $51,8-76,1$ & 40,35 & $27,6-54,2$ & 1,08 & $0,8-1,6$ & 0,88 & $0,6-1,3$ \\
\hline$>5,39$ & 64,62 & $51,8-76,1$ & 42,11 & $29,1-55,9$ & 1,12 & $0,8-1,6$ & 0,84 & $0,6-1,2$ \\
\hline$>5,66$ & 63,08 & $50,2-74,7$ & 43,86 & $30,7-57,6$ & 1,12 & $0,8-1,6$ & 0,84 & $0,6-1,2$ \\
\hline$>5,87$ & 63,08 & $50,2-74,7$ & 45,61 & $32,4-59,3$ & 1,16 & $0,8-1,6$ & 0,81 & $0,5-1,2$ \\
\hline$>6$ & 63,08 & $50,2-74,7$ & 47,37 & $34,0-61,0$ & 1,20 & $0,9-1,7$ & 0,78 & $0,5-1,2$ \\
\hline$>6,2$ & 63,08 & $50,2-74,7$ & 49,12 & $35,6-62,7$ & 1,24 & $0,9-1,7$ & 0,75 & $0,5-1,1$ \\
\hline$>6,31$ & 63,08 & $50,2-74,7$ & 50,88 & $37,3-64,4$ & 1,28 & $0,9-1,8$ & 0,73 & $0,5-1,1$ \\
\hline$>6,57$ & 63,08 & $50,2-74,7$ & 52,63 & $39,0-66,0$ & 1,33 & $1,0-1,8$ & 0,70 & $0,5-1,1$ \\
\hline$>6,62$ & 63,08 & $50,2-74,7$ & 54,39 & $40,7-67,6$ & 1,38 & $1,0-1,9$ & 0,68 & $0,4-1,0$ \\
\hline$>6,64$ & 61,54 & $48,6-73,3$ & 54,39 & $40,7-67,6$ & 1,35 & $1,0-1,8$ & 0,71 & $0,5-1,1$ \\
\hline$>7,23$ & 61,54 & $48,6-73,3$ & 56,14 & $42,4-69,3$ & 1,40 & $1,0-1,9$ & 0,69 & $0,4-1,0$ \\
\hline$>7,3$ & 61,54 & $48,6-73,3$ & 57,89 & $44,1-70,9$ & 1,46 & $1,1-2,0$ & 0,66 & $0,4-1,0$ \\
\hline$>7,9$ & 60,00 & $47,1-72,0$ & 57,89 & $44,1-70,9$ & 1,42 & $1,1-1,9$ & 0,69 & $0,5-1,1$ \\
\hline$>8,5$ & 58,46 & $45,6-70,6$ & 57,89 & $44,1-70,9$ & 1,39 & $1,0-1,9$ & 0,72 & $0,5-1,1$ \\
\hline$>8,7$ & 58,46 & $45,6-70,6$ & 59,65 & $45,8-72,4$ & 1,45 & $1,1-1,9$ & 0,70 & $0,5-1,1$ \\
\hline$>8,78$ & 56,92 & $44,0-69,1$ & 59,65 & $45,8-72,4$ & 1,41 & $1,0-1,9$ & 0,72 & $0,5-1,1$ \\
\hline$>9,7$ & 56,92 & $44,0-69,1$ & $61,40^{\prime}$ & $47,6-74,0$ & 1,47 & $1,1-2,0$ & 0,70 & $0,5-1,1$ \\
\hline$>10,6$ & 56,92 & $44,0-69,1$ & 63,16 & $49,3-75,5$ & 1,55 & $1,2-2,1$ & 0,68 & $0,4-1,1$ \\
\hline$>10,8$ & 55,38 & $42,5-67,7$ & 63,16 & $49,3-75,5$ & 1,50 & $1,1-2,0$ & 0,71 & $0,5-1,1$ \\
\hline$>11,3$ & 55,38 & $42,5-67,7$ & 64,91 & $51,1-77,1$ & 1,58 & $1,2-2,1$ & 0,69 & $0,4-1,1$ \\
\hline$>11,6$ & 55,38 & $42,5-67,7$ & 66,67 & $52,9-78,6$ & 1,66 & $1,2-2,2$ & 0,67 & $0,4-1,1$ \\
\hline$>12,2$ & 53,85 & $41,0-66,3$ & 66,67 & $52,9-78,6$ & 1,62 & $1,2-2,2$ & 0,69 & $0,4-1,1$ \\
\hline$>12,3$ & 50,77 & $38,1-63,4$ & 66,67 & $52,9-78,6$ & 1,52 & $1,1-2,1$ & 0,74 & $0,5-1,1$ \\
\hline$>12,5$ & 50,77 & $38,1-63,4$ & 68,42 & $54,8-80,1$ & 1,61 & $1,2-2,2$ & 0,72 & $0,5-1,1$ \\
\hline$>12,7$ & 50,77 & $38,1-63,4$ & 70,18 & $56,6-81,6$ & 1,70 & $1,3-2,3$ & 0,70 & $0,4-1,1$ \\
\hline$>12,9$ & 49,23 & $36,6-61,9$ & 70,18 & $56,6-81,6$ & 1,65 & $1,2-2,2$ & 0,72 & $0,5-1,2$ \\
\hline$>13,2$ & 49,23 & $36,6-61,9$ & 71,93 & $58,5-83,0$ & 1,75 & $1,3-2,4$ & 0,71 & $0,4-1,1$ \\
\hline$>13,4$ & 47,69 & $35,1-60,5$ & 71,93 & $58,5-83,0$ & 1,70 & $1,3-2,3$ & 0,73 & $0,5-1,2$ \\
\hline$>13,78$ & 46,15 & $33,7-59,0$ & 71,93 & $58,5-83,0$ & 1,64 & $1,2-2,2$ & 0,75 & $0,5-1,2$ \\
\hline$>14$ & 46,15 & $33,7-59,0$ & 73,68 & $60,3-84,5$ & 1,75 & $1,3-2,4$ & 0,73 & $0,4-1,2$ \\
\hline$>14,2$ & 44,62 & $32,3-57,5$ & 73,68 & $60,3-84,5$ & 1,70 & $1,2-2,3$ & 0,75 & $0,5-1,2$ \\
\hline$>14,4$ & 43,08 & $30,9-56,0$ & 73,68 & $60,3-84,5$ & 1,64 & $1,2-2,3$ & 0,77 & $0,5-1,3$ \\
\hline$>15,3$ & 43,08 & $30,9-56,0$ & 75,44 & $62,2-85,9$ & 1,75 & $1,3-2,4$ & 0,75 & $0,5-1,2$ \\
\hline$>15,7$ & 43,08 & $30,9-56,0$ & 77,19 & $64,2-87,2$ & 1,89 & $1,4-2,6$ & 0,74 & $0,4-1,2$ \\
\hline$>16,6$ & 41,54 & $29,4-54,4$ & 77,19 & $64,2-87,2$ & 1,82 & $1,3-2,5$ & 0,76 & $0,5-1,3$ \\
\hline$>17,4$ & 41,54 & $29,4-54,4$ & 78,95 & $66,1-88,6$ & 1,97 & $1,4-2,7$ & 0,74 & $0,4-1,3$ \\
\hline$>17,5$ & 36,92 & $25,3-49,8$ & 82,46 & $70,1-91,2$ & 2,10 & $1,5-3,0$ & 0,76 & $0,4-1,4$ \\
\hline$>17,9$ & 36,92 & $25,3-49,8$ & 84,21 & $72,1-92,5$ & 2,34 & $1,7-3,3$ & 0,75 & $0,4-1,4$ \\
\hline$>18,6^{\circ}$ & 36,92 & $25,3-49,8$ & 85,96 & $74,2-93,7$ & 2,63 & $1,9-3,7$ & 0,73 & $0,4-1,4$ \\
\hline$>20,4$ & 35,38 & $23,9-48,2$ & ' 85,96 ' & $74,2-93,7$ & 2,52 & $1,8-3,6$ & 0,75 & $0,4-1,5$ \\
\hline$>20,6$ & 33,85 & $22,6-46,6$ & 85,96 & $74,2-93,7$ & 2,41 & $1,7-3,4$ & 0,77 & $0,4-1,5$ \\
\hline$>21,2$ & 32,31 & $21,2-45,1$ & 85,96 & $74,2-93,7$ & 2,30 & $1,6-3,3$ & 0,79 & $0,4-1,5$ \\
\hline$>22,1$ & 29,23 & $18,6-41,8$ & 85,96 & $74,2-93,7$ & 2,08 & $1,4-3,1$ & 0,82 & $0,4-1,6$ \\
\hline$>22,2$ & 29,23 & $18,6-41,8$ & 87,72 & $76,3-94,9$ & 2,38 & $1,6-3,5$ & 0,81 & $0,4-1,6$ \\
\hline$>22,4$ & 27,69 & $17,3-40,2$ & 87,72 & $76,3-94,9$ & 2,25 & $1,5-3,4$ & 0,82 & $0,4-1,7$ \\
\hline
\end{tabular}


Anexo K. Valores de lgE específica para leite que compuseram a curva ROC (pacientes anafiláticos e não anafiláticos)

\begin{tabular}{|c|c|c|c|c|c|c|c|c|}
\hline$>24,1$ & 27,69 & $17,3-40,2$ & 89,47 & $78,5-96,0$ & 2,63 & $1,8-3,9$ & 0,81 & $0,4-1,7$ \\
\hline$>24,8$ & 27,69 & $17,3-40,2$ & 91,23 & $80,7-97,1$ & 3,16 & $2,1-4,7$ & 0,79 & $0,3-1,9$ \\
\hline$>26,1$ & 27,69 & $17,3-40,2$ & 92,98 & $83,0-98,0$ & 3,95 & $2,6-5,9$ & 0,78 & $0,3-2,0$ \\
\hline$>27,4$ & 26,15 & $16,0-38,5$ & 92,98 & $83,0-98,0$ & 3,73 & $2,5-5,6$ & 0,79 & $0,3-2,1$ \\
\hline$>27,9$ & 24,62 & $14,8-36,9$ & 92,98 & $83,0-98,0$ & 3,51 & $2,3-5,4$ & 0,81 & $0,3-2,1$ \\
\hline$>34,2$ & 23,08 & $13,5-35,2$ & 92,98 & $83,0-98,0$ & 3,29 & $2,1-5,2$ & 0,83 & $0,3-2,1$ \\
\hline$>35$ & 21,54 & $12,3-33,5$ & 92,98 & $83,0-98,0$ & 3,07 & $1,9-4,9$ & 0,84 & $0,3-2,2$ \\
\hline$>38,2$ & 21,54 & $12,3-33,5$ & 94,74 & $85,4-98,8$ & 4,09 & $2,6-6,5$ & 0,83 & $0,3-2,5$ \\
\hline$>38,6$ & 20,00 & $11,1-31,8$ & 94,74 & $85,4-98,8$ & 3,80 & $2,3-6,2$ & 0,84 & $0,3-2,6$ \\
\hline$>39,5$ & 20,00 & $11,1-31,8$ & 96,49 & $87,9-99,5$ & 5,70 & $3,5-9,3$ & 0,83 & $0,2-3,3$ \\
\hline$>40,7$ & 18,46 & $9,9-30,0$ & 96,49 & $87,9-99,5$ & 5,26 & $3,1-8,8$ & 0,85 & $0,2-3,3$ \\
\hline$>41,6$ & 16,92 & $8,8-28,3$ & 96,49 & $87,9-99,5$ & 4,82 & $2,8-8,3$ & 0,86 & $0,2-3,4$ \\
\hline$>63,3$ & 15,38 & $7,6-26,5$ & 96,49 & $87,9-99,5$ & 4,38 & $2,5-7,8$ & 0,88 & $0,2-3,4$ \\
\hline$>65$ & 13,85 & $6,5-24,7$ & 96,49 & $87,9-99,5$ & 3,95 & $2,1-7,3$ & 0,89 & $0,2-3,5$ \\
\hline$>70,1$ & 12,31 & $5,5-22,8$ & 96,49 & $87,9-99,5$ & 3,51 & $1,8-6,7$ & 0,91 & $0,2-3,6$ \\
\hline$>73,2$ & 10,77 & $4,5-20,9$ & 96,49 & $87,9-99,5$ & 3,07 & $1,5-6,2$ & 0,92 & $0,2-3,6$ \\
\hline$>86,9$ & 9,23 & $3,5-19,0$ & 96,49 & $87,9-99,5$ & 2,63 & $1,2-5,6$ & 0,94 & $0,2-3,7$ \\
\hline$>98,3$ & 9,23 & $3,5-19,0$ & 98,25 & $90,6-99,7$ & 5,26 & $2,5-11,3$ & 0,92 & $0,1-6,5$ \\
\hline$>100$ & 0,00 & $0,0-5,6$ & 100,00 & $93,7-100,0$ & & & 1,00 & \\
\hline
\end{tabular}


Anexo L. Valores de IgE específica para leite que compuseram a curva ROC (pacientes anafiláticos e demais integrantes da casuística)

\begin{tabular}{|c|c|c|}
\hline \multicolumn{3}{|l|}{ ROC curve } \\
\hline Variable & \multicolumn{2}{|c|}{ RASTLV } \\
\hline Classification variable & \multicolumn{2}{|c|}{ anafilaxia } \\
\hline \multicolumn{3}{|l|}{ Positive group } \\
\hline anafilaxia & \multicolumn{2}{|l|}{$=1$} \\
\hline Sample size & \multicolumn{2}{|l|}{65} \\
\hline \multicolumn{3}{|l|}{ Negative group } \\
\hline anafilaxia & \multicolumn{2}{|l|}{$=0$} \\
\hline Sample size & \multicolumn{2}{|l|}{118} \\
\hline \multicolumn{2}{|l|}{ Disease prevalence $(\%)$} & unknown \\
\hline \multicolumn{2}{|c|}{ Area under the ROC curve (AUC) } & 0,760 \\
\hline \multicolumn{2}{|c|}{ Standard Error } & 0,039 \\
\hline \multicolumn{2}{|l|}{$95 \%$ Confidence Interval } & 0,692 to 0,820 \\
\hline \multicolumn{2}{|l|}{$z$ statistic } & 6,682 \\
\hline \multicolumn{2}{|c|}{ Significance level P (Area $=0.5)$} & 0,0001 \\
\hline
\end{tabular}

Criterion values and coordinates of the ROC curve [Hide]

\begin{tabular}{|c|c|c|c|c|c|c|c|c|}
\hline Criterion & Sensitivity & $95 \% \mathrm{Cl}$ & Specificity & $95 \% \mathrm{Cl}$ & + LR & $95 \% \mathrm{Cl}$ & -LR & $95 \% \mathrm{Cl}$ \\
\hline$>=0,35$ & 100,00 & $94,4-100,0$ & 0,00 & $0,0-3,1$ & 1,00 & & & \\
\hline$>0,35$ & 93,85 & $85,0-98,3$ & 32,20 & $23,9-41,4$ & 1,38 & $1,1-1,8$ & 0,19 & $0,07-0,5$ \\
\hline$>0,36$ & 93,85 & $85,0-98,3$ & 35,59 & $27,0-44,9$ & 1,46 & $1,1-1,9$ & 0,17 & $0,07-0,5$ \\
\hline$>0,39$ & 92,31 & $82,9-97,4$ & 36,44 & $27,8-45,8$ & 1,45 & $1,1-1,9$ & 0,21 & $0,09-0,5$ \\
\hline$>0,4$ & 92,31 & $82,9-97,4$ & 37,29 & $28,6-46,7$ & 1,47 & $1,2-1,9$ & 0,21 & $0,09-0,5$ \\
\hline$>0,46$ & 92,31 & $82,9-97,4$ & 38,98 & $30,1-48,4$ & 1,51 & $1,2-1,9$ & 0,20 & $0,08-0,5$ \\
\hline$>0,49$ & 90,77 & $81,0-96,5$ & 38,98 & $30,1-48,4$ & 1,49 & $1,2-1,9$ & 0,24 & $0,1-0,5$ \\
\hline$>0,5$ & 89,23 & $79,1-95,5$ & 40,68 & $31,7-50,1$ & 1,50 & $1,2-1,9$ & 0,26 & $0,1-0,5$ \\
\hline$>0,51$ & 87,69 & $77,2-94,5$ & 40,68 & $31,7-50,1$ & 1,48 & $1,2-1,9$ & 0,30 & $0,2-0,6$ \\
\hline$>0,54$ & 87,69 & $77,2-94,5$ & 41,53 & $32,5-51,0$ & 1,50 & $1,2-1,9$ & 0,30 & $0,2-0,6$ \\
\hline$>0,6$ & 87,69 & $77,2-94,5$ & 42,37 & $33,3-51,8$ & 1,52 & $1,2-1,9$ & 0,29 & $0,1-0,6$ \\
\hline$>0,64$ & 87,69 & $77,2-94,5$ & 43,22 & $34,1-52,7$ & 1,54 & $1,2-1,9$ & 0,28 & $0,1-0,6$ \\
\hline$>0,65$ & 87,69 & $77,2-94,5$ & 44,07 & $34,9-53,5$ & 1,57 & $1,3-2,0$ & 0,28 & $0,1-0,5$ \\
\hline$>0,68$ & 87,69 & $77,2-94,5$ & 44,92 & $35,7-54,3$ & 1,59 & $1,3-2,0$ & 0,27 & $0,1-0,5$ \\
\hline$>0,73$ & 87,69 & $77,2-94,5$ & 45,76 & $36,6-55,2$ & 1,62 & $1,3-2,0$ & 0,27 & $0,1-0,5$ \\
\hline$>0,74$ & 87,69 & $77,2-94,5$ & 46,61 & $37,4-56,0$ & 1,64 & $1,3-2,0$ & 0,26 & $0,1-0,5$ \\
\hline$>0,76$ & 87,69 & $77,2-94,5$ & 48,31 & $39,0-57,7$ & 1,70 & $1,4-2,1$ & 0,25 & $0,1-0,5$ \\
\hline$>0,8$ & 87,69 & $77,2-94,5$ & 49,15 & $39,8-58,5$ & 1,72 & $1,4-2,1$ & 0,25 & $0,1-0,5$ \\
\hline$>0,86$ & 86,15 & $75,3-93,5$ & 50,85 & $41,5-60,2$ & 1,75 & $1,4-2,1$ & 0,27 & $0,1-0,5$ \\
\hline$>0,94$ & 84,62 & $73,5-92,4$ & 50,85 & $41,5-60,2$ & 1,72 & $1,4-2,1$ & 0,30 & $0,2-0,6$ \\
\hline$>0,96$ & 84,62 & $73,5-92,4$ & 51,69 & $42,3-61,0$ & 1,75 & $1,4-2,1$ & 0,30 & $0,2-0,5$ \\
\hline$>1,02$ & 83,08 & $71,7-91,2$ & 51,69 & $42,3-61,0$ & 1,72 & $1,4-2,1$ & 0,33 & $0,2-0,6$ \\
\hline$>1,04$ & 81,54 & $70,0-90,1$ & 51,69 & $42,3-61,0$ & 1,69 & $1,4-2,1$ & 0,36 & $0,2-0,6$ \\
\hline$>1,1$ & 81,54 & $70,0-90,1$ & 52,54 & $43,1-61,8$ & 1,72 & $1,4-2,1$ & 0,35 & $0,2-0,6$ \\
\hline$>1,3$ & 81,54 & $70,0-90,1$ & 53,39 & $44,0-62,6$ & 1,75 & $1,4-2,1$ & 0,35 & $0,2-0,6$ \\
\hline$>1,34$ & 80,00 & $68,2-88,9$ & 53,39 & $44,0-62,6$ & 1,72 & $1,4-2,1$ & 0,37 & $0,2-0,6$ \\
\hline$>1,35$ & 80,00 & $68,2-88,9$ & 54,24 & $44,8-63,4$ & 1,75 & $1,4-2,1$ & 0,37 & $0,2-0,6$ \\
\hline$>1,37$ & 80,00 & $68,2-88,9$ & 55,08 & $45,7-64,3$ & 1,78 & $1,5-2,2$ & 0,36 & $0,2-0,6$ \\
\hline$>1,45$ & 80,00 & $68,2-88,9$ & 55,93 & $46,5-65,1$ & 1,82 & $1,5-2,2$ & 0,36 & $0,2-0,6$ \\
\hline$>1,54$ & 78,46 & $66,5-87,7$ & 55,93 & $46,5-65,1$ & 1,78 & $1,5-2,2$ & 0,39 & $0,2-0,6$ \\
\hline$>1.58$ & 78,46 & $66,5-87.7$ & 56.78 & $47,3-65,9$ & 1,82 & $1,5-2,2$ & 0.38 & $0.2-0.6$ \\
\hline
\end{tabular}


Anexo L. Valores de IgE específica para leite que compuseram a curva ROC (pacientes anafiláticos e demais integrantes da casuística)

\begin{tabular}{|c|c|c|c|c|c|c|c|c|}
\hline$>1,64$ & 78,46 & $66,5-87,7$ & 57,63 & $48,2-66,7$ & 1,85 & $1,5-2,3$ & 0,37 & $0,2-0,6$ \\
\hline$>1,67$ & 78,46 & $66,5-87,7$ & 58,47 & $49,0-67,5$ & 1,89 & $1,5-2,3$ & 0,37 & $0,2-0,6$ \\
\hline$>1,83$ & 78,46 & $66,5-87,7$ & 60,17 & $50,7-69,1$ & 1,97 & $1,6-2,4$ & 0,36 & $0,2-0,6$ \\
\hline$>1,87$ & 76,92 & $64,8-86,5$ & 60,17 & $50,7-69,1$ & 1,93 & $1,6-2,4$ & 0,38 & $0,2-0,6$ \\
\hline$>2,18$ & 75,38 & $63,1-85,2$ & 60,17 & $50,7-69,1$ & 1,89 & $1,5-2,3$ & 0,41 & $0,3-0,7$ \\
\hline$>2,28$ & 73,85 & $61,5-84,0$ & 60,17 & $50,7-69,1$ & 1,85 & $1,5-2,3$ & 0,43 & $0,3-0,7$ \\
\hline$>2,29$ & 72,31 & $59,8-82,7$ & 60,17 & $50,7-69,1$ & 1,82 & $1,5-2,2$ & 0,46 & $0,3-0,7$ \\
\hline$>2,51$ & 70,77 & $58,2-81,4$ & 60,17 & $50,7-69,1$ & 1,78 & $1,4-2,2$ & 0,49 & $0,3-0,8$ \\
\hline$>2,58$ & 69,23 & $56,6-80,1$ & 60,17 & $50,7-69,1$ & 1,74 & $1,4-2,2$ & 0,51 & $0,3-0,8$ \\
\hline$>2,7$ & 69,23 & $56,6-80,1$ & 61,02 & $51,6-69,9$ & 1,78 & $1,4-2,2$ & 0,50 & $0,3-0,8$ \\
\hline$>2,87$ & 69,23 & $56,6-80,1$ & 61,86 & $52,5-70,6$ & 1,82 & $1,5-2,3$ & 0,50 & $0,3-0,8$ \\
\hline$>3,04$ & 69,23 & $56,6-80,1$ & 62,71 & $53,3-71,4$ & 1,86 & $1,5-2,3$ & 0,49 & $0,3-0,8$ \\
\hline$>3,06$ & 69,23 & $56,6-80,1$ & 63,56 & $54,2-72,2$ & 1,90 & $1,5-2,3$ & 0,48 & $0,3-0,7$ \\
\hline$>3,44$ & 69,23 & $56,6-80,1$ & 64,41 & $55,1-73,0$ & 1,95 & $1,6-2,4$ & 0,48 & $0,3-0,7$ \\
\hline$>3,5$ & 69,23 & $56,6-80,1$ & 65,25 & $55,9-73,8$ & 1,99 & $1,6-2,5$ & 0,47 & $0,3-0,7$ \\
\hline$>3,51$ & 67,69 & $54,9-78,8$ & 65,25 & $55,9-73,8$ & 1,95 & $1,6-2,4$ & 0,50 & $0,3-0,8$ \\
\hline$>3,57$ & 67,69 & $54,9-78,8$ & 66,10 & $56,8-74,6$ & 2,00 & $1,6-2,5$ & 0,49 & $0,3-0,8$ \\
\hline$>3,6$ & 66,15 & $53,4-77,4$ & 66,10 & $56,8-74,6$ & 1,95 & $1,6-2,4$ & 0,51 & $0,3-0,8$ \\
\hline$>3,98$ & 66,15 & $53,4-77,4$ & 66,95 & $57,7-75,3$ & 2,00 & $1,6-2,5$ & 0,51 & $0,3-0,8$ \\
\hline$>4$ & 66,15 & $53,4-77,4$ & 67,80 & $58,6-76,1$ & 2,05 & $1,7-2,5$ & 0,50 & $0,3-0,8$ \\
\hline$>4,26$ & 66,15 & $53,4-77,4$ & 68,64 & $59,5-76,9$ & 2,11 & $1,7-2,6$ & 0,49 & $0,3-0,8$ \\
\hline$>4,38$ & 64,62 & $51,8-76,1$ & 68,64 & $59,5-76,9$ & 2,06 & $1,7-2,6$ & 0,52 & $0,3-0,8$ \\
\hline$>4,46$ & 64,62 & $51,8-76,1$ & 69,49 & $60,3-77,6$ & 2,12 & $1,7-2,6$ & 0,51 & $0,3-0,8$ \\
\hline$>4,84$ & 64,62 & $51,8-76,1$ & 70,34 & $61,2-78,4$ & 2,18 & $1,8-2,7$ & 0,50 & $0,3-0,8$ \\
\hline$>5,11$ & 64,62 & $51,8-76,1$ & 71,19 & $62,1-79,1$ & 2,24 & $1,8-2,8$ & 0,50 & $0,3-0,8$ \\
\hline$>5,39$ & 64,62 & $51,8-76,1$ & 72,03 & $63,0-79,9$ & 2,31 & $1,9-2,9$ & 0,49 & $0,3-0,8$ \\
\hline$>5,66$ & 63,08 & $50,2-74,7$ & 72,88 & $63,9-80,7$ & 2,33 & $1,9-2,9$ & 0,51 & $0,3-0,8$ \\
\hline$>5,87$ & 63,08 & $50,2-74,7$ & 73,73 & $64,8-81,4$ & 2,40 & $1,9-3,0$ & 0,50 & $0,3-0,8$ \\
\hline$>6$ & 63,08 & $50,2-74,7$ & 74,58 & $65,7-82,1$ & 2,48 & $2,0-3,1$ & 0,50 & $0,3-0,8$ \\
\hline$>6,2$ & 63,08 & $50,2-74,7$ & 75,42 & $66,6-82,9$ & 2,57 & $2,1-3,2$ & 0,49 & $0,3-0,8$ \\
\hline$>6,31$ & 63,08 & $50,2-74,7$ & 76,27 & $67,6-83,6$ & 2,66 & $2,2-3,3$ & 0,48 & $0,3-0,8$ \\
\hline$>6,57$ & 63,08 & $50,2-74,7$ & 77,12 & $68,5-84,3$ & 2,76 & $2,2-3,4$ & 0,48 & $0,3-0,8$ \\
\hline$>6,62$ & 63,08 & $50,2-74,7$ & 77,97 & $69,4-85,1$ & 2,86 & $2,3-3,5$ & 0,47 & $0,3-0,8$ \\
\hline$>6,64$ & 61,54 & $48,6-73,3$ & 77,97 & $69,4-85,1$ & 2,79 & $2,3-3,5$ & 0,49 & $0,3-0,8$ \\
\hline$>7,23$ & 61,54 & $48,6-73,3$ & 78,81 & $70,3-85,8$ & 2,90 & $2,3-3,6$ & 0,49 & $0,3-0,8$ \\
\hline$>7,3^{\circ}$ & 61,54 & $48,6-73,3$ & 79,66 & $71,3-86,5$ & 3,03 & $2,4-3,7$ & 0,48 & $0,3-0,8$ \\
\hline$>7,9$ & 60,00 & $47,1-72,0$ & 79,66 & $71,3-86,5$ & 2,95 & $2,4-3,7$ & 0,50 & $0,3-0,8$ \\
\hline$>8,5$ & 58,46 & $45,6-70,6$ & 79,66 & $71,3-86,5$ & 2,87 & $2,3-3,6$ & 0,52 & $0,3-0,8$ \\
\hline$>8,7$ & 58,46 & $45,6-70,6$ & 80,51 & $72,2-87,2$ & 3,00 & $2,4-3,7$ & 0,52 & $0,3-0,8$ \\
\hline$>8,78$ & 56,92 & $44,0-69,1$ & 80,51 & $72,2-87,2$ & 2,92 & $2,3-3,7$ & 0,54 & $0,3-0,8$ \\
\hline$>9,7$ & 56,92 & $44,0-69,1$ & 81,36 & $73,1-87,9$ & 3,05 & $2,4-3,8$ & 0,53 & $0,3-0,8$ \\
\hline$>10,6$ & 56,92 & $44,0-69,1$ & 82,20 & $74,1-88,6$ & 3,20 & $2,5-4,0$ & 0,52 & $0,3-0,8$ \\
\hline$>10,8$ & 55,38 & $42,5-67,7$ & 82,20 & $74,1-88,6$ & 3,11 & $2,5-3,9$ & 0,54 & $0,3-0,9$ \\
\hline$>11,3$ & 55,38 & $42,5-67,7$ & 83,05 & $75,0-89,3$ & 3,27 & $2,6-4,1$ & 0,54 & $0,3-0,9$ \\
\hline$>11,6$ & 55,38 & $42,5-67,7$ & 83,90 & $76,0-90,0$ & 3,44 & $2,7-4,3$ & 0,53 & $0,3-0,9$ \\
\hline$>12,2$ & 53,85 & $41,0-66,3$ & 83,90 & $76,0-90,0$ & 3,34 & $2,6-4,2$ & 0,55 & $0,3-0,9$ \\
\hline$>12,3$ & 50,77 & $38,1-63,4$ & 83,90 & $76,0-90,0$ & 3,15 & $2,5-4,1$ & 0,59 & $0,4-0,9$ \\
\hline$>12,5$ & 50,77 & $38,1-63,4$ & 84,75 & $77,0-90,7$ & 3,33 & $2,6-4,3$ & 0,58 & $0,4-0,9$ \\
\hline$>12,7$ & 50,77 & $38,1-63,4$ & 85,59 & $77,9-91,4$ & 3,52 & $2,7-4,5$ & 0,58 & $0,3-1,0$ \\
\hline$>12,9$ & 49,23 & $36,6-61,9$ & 85,59 & $77,9-91,4$ & 3,42 & $2,6-4,4$ & 0,59 & $0,4-1,0$ \\
\hline$>13,2$ & 49,23 & $36,6-61,9$ & 86,44 & $78,9-92,0$ & 3,63 & $2,8-4,7$ & 0,59 & $0,4-1,0$ \\
\hline$>13,4$ & 47,69 & $35,1-60,5$ & 86,44 & $78,9-92,0$ & 3,52 & $2,7-4,6$ & 0,61 & $0,4-1,0$ \\
\hline$>13,78$ & 46,15 & $33,7-59,0$ & 86,44 & $78,9-92,0$ & 3,40 & $2,6-4,5$ & 0,62 & $0,4-1,0$ \\
\hline$>14$ & 46,15 & $33,7-59,0$ & 87.29 & $79,9-92,7$ & 3,63 & $2,8-4,8$ & 0,62 & $0,4-1,0$ \\
\hline
\end{tabular}


Anexo L. Valores de IgE específica para leite que compuseram a curva ROC (pacientes anafiláticos e demais integrantes da casuística)

\begin{tabular}{|c|c|c|c|c|c|c|c|c|}
\hline$>14,2$ & 44,62 & $32,3-57,5$ & 87,29 & $79,9-92,7$ & 3,51 & $2,7-4,6$ & 0,63 & $0,4-1,1$ \\
\hline$>14,4$ & 43,08 & $30,9-56,0$ & 87,29 & $79,9-92,7$ & 3,39 & $2,5-4,5$ & 0,65 & $0,4-1,1$ \\
\hline$>15,3$ & 43,08 & $30,9-56,0$ & 88,14 & $80,9-93,4$ & 3,63 & $2,7-4,8$ & 0,65 & $0,4-1,1$ \\
\hline$>15,7$ & 43,08 & $30,9-56,0$ & 88,98 & $81,9-94,0$ & 3,91 & $2,9-5,2$ & 0,64 & $0,4-1,1$ \\
\hline$>16,6$ & 41,54 & $29,4-54,4$ & 88,98 & $81,9-94,0$ & 3,77 & $2,8-5,1$ & 0,66 & $0,4-1,1$ \\
\hline$>17,4$ & 41,54 & $29,4-54,4$ & 89,83 & $82,9-94,6$ & 4,08 & $3,0-5,5$ & 0,65 & $0,4-1,2$ \\
\hline$>17,5$ & 36,92 & $25,3-49,8$ & 91,53 & $85,0-95,9$ & 4,36 & $3,2-6,0$ & 0,69 & $0,4-1,3$ \\
\hline$>17,9$ & 36,92 & $25,3-49,8$ & 92,37 & $86,0-96,4$ & 4,84 & $3,5-6,7$ & 0,68 & $0,4-1,3$ \\
\hline$>18,6$ & 36,92 & $25,3-49,8$ & 93,22 & $87,1-97,0$ & 5,45 & $3,9-7,5$ & 0,68 & $0,3-1,4$ \\
\hline$>20,4$ & 35,38 & $23,9-48,2$ & 93,22 & $87,1-97,0$ & 5,22 & $3,7-7,3$ & 0,69 & $0,3-1,4$ \\
\hline$>20,6$ & 33,85 & $22,6-46,6$ & 93,22 & $87,1-97,0$ & 4,99 & $3,5-7,0$ & 0,71 & $0,4-1,4$ \\
\hline$>21,2$ & 32,31 & $21,2-45,1$ & 93,22 & $87,1-97,0$ & 4,77 & $3,3-6,8$ & 0,73 & $0,4-1,4$ \\
\hline$>22,1$ & 29,23 & $18,6-41,8$ & 93,22 & $87,1-97,0$ & 4,31 & $2,9-6,3$ & 0,76 & $0,4-1,5$ \\
\hline$>22,2$ & 29,23 & $18,6-41,8$ & 94,07 & $88,2-97,6$ & 4,93 & $3,4-7,2$ & 0,75 & $0,4-1,6$ \\
\hline$>22,4$ & 27,69 & $17,3-40,2$ & 94,07 & $88,2-97,6$ & 4,67 & $3,1-6,9$ & 0,77 & $0,4-1,6$ \\
\hline$>24,1$ & 27,69 & $17,3-40,2$ & 94,92 & $89,3-98,1$ & 5,45 & $3,7-8,1$ & 0,76 & $0,3-1,7$ \\
\hline$>24,8$ & 27,69 & $17,3-40,2$ & 95,76 & $90,4-98,6$ & 6,54 & $4,4-9,7$ & 0,76 & $0,3-1,8$ \\
\hline$>26,1$ & 27,69 & $17,3-40,2$ & 96,61 & $91,5-99,0$ & 8,17 & $5,5-12,1$ & 0,75 & $0,3-2,0$ \\
\hline$>27,4$ & 26,15 & $16,0-38,5$ & 96,61 & $91,5-99,0$ & 7,72 & $5,1-11,6$ & 0,76 & $0,3-2,0$ \\
\hline$>27,9$ & 24,62 & $14,8-36,9$ & 96,61 & $91,5-99,0$ & 7,26 & $4,7-11,1$ & 0,78 & $0,3-2,1$ \\
\hline$>34,2$ & 23,08 & $13,5-35,2$ & 96,61 & $91,5-99,0$ & 6,81 & $4,4-10,6$ & 0,80 & $0,3-2,1$ \\
\hline$>35$ & 21,54 & $12,3-33,5$ & 96,61 & $91,5-99,0$ & 6,35 & $4,0-10,1$ & 0,81 & $0,3-2,1$ \\
\hline$>38,2$ & 21,54 & $12,3-33,5$ & 97,46 & $92,7-99,4$ & 8,47 & $5,3-13,5$ & 0,81 & $0,3-2,5$ \\
\hline$>38,6$ & 20,00 & $11,1-31,8$ & 97,46 & $92,7-99,4$ & 7,87 & $4,8-12,8$ & 0,82 & $0,3-2,5$ \\
\hline$>39,5$ & 20,00 & $11,1-31,8$ & 98,31 & $94,0-99,7$ & 11,80 & $7,3-19,2$ & 0,81 & $0,2-3,2$ \\
\hline$>40,7$ & 18,46 & $9,9-30,0$ & 98,31 & $94,0-99,7$ & 10,89 & $6,5-18,2$ & 0,83 & $0,2-3,3$ \\
\hline$>41,6$ & 16,92 & $8,8-28,3$ & 98,31 & $94,0-99,7$ & 9,98 & $5,8-17,1$ & 0,85 & $0,2-3,4$ \\
\hline$>63,3$ & 15,38 & $7,6-26,5$ & 98,31 & $94,0-99,7$ & 9,08 & $5,1-16,1$ & 0,86 & $0,2-3,4$ \\
\hline$>65$ & 13,85 & $6,5-24,7$ & 98,31 & $94,0-99,7$ & 8,17 & $4,5-15,0$ & 0,88 & $0,2-3,5$ \\
\hline$>70,1$ & 12,31 & $5,5-22,8$ & 98,31 & $94,0-99,7$ & 7,26 & $3,8-13,9$ & 0,89 & $0,2-3,5$ \\
\hline$>73,2$ & 10,77 & $4,5-20,9$ & 98,31 & $94,0-99,7$ & 6,35 & $3,2-12,8$ & 0,91 & $0,2-3,6$ \\
\hline$>86,9$ & 9,23 & $3,5-19,0$ & 98,31 & $94,0-99,7$ & 5,45 & $2,5-11,7$ & 0,92 & $0,2-3,7$ \\
\hline$>98,3$ & 9,23 & $3,5-19,0$ & 99,15 & $95,4-99,9$ & 10,89 & $5,1-23,3$ & 0,92 & $0,1-6,5$ \\
\hline$>100$ & 0,00 & $0,0-5,6$ & 100,00 & $96,9-100,0$ & & & 1,00 & \\
\hline
\end{tabular}


Referências 


\section{REFERÊNCIAS}

Aalberse RC, Kleine Budde I, Stapel SO, van Ree R. Structural aspects ofcross-reactivity and its relation to antibody affinity. Allergy. 2001;56 (Suppl67):27-9.

Ahlstedt S, Holmquist I, Kober A, Perborn H. Accuracy of specific IgE antibodyassays for diagnosis of cow's milk allergy. Ann Allergy Asthma Immunol. 2002;89(6 Suppl 1):21-5.

Ahlstedt S, Murray CS. In vitro diagnosis of allergy: how to interpret $\lg E$ antibody results in clinical practice. Prim Care Respir J. 2006;15(4):228-36. .

Arias $\mathrm{K}$, Waserman S, Jordana M. Management of food-induced anaphylaxis:unsolved challenges. Curr Clin Pharmacol. 2009; 4:113-25.

Akdis CA, Akdis M, Bieber T, Bindslev-Jensen C, Boguniewicz $M$, Eigenmann P, Hamid Q, Kapp A, Leung DY, Lipozencic J, Luger TA, Muraro A, Novak N, Platts-Mills TA, Rosenwasser L, Scheynius A, Simons FE, Spergel J, Turjanmaa K, Wahn U, Weidinger S, Werfel T, Zuberbier T; European Academy of Allergology; Clinical Immunology/American Academy of Allergy, Asthma and Immunology/PRACTALL Consensus Group. Diagnosis and treatment of atopic dermatitis in children and adults: European Academy of Allergology and Clinical Immunology/American Academy of Allergy, Asthma and Immunology/PRACTALL Consensus Report. Allergy. 2006;61:969-87. 
de Benedictis FM, Franceschini F, Hill D, Naspitz C, Simons FE, Wahn U, Warner JO, de Longueville M; EPAAC Study Group. The allergic sensitization in infants with atopic eczema from different countries.Allergy. 2009;64:295-303.

Benhamou AH, Zamora SA, Eigenmann PA. Correlation between specific immunoglobulin E levels and the severity of reactions in egg allergic patients. Pediatr Allergy Immunol. 2008;19:173-9.

Benhamou AH, Schäppi Tempia MG, Belli DC, Eigenmann PA. An overview of cow's milk allergy in children. Swiss Med Wkly. 2009;139:300-7.

Björkstén B. Genetic and environmental risk factors for the development of food allergy. Curr Opin Allergy Clin Immunol. 2005;5:249-53.

Bock SA. Prospective appraisal of complaints of adverse reactions to foods in children during the first 3 years of life. Pediatrics. 1987;79:683-8.

Bock SA, Sampson HA, Atkins FM, Zeiger RS, Lehrer S, Sachs M, Bush RK, Metcalfe DD. Double-blind placebo-controlled food challenge (DBPCFC) as an office procedure: A manual. J Allergy Clin Immunol. 1988;82:986-97.

Bock SA, Atkins FM. Patterns of food hypersensitivity during sixteen years of double-blind, placebo-controlled food challenges. J Pediatr. 1990;117:561-7. 
Bousquet J, Chanez P, Chanal I, Michel F-B. Comparison between RAST and Pharmacia CAP system: A new automated specific IgE assay. J Allergy Clin Immunol. 1990;85:1039-43.

Boyano MT,Garcia-Ara C, Diaz-PenaJM, Munoz FM, Garcia SG, Esteban MM. Validity of specific IgE antibodies in children with egg allergy. Clin Exp Allergy. 2001;31:1464-9.

Branum AM, Lukacs SL. Food allergy among U.S. children: Trends in prevalence and hospitalizations. NCHS data brief, no 10. Hyattsville, MD: National Center for Health Statistics; 2008.

Burks AW, James JM, Hiegel A, Hiegel A, Wilson G, Wheeler JG, Jones SM, Zuerlein N. Atopic dermatitis and food hypersensitivity reactions. $J$ Pediatr. 1998:132:132-6.

Burks AW, Sampson HA. Anaphylaxis and food allergy. Clin Rev Allergy Immunol.1999;17:339-60

Caffarelli C, Petroccione T. False-negative food challenges in children with suspected food allergy. Lancet. 2001;358:1871-2.

Castro APBM, Gushken AKF, Frayha FR. Diagnóstico in vivo. In: Castro FFM, Jacob CMA, Castro APBM, Yang AC. Alergia Alimentar. Barueri, SP: Manole 2010. - Serie Alergias p(39-52). 
Celik-Bilgili S, Mehl A, Verstege A, Staden U, Nocon M, Beyer K, Niggemann B. The predictive value of specific immunoglobulin $E$ levels in serum for the outcome of oral food challenges. Clin Exp Allergy. 2005;35:268-73.

Champion $\mathrm{RH}$. A practical approach to the urticarial syndromes--a dermatologist's view. Clin Exp Allergy. 1990;20:221-4.

Chehade M, Mayer L. Oral tolerance and its relation to food hypersensitivities. J Allergy Clin Immunol. 2005;115:3-12.

Clark AT, Ewan PW. Food allergy in childhood. Arch Dis Child. 2003;88:7981

Deeks JJ, Altman DG. Diagnostic tests 4: likelihood ratios. BMJ 2004;329:168-9

Dolen WK. It is not yet time to stop skin testing, but... J Allergy Clin Immunol. 2000:105:1074-6

Doria-Filho U. Introdução à bioestatística: para simples mortais. São Paulo: Negócio Editora; 1999. 158p.

Eigenmann PA, Sampson HA. Interpreting skin prick tests in the evaluation of food allergy in children. Pediatr Allergy Immunol. 1998;9:186-91.

Eigenmann PA, Calza AM. Diagnosis of IgE-mediated food allergy among Swiss children with atopic dermatitis. Pediatr Allergy Immunol. 2000:11:95100. 
Fonacier LS, Dreskin SC, Leung DY. 12. Allergic skin diseases. J Allergy Clin Immunol. 2009 Nov 23. [Epub ahead of print].

Frossard CP, Tropia L, Hauser C, Eigenmann PA. Lymphocytes in Peyer patches regulate clinical tolerance in a murine model of food allergy. $J$ Allergy Clin Immunol. 2004;113:958-64.

Garcia-Ara C, Boyano-Martinez T, Diaz-Pena JM, Martin-Munoz F, RecheFrutos M, Martin-Esteban M. Specific IgE levels in the diagnosis of immediate hypersensitivity to cow's milk protein in the infant. $J$ Allergy Clin Immunol. 2001;107:185-90.

García C, El-Qutob D, Martorell A, Febrer I, Rodríguez M, Cerdá JC, Félix.Sensitization in early age to food allergens in children with atopic dermatitis. Allergol Immunopathol (Madr). 2007;35:1520.

Garside $\mathrm{P}$, Milligton $\mathrm{O}$, Smith $\mathrm{KM}$. The anatomy of mucosal immune responses. Ann NY Acad Sci. 2004;1029:9-15.

Gellerstedt M, Bengtsson U, Niggemann B. Methodological issues in the diagnostic work-up of food allergy: a real challenge. J Investig Allergol Clin Immunol. 2007;17:350-6

Gupta R, Sheikh A, Strachan DP, Anderson HR. Time trends in allergic disordersin the UK. Thorax. 2007;62:91-6 
Gushken AKF. Adaptação do Teste de Provocação Oral Duplo Cego Placebo Controlado para o diagnóstico de Alergia às Proteínas do Leite de Vaca mediada pela Imunoglobulina E, na faixa etária pediátrica (Dissertação). São Paulo: Faculdade de Medicina da Universidade de São Paulo; 2009.

Hahn EL, Bacharier LB. The atopic march: the pattern of allergic disease development in childhood. Immunol Allergy Clin North Am. 2005;25:231-46.

Hamilton RG. Laboratory tests for allergy and immunodeficiency diseases. In: Adkinson NF Jr, Yunginger JW, Busse WW. Adkinson: Middleton's Allergy: Principles and Practice. 6th ed. Philadelphia: Mosby, $2003: 611-30$

Hatanaka VMA, Benseñor, IM Avaliação de Testes Diagnósticos. Benseñor, IM, Lotufo PA. Epidemiologia - Abordagem Prática . 1aㅗ ed. São Paulo: Sarvier, 2005. 14, p. 221-244.

Hauk PJ. The role of food allergy in atopic dermatitis. Curr Allergy Asthma Rep. 2008;8:188-94.

Higa M, Lui C, Melo RS, ; Gushken AKF, Castro APBM, Fomin ABF, Pastorino AC, Jacob CMA. Could Cow's Milk Fractions 
Contribute to Improve Diagnosis of IgE Mediated Cow's Milk Allergy. In: AAAAI - American Academy of Allergy, Asthma \& Immunology, 2008, Philadelphia, Pennsylvania. J Allergy Clin Immunol, 2008; $121: 240$.

Høst A. Frequency of cow's milk allergy in childhood. Ann Allergy Asthma Immunol. 2002;89(6 Suppl 1):33-7.

Illi S, von Mutius E, Lau S, Nickel R, Niggemann B, Sommerfeld C, Wahn U; Multicenter Allergy Study Group. The pattern of atopic sensitization is associated with the development of asthma in childhood. J Allergy Clin Immunol. 2001;108:709-14.

Jacob CMA. .Food Allergy in Latin American. Conferência proferida durante o Annual meeting of American Academy of Allergy Asthma \& Immunology. February 23-27, 2007, San Diego, USA.

James JM. Respiratory manifestation of food allergy. Pediatrics. 2003;108:720-5.

Johansson SGOJ, Yman L. In vitro assays for immunoglobulin E. Methodology, indications and interpretation. Clin Rev Allergy. 1988;6:93-139.

Johansson SG, Bieber T, Dahl R, Friedmann PS, Lanier BQ, Lockey RF, Motala C, Ortega Martell JA, Platts-Mills TA, Ring J, Thien F, Van Cauwenberge P, Williams HC. Revised nomenclature for allergy for global 
use: Report of the Nomenclature Review Committee of the World Allergy Organization, October 2003. J Allergy Clin Immunol. 2004;113:832-6.

Joint Task Force on Practice Parameters, American Academy of Allergy, Asthma and Immunology, American College of Allergy, Asthma and Immunology and Joint Council of Allergy, Asthma and Immunology. The diagnosis and management of anaphylaxis: an updated practice parameter. $J$ Allergy Clin Immunol. 2005;115(Suppl. 2):S483-523.

Kim JS. Food allergy: diagnosis, treatment, prognosis, and prevention. Pediatr Ann. 2008;37:546-51.

Kumar R. Epidemiology and risk factors for the development of food allergy.Pediatr Ann. 2008 ;37:552-8.

Kurowski K, Boxer RW. Food allergies: detection and management. Am Fam Physician. 2008;77:1678-86.

Leimgruber A, Peitrequin R, Mosimann B, Claeys M, Seppey Mm Jaccard Y, PÈcoud A. The Pharmacia CAP System: A new Assay for specific IgE. $J$ Allergy Clin Immunol. 1989;83:176.

Macdougall CF, Cant AJ, Colver AF. How dangerous is food allergy in childhood?The incidence of severe and fatal allergic reactions across the UK and Ireland.Arch Dis Child. 2002;86:236-9. 
Muto T, Hsieh SD, Sakurai Y, Yoshinaga H, Suto H, Okumura K, Ogawa H. Prevalence of atopic dermatitis in Japanese adults. $\mathrm{Br} J$ Dermatol. 2003;148:117-21.

Niggemann B, Sielaff B, Beyer K, Binder C, Wahn U. Outcome of doubleblind, placebo-controlled food challenge tests in 107 children with atopic dermatitis. Clin Exp Allergy. 1999:29:91-6.

Niggemann B, Beyer K. Pitfalls in double-blind, placebo-controlled oral food challenges. Allergy. 2007;62:729-32.

Nowak-Wegrzyn A, Sampson HA, Adverse reactions to foods. Med Clin North Am. 2006;90:97-127.

Nowak-Wegrzyn A, Assa'ad AH, Bahna SL, Bock SA, Sicherer SH, Teuber SS; AdverseReactions to Food Committee of American Academy of Allergy, Asthma \& Immunology ork Group report: oral food challenge testing. $J$ Allergy Clin Immunol. 2009 ;123(6 Suppl):S365-83.

Pastorino AC, Ribeiro LA, Jacob CMA. Manifestações Clínicas da Alergia Alimentar. In: Castro FFM, Jacob CMA, Castro APBM, Yang AC. Alergia Alimentar. Barueri, SP: Manole 2010. - Serie Alergias p(27-38).

Pepys J. Skin testing. Br J Hosp Med. 1975;14:412.

Perry TT, Matsui EC, Conover-Walker MK, Wood RA Risk of oral food challenges.J Allergy Clin Immunol. 2004;114:1164-8 
Poms RE, Klein CL, Anklam E. Methods for allergen analysis in food: a review. Food Addit Contam. 2004;21:1-31.

Poulos LM, Waters AM, Correll PK, Loblay $\mathrm{RH}$, Marks GB. Trends in hospitalizations for anaphylaxis, angioedema, and urticaria in Australia, 1993-1994 to 2004-2005. J Allergy Clin Immunol. 2007;120:878-84.

Rancé F, Juchet A, Brémont F, Dutau G. Correlations between skin prick tests using commercial extracts and fresh foods, specific $\lg E$, and food challenges. Allergy. 1997;52:1031-5

Rancé F. Food allergy in children suffering from atopic eczema. Pediatr Allergy Immunol. 2008:19:279-84.

Roehr CC, Reibel S, Ziegert M, Sommerfeld C, Wahn U, Niggemann B. Atopy patch tests, together with determination of specific IgE levels, reduce the need for oral food challenges in children with atopic dermatitis. $J$ Allergy Clin Immunol. 2001:107:548-53.

Rona RJ, Keil T, Summers C, Gislason D, Zuidmeer L, Sodergren E, Sigurdardottir ST, Lindner T, Goldhahn K, Dahlstrom J, McBride D, Madsen C. The prevalence of food allergy: a meta-analysis. J Allergy Clin Immunol. 2007;120:638-46. 
Saarinen KM, Suomalainen H, Savilahti E. Diagnostic value of skin-prick and patch tests and serum eosinophil cationic protein and cow's milk-specific lgE in infants with cow's milk allergy. Clin Exp Allergy. 2001;31:423-9.

Sampson HA, Albergo R. Comparison of results of skin tests, RAST, and double-blind, placebo-controlled food challenges in children with atopic dermatitis. J Allergy Clin Immunol. 1984;74:26-33.

Sampson H, Ho D. Relationship between food-specific IgE concentration and the risk of positive food challenges in children and adolescents. J Allergy Clin Immunol. 1997;100:444-51.

Sampson HA, Sicherer SH. Eczema and food hypersensitivity. Immunol Allergy Clin North Am 1999; 19:495-518.

Sampson HA. Food Allergy. Parte 1: Immunopathogenesis and clinical disorders. J Allergy Clin Immunol. 1999;103:717-28.

Sampson HA. Utility of food-specific lgE concentrations in predicting symptomatic food allergy. J Allergy Clin Immunol. 2001;107:891-6.

Sampson HA. 9. Food allergy. J Allergy Clin Immunol. 2003;111:S540-7.

Sampson HA. Update on food allergy. J Allergy Clin Immunol. 2004;113:80519 
Shah E, Pongracic J. Food-induced anaphylaxis: who, what, why, and where? Pediatr Ann. 2008;37:536-41.

Shaker M, Woodmansee D. An update on food allergy. Curr Opin Pediatr. $2009 ; 21: 667-74$..

Sicherer SH, Morrow EH, Sampson HA. Dose-response in double-blind, placebo-controlled oral food challenges in children with atopic dermatitis. $J$ Allergy Clin Immunol. 2000;105:582-6.

Sicherer SH, Sampson HA. Food allergy. J Allergy Clin Immunol. 2006;117:S470-5.

Sopo MS, Radzik D, Calvani M. The predictive value of specific immunoglobulin $E$ levels for the first diagnosis of cow's milk allergy. A critical analysis of pediatric literature. Pediatr Allergy Immunol. 2007:18:575-82.

Sporik R, Hill DJ, Hosking CS. Specificity of allergen skin testing in predicting positive open food challenges to milk, egg and peanut in children. Clin Exp Allergy. 2000: 30:1540-6.

Summers CW, Pumphrey RS, Woods CN, McDowell G, Pemberton PW, Arkwright PD.Factors predicting anaphylaxis to peanuts and tree nuts in patients referred to aspecialist center. J Allergy Clin Immunol. 2008;121:632638. 
Vandenplas Y, Koletzko S, Isolauri E, Hill D, Oranje AP, Brueton M, Staiano A, Dupont C. Guidelines for the diagnosis and management of cow's milk protein allergy in infants. Arch Dis Child. 2007;92:902-8.

Vieira MC, ToporovskiM, Morais MB, Spolidoro JV, Fonseca MS, Araújo GT, Castro V, Osmo H. Cow's milk allergy in children: a survey on its main features in Brazil. JPEN. 2005; 29(2): S27.

Vila L, Beyer K, Järvinen KM, Chatchatee P, Bardina L, Sampson HA. Role ofconformational and linear epitopes in the achievement of tolerance in cow's milk allergy. Clin Exp Allergy. 2001;31:1599-606.

Vlieg-Boerstra BJ, Duiverman EJ, van der Heide S, Bijleveld CM, Kukler J, Dubois AE. Should children with a history of anaphylaxis to foods undergo challenge testing? Clin Exp Allergy. 2008;38:1935-42

Wahn U, Von Mutius E. Childhood risk factors for atopy and the importance of early intervention. J Allergy Clin Immunol. 2001;107:567-74.

Wal JM. Bovine milk allergenicity. Ann Allergy Asthma Immunol. 2004;(Suppl 3):S2-S11.

Wang J, Sampson HA.Food anaphylaxis Clin Exp Allergy. 2007;37:651-60.

Wang J, Godbold JH, Sampson HA. Correlation of serum allergy (IgE) tests performed by different assay systems. $J$ Allergy Clin Immunol. 2008;121:1219-24. 
Werfel T, Breuer K. Role of food allergy in atopic dermatitis. Curr Opin Allergy Clin Immunol. 2004;4:379-85.

Werfel T, Ballmer-Weber B, Eigenmann PA, Niggemann B, Rancé F, Turjanmaa K, Worm M. Eczematous reactions to food in atopic eczema: position paper of the EAACI and GA2LEN. Allergy. 2007;62:723-8.

Wide L., Bennich H., Johansson S.G.O.: Diagnosis of allergy by an in vitro test for allergen antibodies. Lancet 1967; 2:1105-07

Williams LW, Bock SA. Skin testing and food challenges in allergy and immunology practice. Clin Rev Allergy Immunol. 1999;17:323-38. 